LA-UR- $97-$

LA-UR- $97-2891$

\title{
Title: Solution High-Energy Burst Assembly (SHEBA) Results from Subprompt Critical Experiments with Uranyl Fluoride Fuel
}

Submitted to:
C. C. Cappiello
K. B. Butterfield
R. G. Sanchez
J. A. Bounds
R. H. Kimpland
R. P. Damjanovich
P. J. Jaegers

\section{DISCLAIMER}

This report was prepared as an account of work sponsored by an agency of the United States Government. Neither the United States Government nor any agency thereof, nor any of their employees, makes any warranty, express or implied, or assumes any legal liability or responsibility for the accuracy, completeness, or usefulness of any information, apparatus, product, or process disclosed, or represents that its use would not infringe privately owned rights. Reference herein to any specific commercial product, process, or service by trade name, trademark, manufacturer, or otherwise does not necessarily constitute or imply its endorsement, recommendation, or favoring by the United States Government or any agency thereof. The views and opinions: of authors expressed herein do not necessarily state or reflect those of the United States Government or any agency thereof.

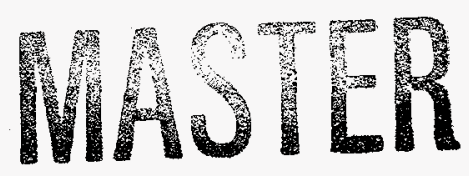

\section{Los Alamos}

NATIONAL LABORATORY

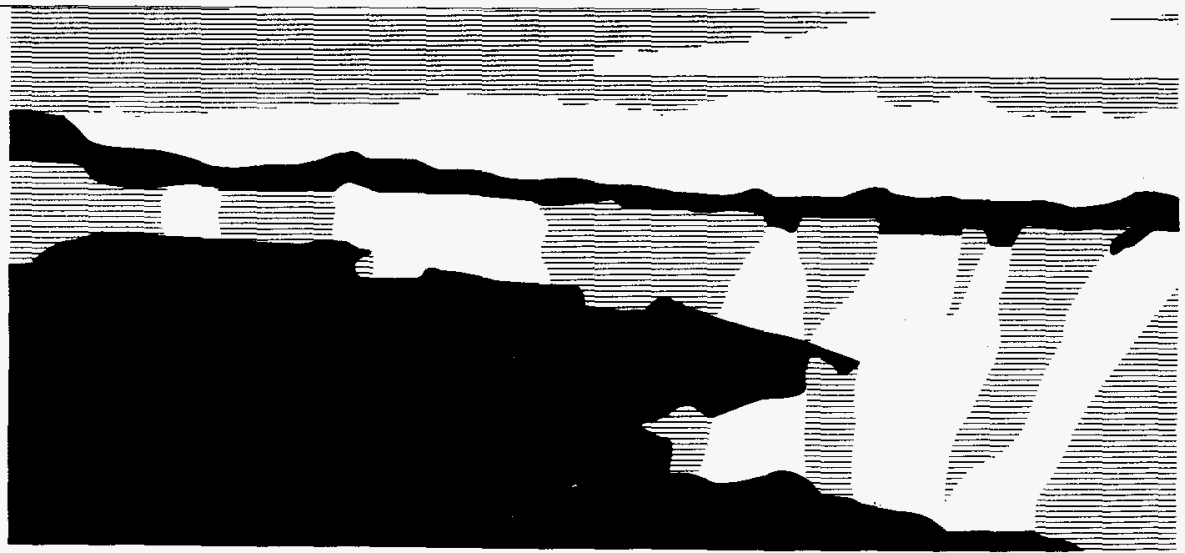

Los Alamos National Laboratory, an affirmative action/equal opportunity employer, is operated by the University of California for the U.S. Department of Energy under contract W-7405-ENG-36. By acceptance of this article, the publisher recognizes that the U.S. Government retains a nonexclusive, royalty-free license to publish or reproduce the published form of this contribution, or to allow others to do so, for U.S. Government purposes. The Los Alamos National Laboratory requests that the publisher identity this article as work pertormed under the auspices of the U.S. Department of Energy. 


\section{DISCLAMMIER}

Portions of this document may be illegible in electronic image products. Images are produced from the best available original document. 


\section{Table of Contents}

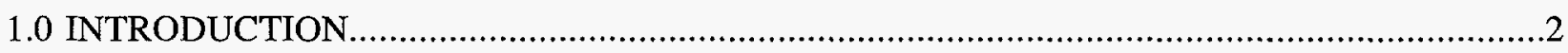

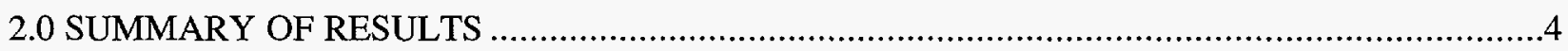

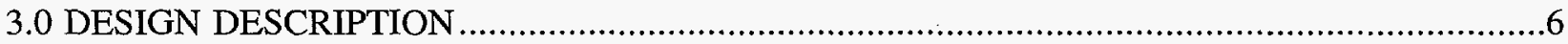

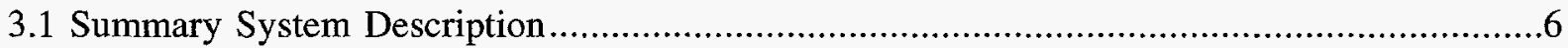

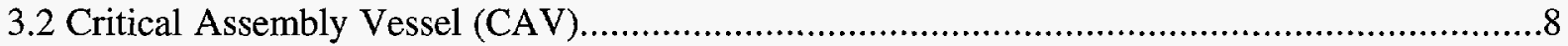

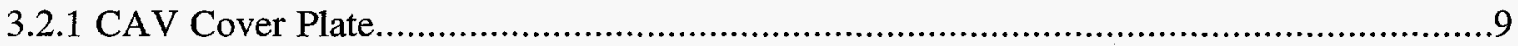

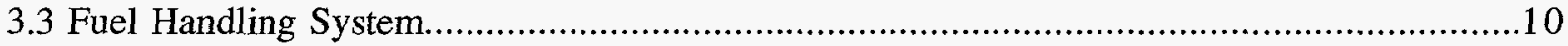

3.3.1 Storage Tanks........................................................................................................

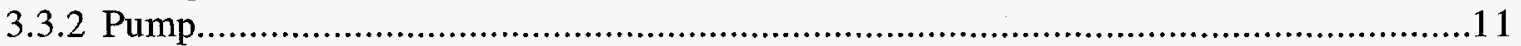

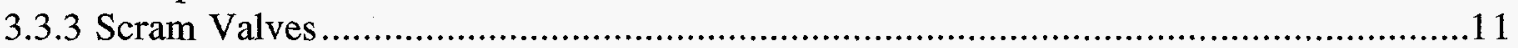

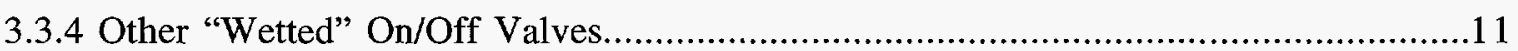

3.3.5 Flow Regulating Valves...................................................................................11

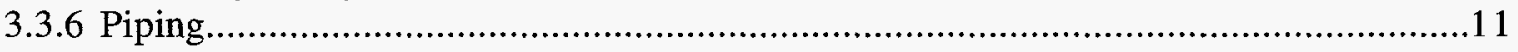

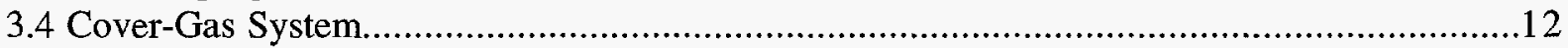

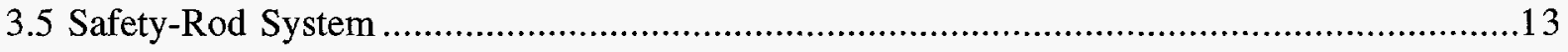

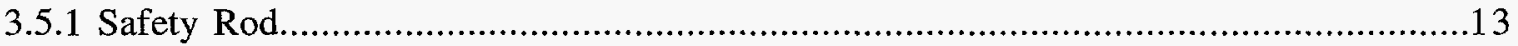

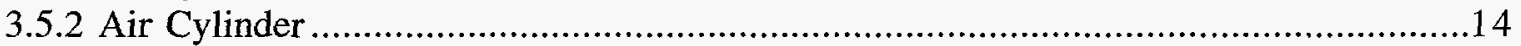

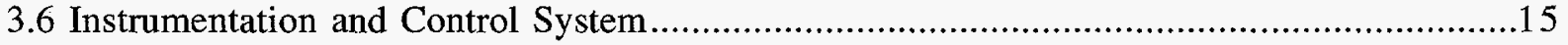

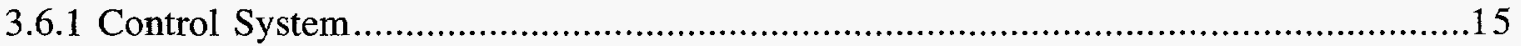

3.6.2 Safety-Related Systems ........................................................................................16

3.6.3 Instrumentation and Electrical Hardware...................................................................17

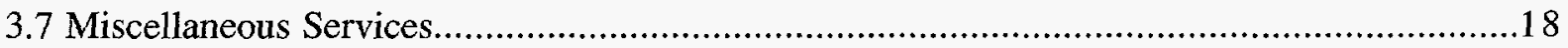

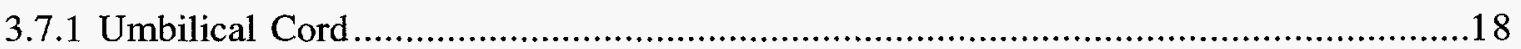

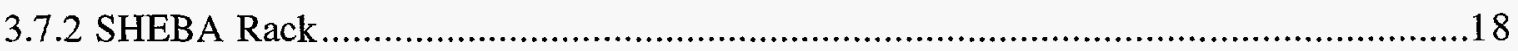

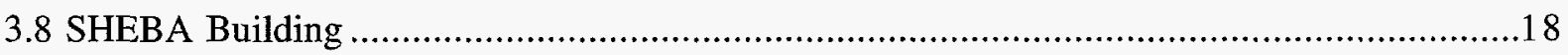

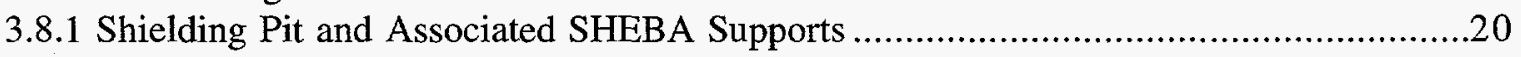

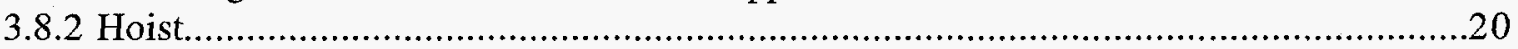

3.9 Fissile Solution Fuel..................................................................................................21

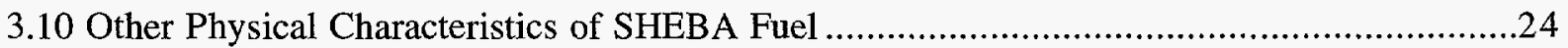

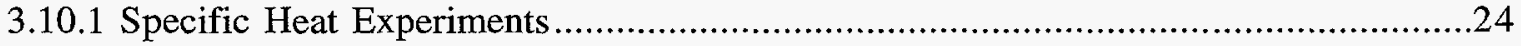

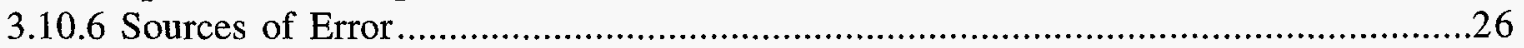

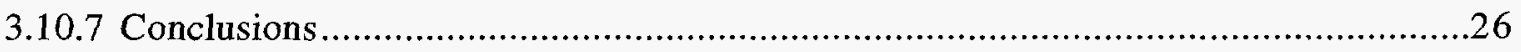

3.11 Volumetric Coefficient of Expansion Experiment.........................................................26

3.11.1 Definition of Volumetric Expansion...................................................................26

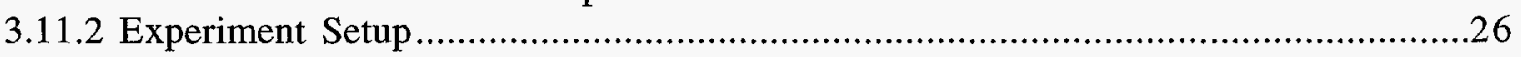

3.11.3 Sources of Error

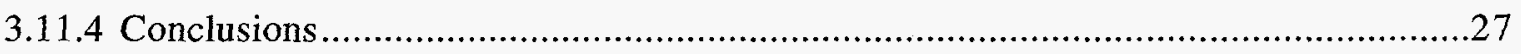

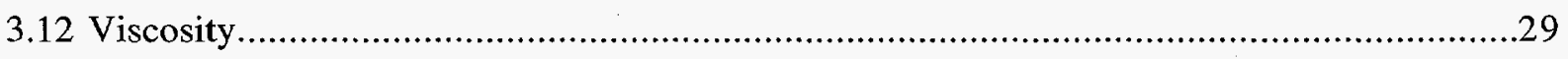

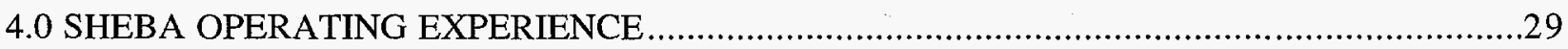

4.1 SHEBA Free Runs Simulating Uranium-Solution Criticality Accidents.................................29

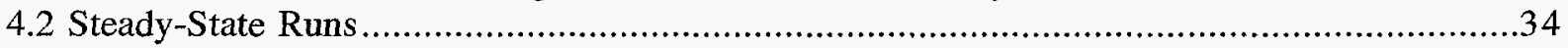

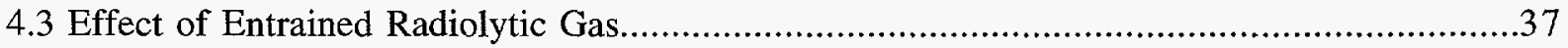




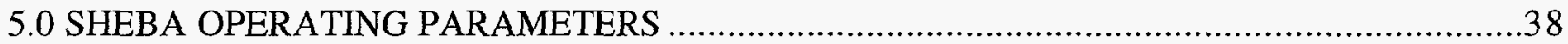

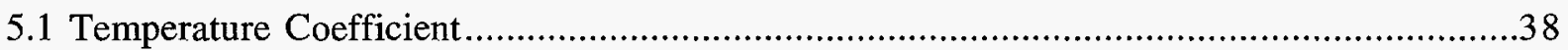

5.2 Reactivity and Reactor Period as a Function of Solution Height ........................................39

5.3 Prompt Neutron Decay Constants in SHEBA …............................................................41

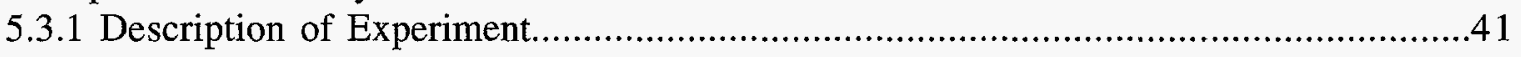

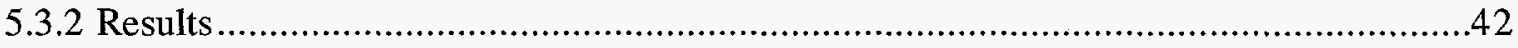

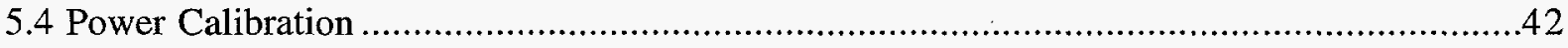

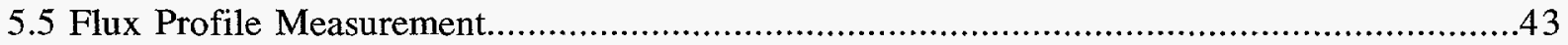

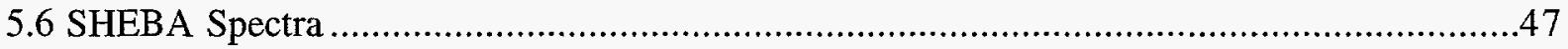

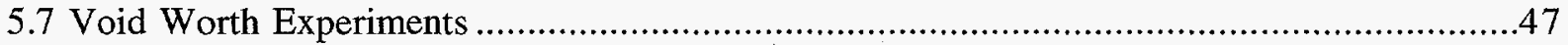

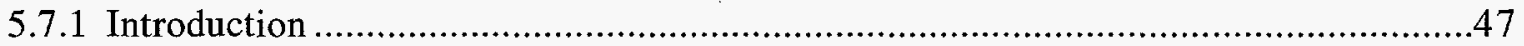

5.7.2 Experimental Apparatus .......................................................................47

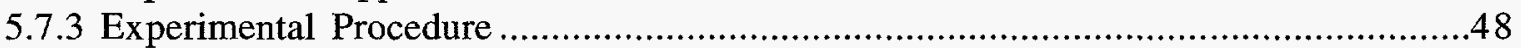

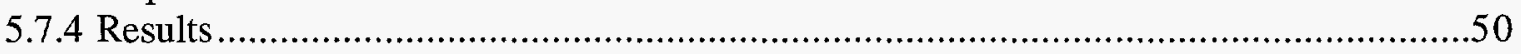

5.7.5 Comparison of Experiment with Calculations.................................................52

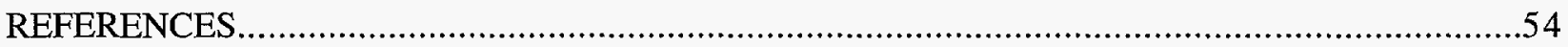

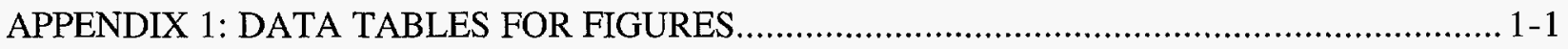

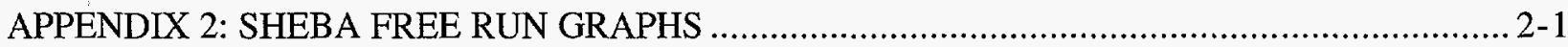


Solution High-Energy Burst Assembly (SHEBA) Results from Subprompt Critical Experiments with Uranyl Fluoride Fuel

\author{
Charlene C. Cappiello, Ken B. Butterfield, Rene G. Sanchez,
}

John A. Bounds, Robert H. Kimpland, Robert P. Damjanovich, and Peter J. Jaegers 


\subsection{Introduction}

The Solution High-Energy Burst Assembly (SHEBA) was originally constructed during 1980 and was designed to be a clean free-field geometry, right-circular, cylindrically symmetric critical assembly employing $\mathrm{U}(5 \%) \mathrm{O}_{2} \mathrm{~F}_{2}$ solution as fuel. A second version of SHEBA, employing the same fuel but equipped with a fuel pump and shielding pit, was commissioned in 1993. This report includes data and operating experience for the 1993 SHEBA only. Figure 1 is a photograph of SHEBA.

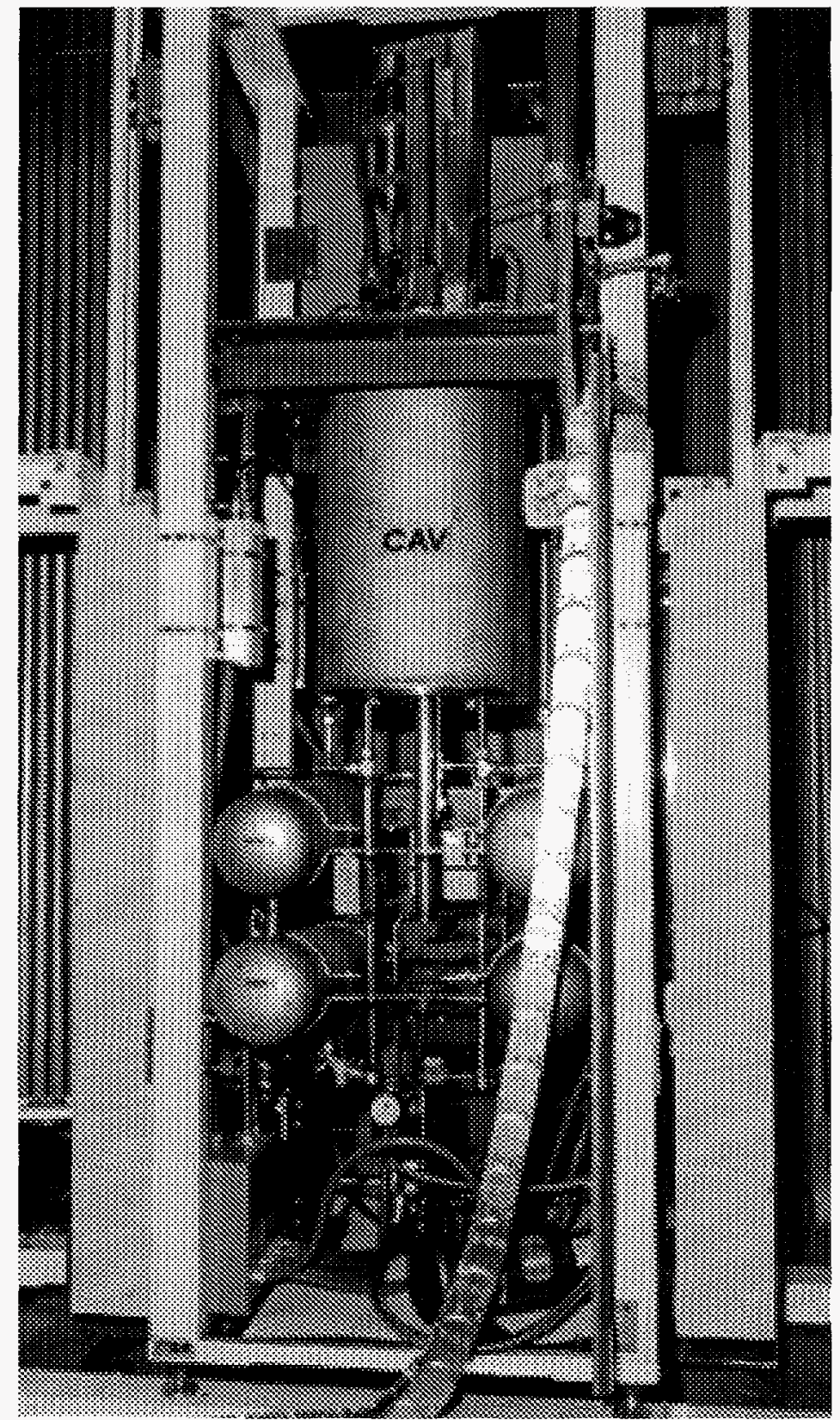

Fig. 1. SHEBA. 
SHEBA is located in a thin metal building. The thin metal walls are nearly transparent to neutron flux, which minimizes the influence of "room-return" neutrons to the experiment and, consequently, provides minimal attenuation of the neutron flux reaching the detector systems and experiments that may be located outside of the building. A pit in the floor of the building provides shielding for "high-power" SHEBA operation and also provides containment of any liquid released from SHEBA.

The major goals of the SHEBA project are

- to study the behavior of nuclear excursions in a low-enrichment solution,

- to evaluate accidental criticality alarm detectors for fuel-processing facilities,

- to provide radiation spectra and dose measurements to benchmark radiation transport calculations on a low-enrichment solution system similar to that encountered in centrifuge enrichment plants, and

- to provide radiation fields to calibrate personnel dosimetry.

Criticality accidents are simulated by "free run" operations and provide a time history of the dose rate, temperature, radiolytic gas production and an integrated dose for a typical event. In addition to the evaluation of criticality alarm response to steady-state, ramp, and burst operations, neutron and gamma spectra have been measured and the responses of personnel dosimeters determined. These measurements may be made from near contact to distances exceeding $500 \mathrm{~m}$. SHEBA is also being used to provide a neutron flux test-bed to benchmark calculations.

The record of accidental criticalities through the 1950 s and early 1960 s worldwide was dominated by process-plant events involving highly enriched uranium solutions. In several cases, fatalities resulted. (This record was in marked contrast to the success of the remote final assembly policy used in the critical assembly laboratories.) These process-plant accidents shared a fairly narrow set of common initializing causes: i.e., error in material inventory control or the use of geometrically unsafe vessels. The accidents were marked by the generation of a power transient or a series of power transients and were ultimately terminated by the mechanical disassembly of the fuel, either by human intervention or by the effect of the deposited energy from the fission transient.

The transient could be accompanied by mechanical shock, rapid gas evolution, the expected blue glow, and, if criticality continued for a sufficient time, eventual solution boiling. The understanding of this broad class of events was the objective of the extensive campaign of experiments utilizing highly enriched uranyl nitrate solutions conducted by the French CEA at their Valduc facility in the late 1960 s and early 1970 s. ${ }^{1}$ The critical dimensions, reactivity rates of addition, energy release, and consequent neutron and gamma-ray radiation environments produced were included in the experimental results. The French CRAC program was solely concerned with highly enriched uranium. The sizes of such solution criticals are small, and the behavior of these assemblies is influenced by a high neutron leakage and the ability to add reactivity rapidly through the addition of modest amounts of fuel.

The results of the French CRAC experiments have been applied to process-plant operations using highly enriched solutions with success. Difficulties arise, however, when these results are applied to solution criticals where the relative importance of the parameter governing transient behavior is altered. This is the case at the low end of the enrichment scale. Because of the low enrichments, these assemblies have lower leakage rates and the amount of core fuel addition required to alter reactivity significantly is large. Rapid insertion rates of reactivity into such systems by fuel addition are difficult to give a credible foundation. The expected excursion is likely to be broad rather than a narrow 
spike, but the high heat capacity of such low enrichment critical volumes suggests the possibility of long-duration power episodes. These differences from the high enrichment behavior observed in the French experiments make measurements using SHEBA a most necessary addition.

Solution-fueled benchmark work at the Los Alamos Critical Experiments Facility (LACEF) focused on the development of a full campaign of experimental measurements of the characterization of SHEBA. A summary of the results are given in the next section. A description of the system and the experimental results are given in some detail in the remaining sections of this report.

\subsection{Summary of Results}

Experiments have been performed to measure a variety of parameters for SHEBA. The measured parameters include

- behavior of the facility during transient and steady-state operation,

- measurement of the characteristics of the SHEBA fuel,

- measurement of the delayed-critical solution height as a function of solution temperature,

- measurement of the initial reactor period and reactivity as a function of solution height,

- calibration of the power level as a function of reactor power instrumentation readings,

- measurement of the flux profile in SHEBA,

- measurement of radiation levels and neutron spectra exterior to the assembly for code verification and criticality alarm and dosimetry purposes, and

- measurement of the effect on reactivity of voids in the fuel.

A summary of the results of these measurements is included below. Details of the experiments and results are included in the following sections of this report, and the raw data corresponding to these results is included in Appendix 1.

For slow-initial-period "free-runs" and steady-state runs with a total energy deposition of less than approximately $8 \times 10^{16}$ fissions, SHEBA behaves much the same as a metal system with a very strong negative temperature coefficient. For free-runs with an initial period of longer than about 40 seconds and for steady-state runs with a total energy deposition of greater than approximately $8 \mathrm{x}$ $10^{16}$ fissions, radiolytic gas becomes a factor in the behavior of the system. Free-runs start to show multiple peaks and occasionally show large power fluctuations as gas forms and migrates out of the system. Steady-state operation may also show large power fluctuations as a result of radiolytic gas. Operation for several days in a row at levels large enough to produce radiolytic gas may also cause subsequent operations to exhibit an increasing initial reactor period as entrained gases escape during initial fill operations.

The wide range of solution-fueled system behavior experienced from operation to date is illustrated in the comparison results with Godiva-IV, shown in Table 1. The characterization of excursions of equal total fission yields is shown for Godiva-IV, the French CEA high-enrichment solution (CRAC), and the SHEBA low-enrichment-solution slow-initial-period free-run. The fastest free-run to date is also included in the table for comparison. 
Table 1. Comparison of Bursts ${ }^{a}$

\begin{tabular}{|l|l|l|l|l|}
\hline \multicolumn{1}{|c|}{ Characteristic } & Godiva-IVb & $\begin{array}{l}\mathbf{1 0}^{16} \text { Fissions } \\
\text { SHEBA c }\end{array}$ & \multicolumn{1}{|c|}{$\begin{array}{c}\text { Near Prompt } \\
\text { SHEBA }\end{array}$} & \multicolumn{1}{|c|}{$\begin{array}{c}\text { French } \\
\text { CRAC }\end{array}$} \\
\hline Initial period & $0.00001 \mathrm{~s}$ & $60 \mathrm{~s}$ & $1 \mathrm{~s}$ & $0.0021 \mathrm{~s}$ \\
\hline Peak width at half-maximum & $0.00005 \mathrm{~s}$ & $403 \mathrm{~s}$ & $6 \mathrm{~s}$ & $0.0015 \mathrm{~s}$ \\
\hline $\begin{array}{l}\text { Typical time to peak } \\
\text { (sourceless start) }\end{array}$ & $2 \mathrm{~s}$ & $900 \mathrm{~s}$ & $20 \mathrm{~s}$ & $2-6 \mathrm{~s}$ \\
\hline $\begin{array}{l}\text { Initial excess reactivity } \\
\text { (above delayed critical) }\end{array}$ & $\$ 1.06$ & $\$ 0.15$ & $\$ 0.79$ & $\$ 1.56$ \\
\hline Fuel & $\mathrm{U}(93)$ metal & $\mathrm{U}(5) \mathrm{O}_{2} \mathrm{~F}_{2}$ & $\mathrm{U}(5) \mathrm{O}_{2} \mathrm{~F}_{2}$ & $\mathrm{U}(93) \mathrm{O}_{2}\left(\mathrm{NO}_{3}\right)_{2}$ \\
\hline Critical mass $\left(^{235} \mathrm{U}\right)$ & $66 \mathrm{~kg}$ & $4.0 \mathrm{~kg}$ & $4.0 \mathrm{~kg}$ & $3.6 \mathrm{~kg}$ \\
\hline Critical volume & $2.5 \mathrm{~L}$ & $79 \mathrm{~L}$ & $79 \mathrm{~L}$ & $18.6 \mathrm{~L}$ \\
\hline Temperature rise & $250^{\circ} \mathrm{C}$ & $5^{\circ} \mathrm{C}$ & $23^{\circ} \mathrm{C}$ & $20^{\circ} \mathrm{C}$ \\
\hline Peak power & $1 \times 10^{8} \mathrm{~kW}$ & $2.1 \mathrm{~kW}$ & $509 \mathrm{~kW}$ & $1.8 \times 10^{5} \mathrm{~kW}$ \\
\hline Energy release & $1.2 \mathrm{MJ}$ & $1.2 \mathrm{MJ}$ & $8.5 \mathrm{MJ}$ & $1.2 \mathrm{MJ}$ \\
\hline Peak dose rate at $2 \mathrm{~m}$ & $\sim 10^{8} \mathrm{rad} / \mathrm{s}$ & $\sim 0.45 \mathrm{rad} / \mathrm{s}$ & $\sim 110 \mathrm{rad} / \mathrm{s}$ & $\sim 4000 \mathrm{rad} / \mathrm{s}$ \\
\hline Dose at 2 m & $\sim 500 \mathrm{rad}$ & $\sim 200 \mathrm{rad}$ & $\sim 1800 \mathrm{rad}$ & $\sim 300 \mathrm{rad}$ \\
\hline Total fissions & $\sim 4 \times 10^{16}$ & $\sim 4 \times 10^{16}$ & $\sim 3 \times 10^{17}$ & $\sim 4 \times 10^{16}$ \\
\hline
\end{tabular}

a Figures are given to illustrate differences for a characteristic burst -- they are not precise for a specific burst.

b Fast metal system.

c Slow solution system, low enrichment.

d High enrichment solution system.

e Note that the total number of fissions and delivered dose are nearly equal in spite of several orders-ofmagnitude differences in other pertinent parameters.

As can be seen from the table, the dose rates for the solution system for a comparable energy release is much lower than the dose rate for Godiva. However, the total dose due to the excursion is similar and appears to be inversely proportional to the total mass of fuel involved.

The largest variation is in the initial period and width of the peak in the excursion. SHEBA produces this dose only $15 \&$ supercritical and with only a $5^{\circ} \mathrm{C}$ temperature rise. Godiva produces this dose at $\$ 1.06$ supercritical (6ф super-prompt critical) with a $250^{\circ} \mathrm{C}$ rise. Thus, low enriched solutions have the potential for a much greater dose commitment and energy release during sub-promptcritical excursions. This is illustrated by the "near prompt" SHEBA run which produced $8.5 \mathrm{MJ}$ and 1800 Rads in a sub-prompt-critical excursion.

Tabulation of the measurements of the initial reactor period vs. fuel height give a value of reactivity of $43.3 \phi / \mathrm{cm}$ for SHEBA out of the pit and $50.8 \phi / \mathrm{cm}$ for SHEBA operated in the shielding pit. In addition, measurements to date show the inhour equation using a $B / 1$ of 200 and the above value for $\phi / \mathrm{cm}$ is very accurate for SHEBA out of the pit. In the pit, however, SHEBA seems to have a longer neutron lifetime or needs a seventh delayed neutron group to properly account for the reflection of the pit. 
The SHEBA fuel for these experiments has the following measured characteristics:

Formula

Uranium content

Isotopic composition:

$$
\begin{aligned}
& { }^{234} \mathrm{U} \\
& { }^{235} \mathrm{U} \\
& { }^{236} \mathrm{U} \\
& { }^{238} \mathrm{U}
\end{aligned}
$$

Impurities (major elements in decreasing order of occurrence)

Specific heat

Coefficient of Thermal expansion

Density

Viscosity

$\mathrm{pH}$
$\mathrm{U}(5 \%) \mathrm{O}_{2} \mathrm{~F}_{2}$

$0.464 \mathrm{gU} / \mathrm{g}$-solution

.0273 atom percent

4.998

.0488

94.926

iron, aluminum, nickel, manganese, copper

$1.89-2.50 \mathrm{~J} / \mathrm{gm}^{\circ}{ }^{\circ} \mathrm{C}$

$2.88 \times 10^{-6}$ to $5.71 \times 10^{-6}$

$2.11 \mathrm{~g} / \mathrm{cc}\left(21^{\circ} \mathrm{C}\right)$

2.13 to $2.15 \mathrm{~g} / \mathrm{cc}$ for temperatures from $40^{\circ} \mathrm{C}$ to $18^{\circ} \mathrm{C}$

$18.5 \mathrm{cp}$

1.0

The temperature coefficient, expressed as the increase in critical height of SHEBA fuel per ${ }^{\circ} \mathrm{C}$ increase in temperature, is $0.10 \mathrm{~cm} /{ }^{\circ} \mathrm{C}$ out of the pit and $0.08 \mathrm{~cm} /{ }^{\circ} \mathrm{C}$ in the pit. However, when operating SHEBA below $15^{\circ} \mathrm{C}$ in the shielding pit, occasionally, the coefficient increases by nearly a factor of 3 .

The measured power calibration for SHEBA is $2.7 \times 10^{18}$ fissions per amp-second on the reactor power monitor ion chamber.

Two flux profile measurements were made, one using thin stainless steel tubing containing copper wires in an otherwise "clean" geometry and one using a large experiment well inserted into SHEBA. It is evident from the data that the flux profile was greatly affected by the flux depression due to the well.

The neutron leakage spectra has been measured for SHEBA using the Bonner Sphere technique.

Void worth experiments were performed and indicated that a void located at the center of the tank has a much greater negative reactivity worth than predicted.

\subsection{Design Description}

\subsection{Summary System Description}

SHEBA is the simplest possible design, in keeping with its application to benchmark calculational methods. Figure 2 shows a layout of the critical assembly machine and the relationship between the critical assembly vessel (CAV) and the solution storage tanks. The system was designed to achieve criticality in a cylindrically symmetric configuration. The SHEBA facility also incorporates a shielding pit into which the entire assembly can be lowered to provide shielding for elevated power runs. 
A completely clean geometry is provided in this simple, unreflected, cylindrical system. Reactivity control is effected by varying the solution level. A safety rod may be inserted in a thimble along the central axis of the CAV for fast shutdown. This construction maintains the cylindrical geometry of the system. Complete shutdown is accomplished by solution dump through two parallel $2.54-\mathrm{cm}$ (1-in.) scram valves.

The SHEBA assembly consists of a critical assembly vessel, a fuel handling system, a flowing cover gas system, a safety rod system and a shielding pit. A schematic of the system is shown in Fig. 3. Each of these systems is described in detail in the following section.

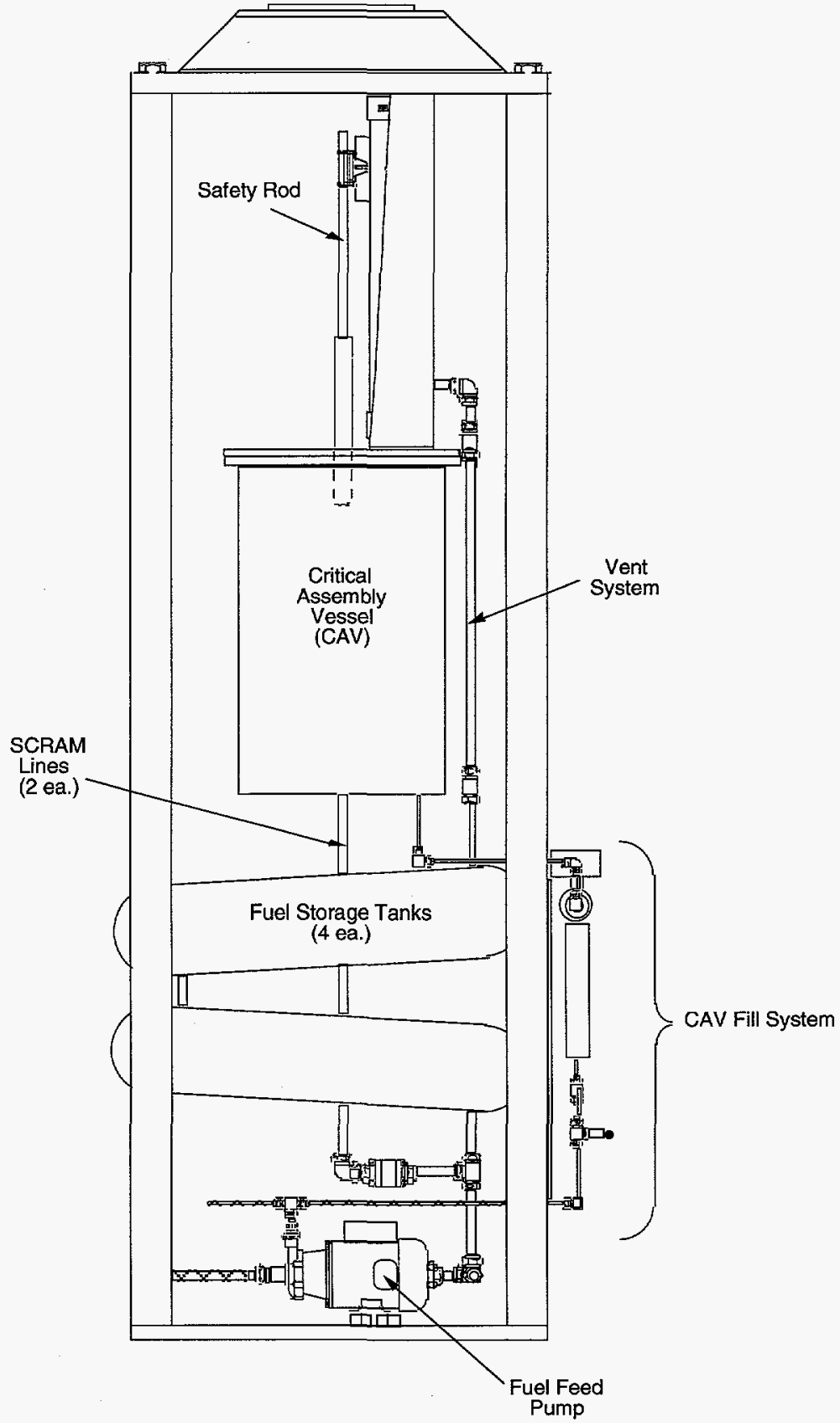

Fig. 2. Layout of the SHEBA critical assembly. 


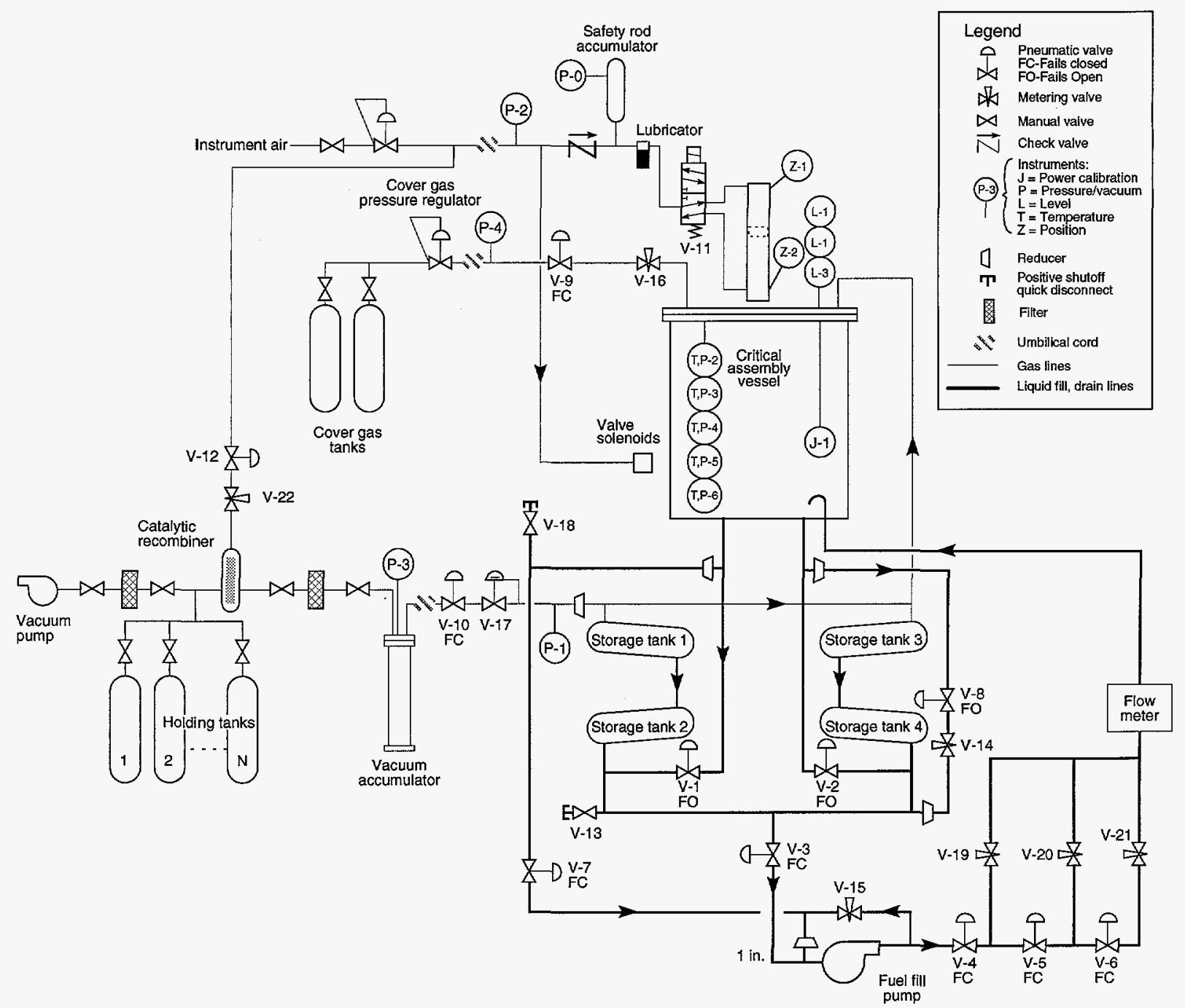

Fig. 3. SHEBA storage tanks, CAV, valves, pumps, and sensors.

The uranyl fluoride solution is highly corrosive $(\mathrm{pH} \sim 1.0)$. Materials that are in contact with the fuel have been selected to be compatible with this solution. These materials include: 300 -series stainless steel, Teflon (TFE), PVDF, ceramic, Viton, and cross-linked polyethylene.

\subsection{Critical Assembly Vessel (CAV)}

The CAV (see Fig. 4) is constructed from a 304L stainless-steel, 20-inch, schedule-20 pipe that is 30 inches long with custom machined flanges at the top and bottom. The inside diameter of the tank is 19.25 inches. A tube passes completely through the center of the tank to allow passage of the safety/burst rod. This tube is 2.5 -inch OD, 2-inch ID, 304L stainless steel. The top flange is machined from 0.75 -inch-thick $304 \mathrm{~L}$ stainless steel plate, 22.5 inches in diameter and is bolted in place. The bottom flange is machined from 1.125-inch-thick 304L stainless-steel plate, 19.5 inches in diameter and welded to the tank.

Connections in the bottom of the CAV provide a 1/2" fill tube and two 1" drain lines. The inlet tube enters the CAV 7-inches radially out from the center of the tank. The tube makes a $180^{\circ}$ bend so that the fuel is directed toward the bottom of the tank. The inlet tube protrudes a total of 
2.0-inches into the tank. The inlet tube is $1 / 2$-inch outside diameter, 0.035 -inch wall thickness, 304 stainless steel tubing. The two drain lines are 1-inch outside diameter with 0.035 -inch wall thickness, 304 stainless steel tubing. Two ports are also provided in the bottom plate to allow instrumentation to be inserted. These two ports are 5/8-inch in diameter and are covered with stainless steel flanges.

The volume/height ratio for this tank is 1.76 liters $/ \mathrm{cm}\left(273 \mathrm{in}^{3} / \mathrm{in}\right)$. The design pressure of this vessel is $150 \mathrm{psi}$. The system operates at a slight vacuum and at ambient temperature (the SHEBA building is heated but not cooled).

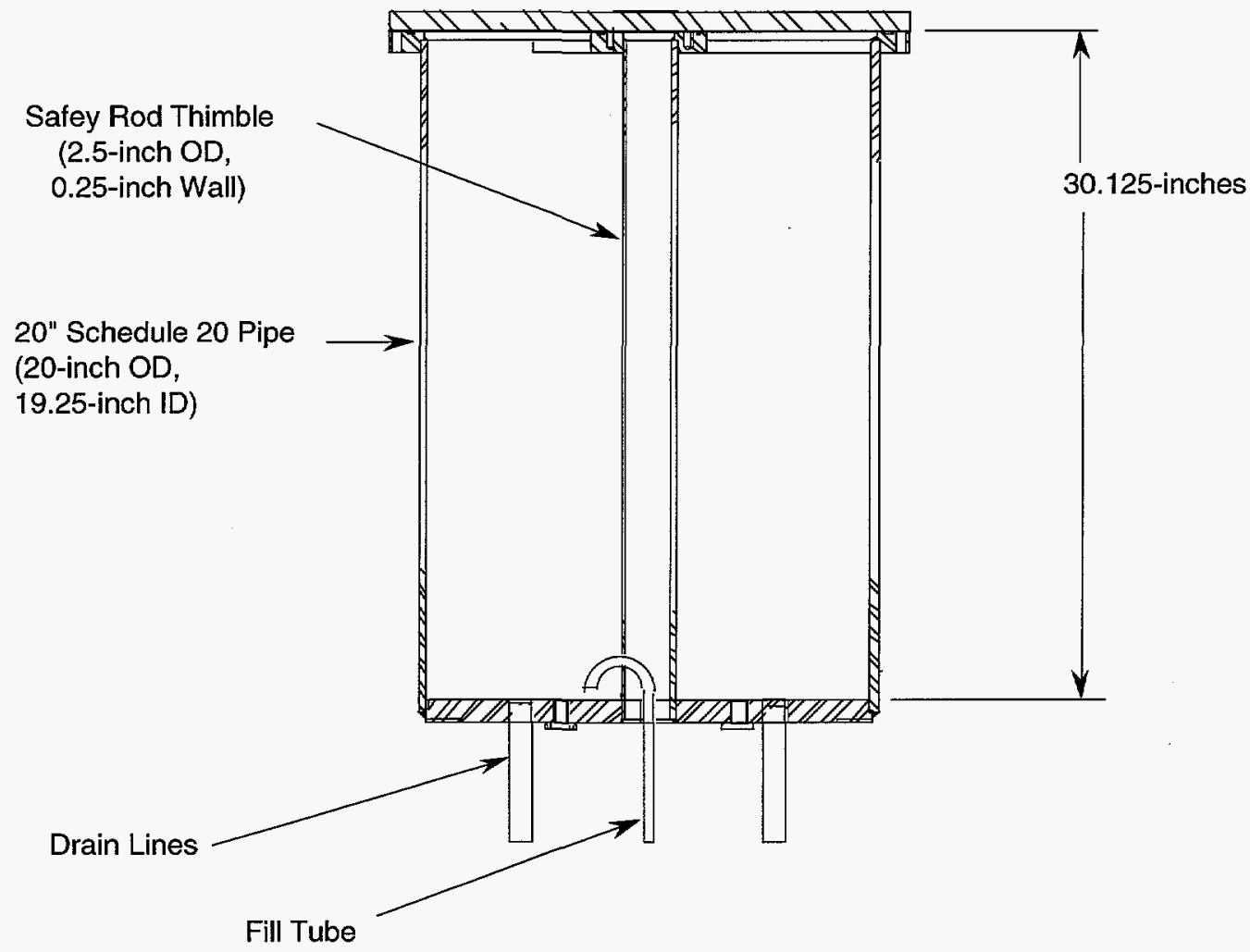

Fig. 4. Diagram of SHEBA critical assembly vessel (CAV).

\subsubsection{CAV Cover Plate}

A 0.75 -inch-thick stainless steel cover plate is provided for the CAV to seal the CAV from the atmosphere and allow access to the CAV for the following items

- Experiment Thimbles, Void Simulators, and a Video Camera

A 3.5-inch-diameter hatch is provided to allow insertion of thimbles to accommodate experiments in which the detectors or material samples cannot come in contact with the fuel. The same hatch may be used to insert items of various volumes to simulate the effects of voids on criticality. A window to allow viewing of the fuel with a video camera may also be installed in this port. A calibration fixture for calibrating the ultrasonic sensors may also be installed in this port.

- Level Probe/Switch (L-1)

One level probe is provided to shut off the high speed fill. This probe is constructed of a 0.0625 -inch diameter 304 stainless-steel rod and a Teflon Swagelok pass-through to 
electrically isolate the probe. The rod may be raised and lowered in the pass-through and then resealed to allow fine adjustment of height.

- Ultrasonic Level Probe (L-2)

Two 1.25-inch NPT threaded holes are provided in the cover to mount two ultrasonic sensors. The sensors provide a readout of the fuel level. One sensor is used for a reference and one to measure the distance to the surface of the solution. A metal shelf, attached 8-inches below the reference sensor, is used as the reference surface.

- Vent and Cover Gas Ports

Two gas fittings are provided for cover gas and vacuum attachment.

- Safety/Burst Rod Actuator

The safety/burst rod actuator mounts on the cover plate with four 3/8-16 UNC bolts.

- Instrumentation Port

A 1-inch NPT port for inserting pressure and temperature sensor arrays into the fuel is also provided. The initial installation has one thermocouple mounted in this location.

The thermocouple is a Chromel-Alumel type $\mathrm{K}$ thermocouple with a 304 stainless steel sheath. The diameter of the thermocouple is 1/4-inch with an insertion length of 24 inches (from the top of the CAV cover plate). ${ }^{2}$ The thermocouple is installed 8.0 -inches radially out from the center of the CAV.

\subsection{Fuel Handling System}

Fuel is added to SHEBA through the fill valve (V-18) which is located at the high point of the storage system. The assembly is drained through the main drain valve (V-26) located at the low point in the system. An auxiliary drain valve $(\mathrm{V}-25)$ is provided at the low point of the flow panel to allow draining of fuel that may be trapped in this area.

Fuel is added to the CAV through one of three possible paths: the fast speed (valves V-4, V-5 and V-6 all open) will fill at a rate of approximately $4 \mathrm{gpm}$. Medium speed (valves V-4 and V-5) will fill at a rate of about $2 \mathrm{gpm}$, and slow speed (valve V-4 only) will fill at a rate of about $0.6 \mathrm{gpm}$. The regulating valves in the medium and slow speed fill lines are provided with the calculated flow resistance near the midpoint of the valve capability to allow adjustment of these two rates over the widest range possible.

A bypass is provided around the pump so that the pump can be left running during slow approaches to critical.

Fuel is lowered from the CAV to the storage tanks through valves $V-8$ and $V-14$. The regulating valve $(\mathrm{V}-14)$ was selected to make this flow equal to the slow fill rate $(0.6 \mathrm{gpm})$.

A recirculating line is provided to allow recirculation of fuel from the CAV through valve V-7; fuel is then pumped into the CAV through one or more of the fill lines.

During a scram, 1-inch valves V-1 and V-2 open, allowing the fuel to flow by gravity into the storage tanks, filling them from the bottom. A vent line with the same cross-sectional area as the scram lines is provided to vent the storage tanks into the CAV while fuel is dumping to prevent pressure buildup. 
A sampling valve (V-25) is located directly below the CAV in the fill line to allow samples of the fuel to be taken for power calibration purposes.

\subsubsection{Storage Tanks}

There are four storage tanks located beneath the CAV. Each tank is made from 8-inch, schedule 40, 304L stainless steel pipe that is 32-inches long with an 8-inch weld cap on each end. The volume of each tank is about 31 liters.

\subsubsection{Pump}

The pump is a turbine pump with a magnetic coupling to eliminate a shaft seal. Materials in contact with the fuel are Kynar, ceramic, Teflon and Viton. The pump has a maximum head of 65 inches of $\mathrm{H}_{2} \mathrm{O}$ (28 psi) with a maximum flow rate of $16 \mathrm{gpm}$.

The pump is isolated from the piping system to minimize vibrations. The inlet and outlet lines immediately adjacent to the pump are equipped with flexible hoses.

\subsubsection{Scram Valves}

The system uses two scram valves. The valves are 1-inch ball valves. In the open position, the valves have the same flow area as the attached piping. The valve body is 316 stainless steel with Teflon (TFE) packings and seats. The valve body O-rings are Dupont Viton-A. Each Valve is equipped with a spring-return, pneumatic actuator powered by a solenoid pilot valve.

Each valve is also equipped with an explosion-proof limit switch to indicate either open or closed position.

Actuation time for these valves is approximately $0.067 \mathrm{sec}$.

\subsubsection{Other "Wetted" On/Off Valves}

All other on/off valves in the system which will come into contact with the fuel or gas effluent are also either 1-inch or 0.5 -inch ball valves. The valve materials are identical to the materials used in the scram valves. Each valve is equipped with a spring-return, pneumatic actuator powered by a solenoid pilot valve.

\subsubsection{Flow Regulating Valves}

The regulating valves in the fuel handling system $(\mathrm{V}-14,-19,-20$, and -25$)$ are tapered-stem-type regulating valves. The body of the valve is 316 stainless steel. The stem tip is a machined, highdensity TFE insert; the valve stem packing material is a ceramic-filled TFE outer gland and a machined virgin TFE inner packing.

The slow fill (V-19) and slow letdown (V-14) regulating valves are 0.25 -inch valves with a $0.156-$ inch orifice with an effective flow coefficient $(\mathrm{Cv})$ range up to 0.3 . The medium speed regulating valve (V-20) and the sampling valve (V-25) are 0.5 -inch valves with a 0.25 -inch orifice with an effective flow coefficient range up to 0.8 . The pump bypass valve $(\mathrm{V}-15)$ is a bellows-sealed regulating valve with a full open flow coefficient of 1.2 . The valve is 316 stainless steel with 321 stainless steel bellows.

\subsubsection{Piping}

The fuel handling piping is 1 -inch, and 1/2-inch 304 stainless steel, schedule 40 tubing with Swagelok fittings. 


\subsection{Cover-Gas System}

When operating at high power (about $2 \mathrm{~kW}$ ), radiolytic gas $\left(\mathrm{H}_{2}\right.$ and $\mathrm{O}_{2}$ ) forms at the rate of $\sim 1 \mathrm{~L} / \mathrm{min}$. An inert-cover-gas system is provided to handle this radiolytic gas. This system also provides vents for the CAV and for the storage tanks. A vacuum accumulator, holding tank array, catalytic recombiner, filters, and pump are provided to recombine the radiolytic gases, remove particulates and droplets, and to provide storage until the effluent has decayed sufficiently to be released. The system is designed to contain two operating days of effluent from the system at a flow rate of 1 liter/min.

The cover-gas-inlet line includes the following:

- a nitrogen-gas regulator to decrease the pressure from gas-bottle pressure (2250 psig) to cover-gas-supply pressure ( 15 psia).

- A pressure-relief valve to relieve the line pressure in the event of a pressure-regulator failure. The relief valve is set to relieve at $50 \mathrm{psi}$ and is located upstream from the check valve so that only clean nitrogen is released when this valve opens. The valve is equipped with a manual opening handle to allow depressurization of the cover gas line for maintenance.

- A normally closed, two-way solenoid valve (V-9) is used for on/off control of the cover gas inlet. The valve plunger and body are stainless steel and the plunger insert is Buna-N.

- A metering valve is used to meter the inlet gas flow. The metering valve has a 316 stainless steel body and stem and a TFE packing system. The calculated $\mathrm{Cv}$ for achieving $\sim 1$ liter $/ \mathrm{min}$ of nitrogen flow at 26 psia inlet, 11 psia outlet is .0017 . This $\mathrm{Cv}$ is achieved with the metering valve open approximately 1 turn.

- A spring loaded check valve (V-22) is used to insure that the nitrogen gas supply is not contaminated with effluent in the event of system failures. The valve body is 316 stainless steel, the O-rings are Buna-N.

The effluent outlet line includes the following:

- A constant flow regulator. This regulator actually consists of two valves, a constant $\triangle \mathrm{P}$ regulator and a metering valve to produce a constant $\Delta \mathrm{P}$ across an orifice. This concept insures that the flow will remain constant even though the downstream pressure will vary, based on the amount of effluent collected in the holding tanks.

- A 0.5 -inch pneumatic on/off ball valve. This valve is identical to the 0.5 -inch pneumatic ball valves used in the fuel-handling system described above.

- A vacuum accumulator. The vacuum accumulator is a 5-inch-diameter, 30-inch-long, schedule 40 stainless steel pipe with 9-inch-diameter, ASA-style flanges on the top, and a 1inch stainless steel plate on the bottom. The internal volume of the accumulator is $608 \mathrm{cu}$. in. (10 liters). The top flange is drilled and tapped with connections for inlet piping, outlet piping, and a port for pressure instrumentation.

- Holding tanks. The holding tanks are carbon steel compressed-gas cylinders, 8 inches in diameter and 48 inches high, with an internal volume of $770 \mathrm{cu}$. in. (12.6 liters). There are six tanks with a total volume of $4,620 \mathrm{cu}$. in. (75.6 liters).

- Catalytic recombiner. The catalytic recombiner is a highly active, high-surface-area precious metal on a ceramic substrate which will recombine a stochiometric mixture of free oxygen and hydrogen to a residual of less than $1 \mathrm{ppm}$ at a flow rate of up to $10 \mathrm{scfh}(4.7 \mathrm{l} / \mathrm{min})$. The recombiner is fully welded construction and all screens, pads, fittings, etc. are 300 series stainless steel. 
- Filter. An activated carbon analytical filter is provided on the outlet from the vacuum pump. This filter is analyzed periodically to verify that radioactive iodine is not being released from the system.

- Vacuum pump. A roughing pump is used to provide the vacuum for this system.

- Manual isolation valves are used to select between the holding tanks and vacuum-pump lines in the effluent treatment system. These valve are 0.75 -inch ball valves, identical to the valves used in the fuel handling system described above.

\subsection{Safety-Rod System}

The safety-rod system is equipped with a poison rod with a pneumatic operator. The rod travels through the CAV in a central thimble and does not come in contact with the fuel or breach the pressure boundary. The safety-rod system includes a pressure accumulator to insure scram action in the event of loss of instrument air. The rod will insert fully in approximately 0.1 second. Withdrawal speed is adjustable from 0.1 to about 0.5 seconds.

The safety rod is equipped with a follower. A source holder may be attached to the follower to pull the source up inside the CAV void when the safety rod is retracted. Detectors and material samples may also be attached to the safety-rod follower for insertion into the central void during operation. Figure 5 shows the SHEBA safety rod in the CAV.

\subsubsection{Safety Rod}

The SHEBA safety rod is a welded stainless steel assembly that consists of three primary parts: the housing for the boron poison, the rod that attaches the assembly to the actuator, and the hollow "follower" housing. The two housings are made from 1.5-inch-diameter schedule 5 pipe (nominal dimensions of this pipe are 1.900 inch OD, 1.770 inch ID) that is 20 inches long and the attaching rod is constructed from 1-inch x 0.065-inch wall tubing that is 24 inches long. Each section is welded to the mating part with a transition piece. A split block is used to attach the assembly to the pneumatic actuator. The poison is boron-loaded epoxy containing a minimum of $30 \%$ natural boron.

The filling for the rod was made from natural boron carbide (20\% Boron-10, $80 \%$ Boron-11). The epoxy is $3 \mathrm{M}$ product number MR-283U000 that has $4.3 \%$ hydrogen by weight and $49.5 \%$ carbon by weight. Other constituents (oxygen and chlorine) in the epoxy have been estimated from standard epoxy compositions since $3 \mathrm{M}$ considers the exact composition proprietary. In a $30 \%$ boron by weight mixture, the composition is:

$\begin{array}{lr}\text { Boron-10 } & 6.0 \% \\ \text { Boron-11 } & 24.0 \% \\ \text { Carbon } & 39.0 \% \\ \text { Hydrogen } & 2.6 \% \\ \text { Oxygen } & \sim 10.6 \% \\ \text { Chlorine } & \sim 17.8 \%\end{array}$

The measured density of the borated filler is $1.49 \mathrm{gm} / \mathrm{cc}$, the measured worth of the safety rod in SHEBA is $\$ 2.90$. 


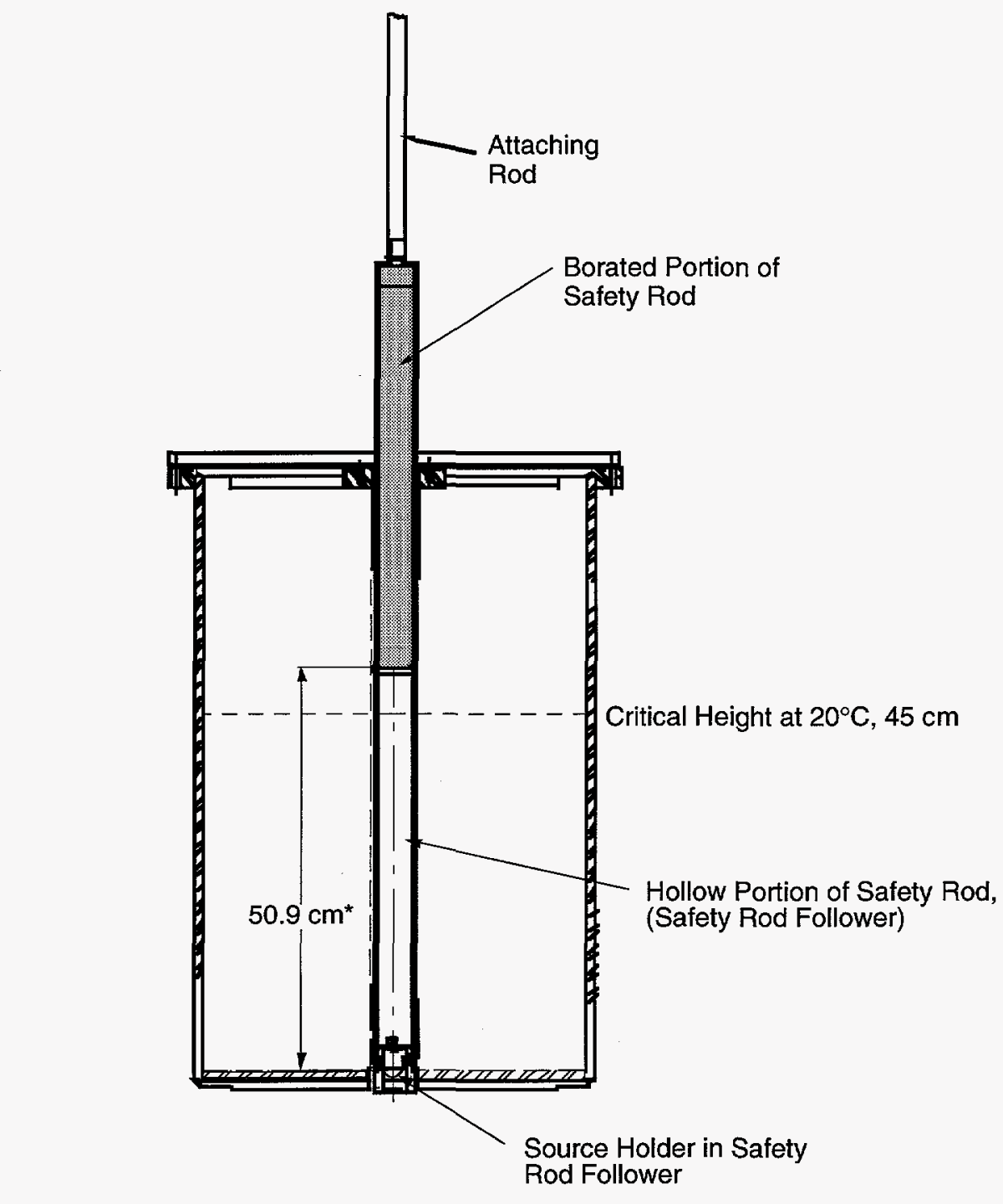

* This distance is adjustable and has been $48.1 \mathrm{~cm}$ as well as the current $50.9 \mathrm{~cm}$.

Fig. 5. SHEBA safety rod in the "up" position.

\subsubsection{Air Cylinder}

The safety-rod-actuation cylinder is a rodless cylinder with a $40-\mathrm{mm}$ bore and a 20 -inch travel. The cylinder is equipped with integral speed control valves and proximity position switches. The cylinder requires $39.0 \mathrm{cu}$. in. of air per stroke. A two-position, four-way, spring-return solenoid valve (V-11) is used to supply and exhaust air to the safety rod air cylinder. The flow capacity $(\mathrm{Cv})$ of the valve with 0.25 -inch NPT connections is 1.4 . At an instrument air pressure of $100 \mathrm{psi}$, the valve will exhaust the $39 \mathrm{cu}$. in. of air in the cylinder in $0.016 \mathrm{sec}$.

A miniature in-line lubricator was selected to provide lubrication for protection of the cylinder seals. The lubricator has an aluminum body with a polycarbonate bowl. An off-the-shelf sample cylinder was selected to provide backup air pressure to the safety rod actuator in the event of a loss of instrument air. 
The safety-rod system is provided with an accumulator to insure the presence of compressed air to move the safety rod in the event of a loss of instrument air. Since each stroke requires $39.0 \mathrm{cu}$. in. $(638 \mathrm{cc})$, a 1000 -cc cylinder was chosen for use as the accumulator. A check valve is provided in the air line to the safety rod accumulator to prevent the line and the accumulator from depressurizing if pressure is lost in the supply air system.

\subsection{Instrumentation and Control System}

SHEBA is operated remotely at Control Room 1 by a computer control system. There is an independent hardwire safety system which will scram the machine if boundary conditions are exceeded. All electrically operated devices on the machine are controlled by an Allen-Bradley remote I/O rack. This rack receives instructions from and transmits status to an Allen-Bradley Programmable Logic Controller (PLC). The PLC contains the operating and interlock logic for the proper and safe operation of SHEBA. The graphical user interface is obtained through an Allen-Bradley Control View station. This station monitors the activity of the PLC and displays the information on a graphics screen in a clear and coherent manner. The operator initiates permissible operations with a consolemounted joystick.

\subsubsection{Control System}

The SHEBA control system is based on present state-of-the-art PLCs. The control system uses an Allen-Bradley (A-B) product employing both commercially available hardware and software. A-B is an industry leader in the development and design of industrial control products. They have an extensive product line which is supported by telephone help services, full documentation, training classes, application engineers, and service personnel. These attributes make A-B an excellent choice of vendors to supply LACEF's electrical control needs.

Overview. The system can be broken down into the following three major subsystems:

1) the operator console, consisting of an IBM/AT-compatible 386 computer running A-B Control View (CV) software;

2) an A-B PLC 5/15 processor running A-B 6203 ladder logic software which implements the interlock and operator inputs to control SHEBA; and

3) an A-B remote $\mathrm{I} / \mathrm{O}$ rack which interfaces to all the real-world electrical devices necessary to control SHEBA.

Operator Console. The operator console communicates with the PLCs via the Data Highway+ (DH+). CV allows the operator to see what the PLC is doing and send system-specific commands. $\mathrm{CV}$ is a multitasking operating system which is database specific. When the operator's console is started, a batch file automatically starts CV and loads the control room database necessary to run SHEBA. CV requires the operator to log in before a machine can be run. Once an operator is logged in and a machine is selected, the graphics for SHEBA are loaded and SHEBA operation can commence, provided all of the safety system requirements have been met.

Programmable Logic Controller (PLC 5/15). The PLC 5/15 is the process control computer. Ladder logic is designed to provide the operations as described in the software design document. The program resides in a removable EEPROM cartridge inside the PLC 5/15 module. The PLC contains all the interlock and control functions for SHEBA. It interfaces to the operator interface (i.e. $\mathrm{CV}$ ) via the $\mathrm{A}-\mathrm{B} \mathrm{DH}+$ and the Remote $\mathrm{I} / \mathrm{O}$ rack via the Remote $\mathrm{I} / \mathrm{O}$ link. The PLC accepts machine-specific input from the operator via the joystick and system specific input via the CV station's keyboard or mouse. It processes this input and sends commands to the remote $\mathrm{I} / \mathrm{O}$ rack to effect operator commands. 
Remote $\mathrm{I} / \mathrm{O}$ Rack. The remote rack communicates with the PLC over the remote $\mathrm{I} / \mathrm{O}$ link at $57.6 \mathrm{~Kb} / \mathrm{s} . \mathrm{An}$ I/O image table and memory blocks are transferred back and forth providing the PLC with machine-state information and the remote rack with state-change information. The protocol is packet switching with error checking. If communication errors are detected, the remote rack will shut-down and set all outputs to their de-energized state.

\subsubsection{Safety-Related Systems}

The SHEBA critical assembly has a number of safety-related systems that insure fail-safe operation under unforeseen circumstances. Most notable is the design philosophy requiring a separate hardwire $\mathrm{AC}$ power interlock chain that can be disabled by any operator at any time manually from the control room. This single feature makes it possible to implement control systems of considerable complexity, without detailed failure analysis of individual components. Failure of the control system, in any manner, will result in the assembly reverting to its least reactive state.

Scram Chain. The SHEBA scram chain contains three links: two fission-power monitors and a manual reset. The fission-power monitors are energized by amplifiers in the control room and the manual reset consists of three series scram switches and a latching local reset.

Computer Watchdog. The computer watchdog is located directly after the scram chain and is required to apply "machine power" to the SHEBA control devices. It is a solid-state relay controlled by a retriggerable monostable circuit that requires both a periodic clock signal and a reset pulse to operate. This control system interlock in the scram AC power chain is an additional safety measure to protect against failures of the control system (see the following sections). Operation of the computer watchdog requires that the scram chain be completed (i.e., all interlocks "made"). Once the scram chain is completed the watchdog will accept a "clock" or "machine-enable" signal. This signal is generated by the successful scan of ladder program rungs by the PLC. In addition, an initial reset pulse must be issued by the "operator" in order to latch the output that controls the application of machine power. This feature insures that, if a watchdog-initiated scram occurs, then the operator must deliberately re-apply machine power. This signal can only be issued when the SHEBA Critical Assembly meets "reset" conditions.

Communication Loss. The control system relies upon serial communication between the PLC and the remote I/O rack to properly control the SHEBA Critical Assembly. This physical layer of this communication link is a $57.6 \mathrm{~Kb} / \mathrm{s}$ balanced signal transmitted on shielded twinax. It is a packet switching, half-duplex arrangement that requires the PLC to initiate a data transfer from the I/O rack. These requests are composed of the digital input and output image tables and block transfers to and from intelligent modules such as the high-speed counter, thermocouple, and analog-to-digital converter. If communication is interrupted or a line fault occurs, then the remote $\mathrm{I} / \mathrm{O}$ rack will set all outputs to their de-energized state. This action will "safe" the machine in two ways: (1) scram AC power will be interrupted by the computer watchdog and (2) all valves and other electrical devices will go to their least-reactive state.

Computer Operating Properly. The PLC control program is written in Ladder Language and resembles relay circuits. The PLC scans the rungs of the ladder and initiates actions based upon the conditions of the rungs (i.e. interlock signals and operator input). As in any computer control system, there is a possibility of the program "hanging up" or ceasing to operate properly. Therefore, the PLC must be able to develop a clock signal at the proper frequency to maintain machine power via the computer watchdog. This is done by setting an output bit that is fed back to an input bit, then resetting the output if the input indeed toggled. This closed-loop feedback generates a clock signal whose frequency is half that of the PLC's 
ladder program scan time. Should the program execution time significantly increase or "hang," then the clock frequency will decrease, thus causing the watchdog monostable to "time out" and create a watchdog scram.

\subsubsection{Instrumentation and Electrical Hardware}

Electrical I/O devices are interfaced to the control computer by connection to the A-B remote rack. The remote rack resides in an electrical cabinet in the SHEBA building. Multiconductor and coaxial cables carry the signals between SHEBA and the electrical cabinet.

Limit Switches. The following dry-contact limit switches are read by an A-B DC input module located in the remote rack.

- Upper- and lower-limit switches sense the position of the safety rod.

- Level probe provides a hard limit for disabling the high-speed fill rate.

- Switches determine the presence of control air, cover gas, and vacuum pressure.

- Valve-position switches

Liquid-Level Measurement System. The liquid-level measurement system uses ultrasonic ranging transducers. In general, a sonic burst is transmitted into the cavity and the echo from the liquid surface is detected. The time interval between the burst and the echo is digitized by the very high speed counting module. This time interval is proportional to the distance. In order to increase the accuracy of the system, two transducers are used. One measures a known reference target and the other the surface of the fluid. This system, purchased from Contaq Corp., boasts a resolution of $0.18 \mathrm{~mm}$ with $\pm 1 \%$ accuracy.

The standard electronics package required modification to allow external digitization of the time interval. A latch was installed to drive the stop/start input on the A-B counting module. The transducers themselves are also slightly different from the off-the-shelf standard: (1) to accommodate a closed system, they are of one-piece construction with a hermetically sealed connector and (2) to prevent condensation on the transducer element, an integral heating element was added.

Calibration of the liquid level system is performed by experimentally determining the exact reference distance. This is done with a precise, variable test target that is varied over several inches while recording the number of counts obtained at each distance. This measurement defines the speed of sound (in counts $/ \mathrm{mm}$ ) which can then be used to determine the exact reference target distance based on the number of counts to the reference target. Since the speed of sound is highly dependent upon temperature, this procedure should be carried out at a constant temperature. Recalibration is required whenever a system parameter is changed (i.e., transducer, gain, tuning, etc.).

Mass-Flow Meter. The mass flow is measured by a MicroMotion mass-flow and density sensor. The sensor uses an oscillator to vibrate the flow tube at the resonant frequency of the tube and measures the resonant frequency change as the fluid moves through the tube. The sensor is installed in the CAV fill line to measure the fill rate of the system. The transducer interface provides both a $4-20 \mathrm{~mA}$ and $0-10 \mathrm{KHz}$ output that are proportional to the flow rate. The current signal drives a local process indicator while the frequency output will interface to the A-B high speed counting module.

Pressure. Pressure in the CAV is measured using a Baratron pressure sensor. The sensor is located in the vent line which connects the CAV to the storage tanks to equalize the pressure in the system. 
Temperature. The temperature of the fuel is measured with a type $\mathrm{K}$ thermocouple that transmits to an A-B temperature module. The thermocouple is located radially $20.2 \mathrm{~cm}$ from the center of the tank with the tip located at $25 \mathrm{~cm}$ from the bottom of the tank.

\subsection{Miscellaneous Services}

\subsubsection{Umbilical Cord}

An umbilical cord is provided to allow hoisting SHEBA out of and into the crypt without disconnecting the service supply lines. The cord contains

- AC power

- Signal cables

- Cover-gas supply (0.25 inch hose)

- Instrument-air supply (0.25 inch hose)

- Vent line (0.75 inch hose)

The umbilical employs the cable drag chain technology used on machine tools to provide protection and guiding to the cables.

The flexible portion of the vent line that travels in the umbilical cord is made from cross-linked polyethylene designed to withstand hydrofluoric acid. The selected hose is designed for full vacuum service with stainless steel, PT-type couplers on both ends. A 0.75 -inch-diameter hose was selected based on conductance calculations and the required bend radius to accommodate the SHEBA motion.

Compressed air hose with AN swivel connections on both ends are used for the compressed gas and nitrogen hoses in the umbilical cord. The hose has a rubber inner tube, nylon braid, and a 250psi pressure rating.

\subsubsection{SHEBA Rack}

A rack is provided to mount and support all of the SHEBA equipment that is to be located inside the crypt. The rack is equipped with lifting and guiding provisions to allow the assembly to be raised and lowered. The rack is provided with leveling feet for positioning the CAV to within $1^{\circ}$ of vertical in both the down-hole and on-the-cover positions.

\subsection{SHEBA Building}

The SHEBA assembly is located in a thin metal building. The thin metal walls are nearly transparent to neutron flux, which minimizes the influence of "room-return" neutrons to the experiment and, consequently, provides minimal attenuation of the neutron flux reaching the detector systems and experiments that may be located outside of the building. A pit in the floor of the building provides shielding for elevated-power SHEBA operation. A cross section of the SHEBA building is shown in Fig. 6 and a plan view of the building is shown in Fig 7. 


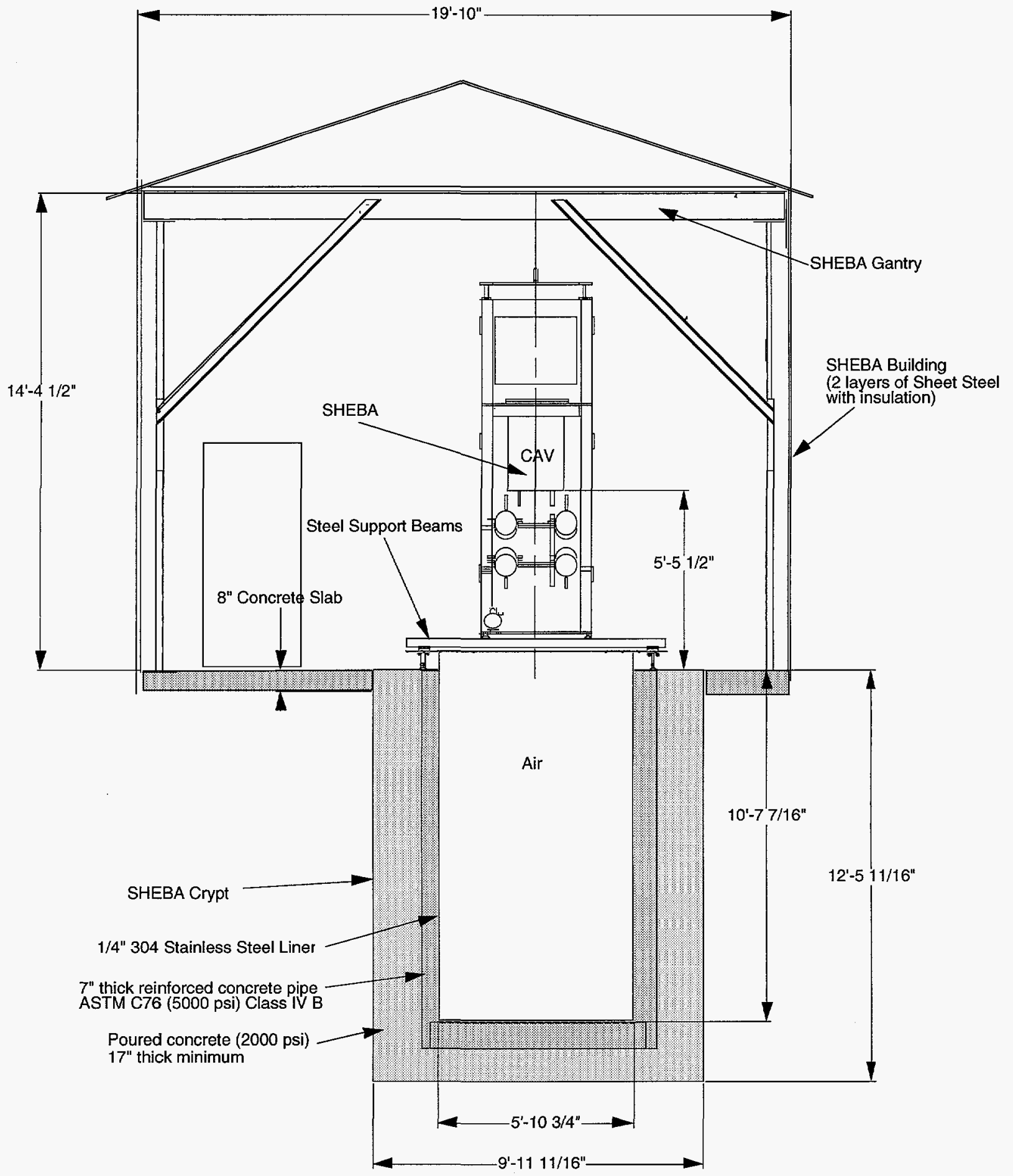

Fig. 6. SHEBA building elevation view. 

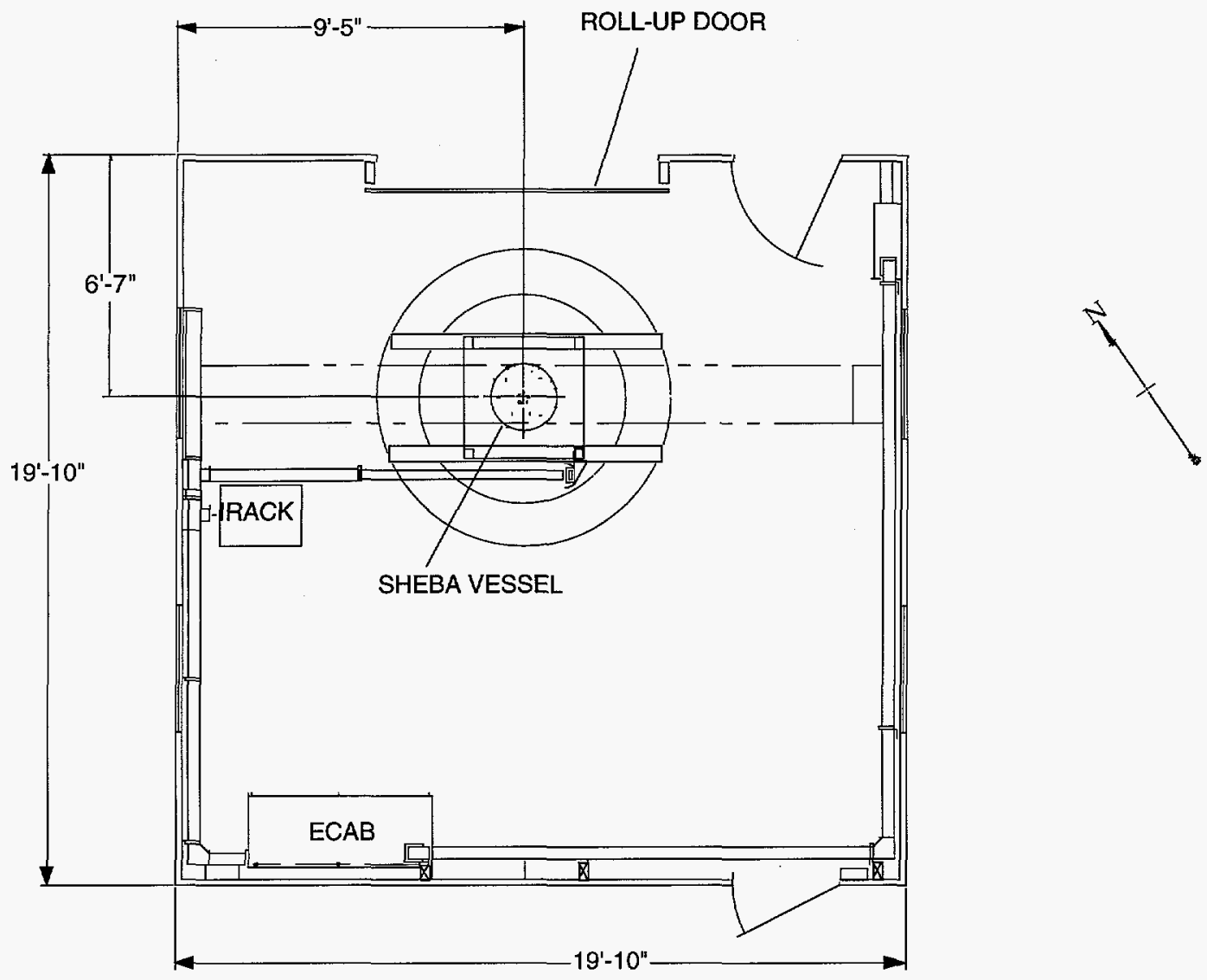

Fig. 7. Plan view of SHEBA building.

\subsubsection{Shielding Pit and Associated SHEBA Supports}

The shielding pit is a steel and concrete lined hole. The hole is 6 feet in diameter and 133 inches deep. Guides are provided on two sides to guide the SHEBA rack during insertion and removal from the crypt. The steel liner is equipped with a support ring to hold the steel liner down in the case of flooding of the concrete hole behind the liner. The crypt liner also serves as a catch pan in case of a fuel leak.

A support structure consisting of two 4- $\mathrm{x}$ 6-foot pieces of structural tubing with guides and supports at each end that support the full weight of SHEBA ( $3900 \mathrm{lbs})$ to allow operation of SHEBA above ground. The supports are put in place and removed manually.

Polyetheylene covers are provided to keep personnel from falling into the crypt while working around the machine and to provide additional shielding when SHEBA is operated in the pit.

\subsubsection{Hoist}

A stationary three-ton electric hoist system is provided to lower SHEBA into the crypt and to raise the system out of the crypt. The upper portion of the hoist structure provides guide rails to guide SHEBA during hoisting operations. The hoist hook remains in place at all times, precluding the need for remote attachment. 


\subsection{Fissile Solution Fuel}

SHEBA is approved for use with one of two fuels including uranyl fluoride and uranyl nitrate. The uranyl fluoride fuel for is low-enriched (nominal $5 \%{ }^{235} \mathrm{U}$ ), $\mathrm{U}(5.0) \mathrm{O}_{2} \mathrm{~F}_{2}$ with an $\mathrm{H} /{ }^{235} \mathrm{U}$ ratio of 450 .

The second fuel is a solution of up to $20 \%$ enriched uranyl nitrate, $\mathrm{U}(20) \mathrm{O}_{2}\left(\mathrm{NO}_{3}\right)_{2} * 6 \mathrm{H}_{2} \mathrm{O}+$ $\mathrm{HNO}_{3}+\mathrm{H}_{2} \mathrm{O} * \mathrm{U}(20)$. This fuel was obtained by diluting some of the $93 \%$ enriched uranyl nitrate in storage at LACEF with depleted uranyl nitrate. This fuel has a variable uranium concentration of 150 to $190 \mathrm{gmU} /$ /iter of solution or an $\mathrm{H} /{ }^{235} \mathrm{U}$ ratio of 687 to 870 . SHEBA is scheduled to be refueled with this second fuel in 1997. All of the results shown in this report are for the uranyl fluoride solution.

Fuel for the SHEBA experiments was originally mixed at Los Alamos and the starting density of the fuel was $2.16 \mathrm{gm} / \mathrm{cc}$ of solution. Prior to operation of the first SHEBA, the assembly was tested with water. Most, but not all of the water was drained out of the assembly prior to loading of the fuel. Several samples were taken after the fuel was then drained out of the original SHEBA and placed in storage. The average density of the fuel after draining was $2.12 \mathrm{gm} / \mathrm{cc}$, indicating a decrease of about $1.9 \%$ due to the dilution with water.

Prior to the fuel loading of the second SHEBA, the assembly was again tested first with water. The design of the second SHEBA allowed for a more complete drain of the water, but some residual water remained when the fuel was loaded. Samples taken from the second SHEBA in 1996 indicate that the density is now down to $2.11 \mathrm{~g} / \mathrm{cc}$. Table 2 is a comparison of the analyses of SHEBA including density, uranium content, and uranium isotopic analysis.

Assuming a fuel composition of $\mathrm{UO}_{2} \mathrm{~F}_{2}+\mathrm{H}_{2} \mathrm{O}+0.5 \mathrm{MHF}$, and the Table 2 values for the isotopic concentrations, the fuel is calculated ${ }^{3}$ to contain:

$\begin{array}{cc}\text { Isotope } & \begin{array}{c}\text { Concentration } \\ \text { (atoms/barn-cm) }\end{array} \\ \mathrm{H} & 5.5997 \times 10^{-2} \\ \mathrm{O} & 3.2800 \times 10^{-2} \\ \mathrm{~F} & 5.2538 \times 10^{-2} \\ { }^{234} \mathrm{U} & 6.7728 \times 10^{-7} \\ { }^{235} \mathrm{U} & 1.2376 \times 10^{-4} \\ { }^{236} \mathrm{U} & 1.2085 \times 10^{-6} \\ { }^{238} \mathrm{U} & 2.3507 \times 10^{-3}\end{array}$

The SHEBA fuel is stored in critically safe FL10 bottles when it is not in the SHEBA fuel tanks. The bottles are stored in racks that maintain physical separation. Only one bottle at a time may be moved. This prevents accidental criticality that might result from collecting several bottles in a tight array. Any leaks from the SHEBA assembly are contained by the SHEBA pit. The large area of the SHEBA pit assures that a safe geometry is maintained even if the total inventory were to leak into the pit. There are no drains in the SHEBA building and there are no regions where an unsafe amount of fuel might collect outside the pit. 
Table 2. Analysis of $\mathrm{UO}_{2} \mathrm{~F}_{2}$ SHEBA fuel

\begin{tabular}{|c|c|c|c|c|c|c|}
\hline \multirow{2}{*}{$\begin{array}{l}\text { Sample } \\
\text { Date-Number }\end{array}$} & \multirow{2}{*}{$\begin{array}{c}\text { Density of } \\
\text { Solution } \\
(\mathrm{g} / \mathrm{cc})\end{array}$} & \multirow{2}{*}{$\begin{array}{c}\text { Uranium } \\
\text { Content } \\
(\mathrm{g} / \mathrm{g}) \\
\end{array}$} & \multicolumn{4}{|c|}{ Atom Percent } \\
\hline & & & ${ }^{234} \mathrm{U}$ & ${ }^{235} \mathrm{U}$ & ${ }^{236} \mathrm{U}$ & ${ }^{238} \mathrm{U}$ \\
\hline $1^{(4)}$ & 2.16 & 0.486 & 0.028 & 5.05 & 0.051 & 94.97 \\
\hline $2^{(4)}$ & 2.16 & 0.486 & 0.026 & 4.98 & 0.049 & 94.94 \\
\hline $3^{(4)}$ & 2.16 & 0.477 & 0.027 & 5.04 & 0.050 & 94.98 \\
\hline $4^{(4)}$ & 2.16 & 0.486 & 0.025 & 4.99 & 0.050 & 94.94 \\
\hline $5^{(4)}$ & 2.16 & 0.477 & 0.026 & 5.01 & 0.048 & 94.92 \\
\hline \multicolumn{7}{|l|}{ First SHEBA Drained } \\
\hline $2 / 7 / 89-15 S^{(5)}$ & & 0.465 & 0.028 & 5.00 & 0.049 & 94.92 \\
\hline 2/14/89-SHEBA \# $1^{(6)}$ & 2.126 & 0.454 & 0.028 & 5.02 & 0.049 & 94.90 \\
\hline 3/19/91-SHEBA3(S1) ${ }^{(7)}$ & 2.12 & 0.467 & 0.028 & 5.00 & 0.050 & 94.92 \\
\hline 3/19/91-SHEBA3(S2) ${ }^{(7)}$ & 2.12 & 0.467 & 0.028 & 5.00 & 0.050 & 94.92 \\
\hline \multicolumn{7}{|l|}{ Second SHEBA Loaded } \\
\hline $9 / 22 / 95-\# 1^{(8)}$ & 2.07 & 0.491 & 0.026 & 4.942 & 0.048 & 94.983 \\
\hline $9 / 22 / 95-\# 2^{(8)}$ & 2.15 & 0.493 & 0.027 & 4.943 & 0.049 & 94.981 \\
\hline 2/5/96-SHEBAS $1-B 1^{(9)}$ & $2.109\left(\right.$ at $\left.21^{\circ} \mathrm{C}\right)$ & 0.4637 & 0.0274 & 4.9981 & 0.0486 & 94.9258 \\
\hline 2/5/96-SHEBAS2-B2 $2^{(9)}$ & 2.109 (at $21^{\circ} \mathrm{C}$ ) & 0.4639 & 0.0273 & 4.9973 & 0.0490 & 94.9265 \\
\hline
\end{tabular}

Impurities in the uranyl fluoride were measured in $1995^{8}$. These measurements were made to determine the extent of corrosion in the stainless steel due to contact with uranyl fluoride. Three identical samples were taken from SHEBA and then analyzed. One of the samples was contaminated with aluminum from the sample container lid during transport to the analysis laboratory. Table 3 is a summary of the results from the analysis of the other two samples. A blank in the table means that this element was sampled for but the results were below the detection limit of the system. Several of the major impurities, iron, nickel, manganese, do indicate some corrosion of the stainless steel. 
Table 3. Measured impurities in SHEBA fuel

\begin{tabular}{|c|c|c|}
\hline Element & $\begin{array}{c}\text { Sample } 1 \\
(\mathbf{p p m})\end{array}$ & $\begin{array}{c}\text { Sample } 2 \\
(\mathbf{p p m})\end{array}$ \\
\hline $\mathrm{Al}$ & 34.0 & 43.6 \\
\hline \multicolumn{3}{|l|}{$\mathrm{Bi}$} \\
\hline B & & 0.33 \\
\hline $\mathrm{Cd}$ & 0.41 & 0.50 \\
\hline \multicolumn{3}{|l|}{$\mathrm{Ca}$} \\
\hline \multicolumn{3}{|l|}{$\mathrm{Cr}$} \\
\hline $\mathrm{Co}$ & 0.85 & 3.04 \\
\hline $\mathrm{Cu}$ & 8.5 & 10.71 \\
\hline \multicolumn{3}{|l|}{ In } \\
\hline $\mathrm{Fe}$ & 288 & 181 \\
\hline $\mathrm{Pb}$ & & 3.43 \\
\hline $\mathrm{Mg}$ & 2.4 & 0.52 \\
\hline $\mathrm{Mn}$ & 4.26 & 11.28 \\
\hline \multicolumn{3}{|l|}{ Mo } \\
\hline $\mathrm{Ni}$ & 50.9 & 14.11 \\
\hline \multicolumn{3}{|l|}{$\mathrm{Si}$} \\
\hline $\mathrm{Sn}$ & 0.96 & \\
\hline \multicolumn{3}{|l|}{$\mathrm{Ti}$} \\
\hline \multicolumn{3}{|l|}{$W$} \\
\hline \multicolumn{3}{|l|}{$\mathrm{V}$} \\
\hline $\mathrm{Zn}$ & 8.34 & 8.93 \\
\hline $\mathrm{Ba}$ & & 11.58 \\
\hline \multicolumn{3}{|l|}{$\mathrm{Na}$} \\
\hline $\mathrm{Zr}$ & & 57.42 \\
\hline $\mathrm{Bg} 1$ & .048 & 0.13 \\
\hline Bg2 & 1.42 & 2.56 \\
\hline $\mathrm{Bg} 3$ & 0.27 & 0.58 \\
\hline
\end{tabular}




\subsection{Other Physical Characteristics of SHEBA Fuel}

\subsubsection{Specific Heat Experiments}

A simple experiment was designed to determine the specific heat of the SHEBA fuel. After a series of trials, the following values were determined:

$2.17 \mathrm{~J} / \mathrm{gm}-{ }^{\circ} \mathrm{C}+.37,-.28$

\subsubsection{Definition of Specific Heat}

Specific heat is defined as the quantity of energy required to change the temperature of a given substance. For water, the baseline is 1 calorie/gram $/{ }^{\circ} \mathrm{C}$. This converts to 4.18 Joules/gram- ${ }^{\circ} \mathrm{C}$.

\subsubsection{Design of the Experiment}

The experimental setup involved placing the SHEBA fuel into a vacuum dewar with a Styrofoam lid. A heating element was connected to a watt-hour meter in such a way that the total energy into the system (in units of kilowatt-hours, later converted to Joules) was displayed, and then later printed out for a permanent record. The heater consumed an average of 390 watts, with an average running time of three to five minutes. The thermocouple was placed through the Styrofoam lid on the container and set to display the temperature in degrees Celsius. Mixing of the fuel during the experiment was accomplished by gently rotating the vacuum container and gently stirring occasionally with a glass stir rod.

The heater was turned on for a short interval and then turned off. The fuel was stirred until an apparent equilibrium temperature was reached. Both the watt-hours and the fuel temperature was recorded and the process was repeated.

The Specific Heat of the fuel is then calculated by:

$\mathrm{S}=($ Power $)($ Time $) /$ (Mass) $($ Change in Temperature $)$.

\subsubsection{Experimental Equipment}

- Heating Element: Quartz Heater, FISHER SCIENTIFIC Cat. No. 11-463-15, 115 VAC, 400 W, $3.5 \mathrm{~A}$.

- Watt-Hour Meter: Single phase watt/watt hour meter BMJ Model No. 3030A

- Two-Liter Thermos Bottle

- Styrofoam Lid for Thermos Bottle

- Thermocouple and Readout, accurate to $0.1{ }^{\circ} \mathrm{C}$.

\subsubsection{Results}

The first experiment was run using uranyl fluoride with five intervals of temperature. The results are as follows:

Mass of uranyl fluoride $=6555$ grams

$\begin{array}{lc}\text { Interval }\left({ }^{\circ} \mathrm{C}\right) & \text { Specific heat }\left(\mathrm{J} / \mathrm{g}-{ }^{\circ} \mathrm{C}\right) \\ 1(21.6-27.5) & 2.50 \pm .15 \\ 2(28.5-37.1) & 2.10 \pm .15 \\ 3(37.7-46.0) & 2.18 \pm .15 \\ 4(46.7-54.4) & 2.35 \pm .15 \\ 5(55.2-62.9) & 2.35 \pm .15\end{array}$


Tap water was also tested for comparison. For water, the measured specific heat is $4.60 \mathrm{~J} / \mathrm{g}-{ }^{\circ} \mathrm{C}$, as opposed to an accepted value of $4.18 \mathrm{~J} / \mathrm{g}-{ }^{\circ} \mathrm{C}$. However, we performed this "calibration" experiment first, and as seen above, the first specific heat calculated for the SHEBA fuel is off from the others.

The second run of the specific heat concentrated on the expected operating temperature range of SHEBA. The fuel was cooled in an ice bath prior to starting the experiment to obtain data below $20^{\circ} \mathrm{C}$.

The results for uranyl fluoride are presented in Table 4. Figure 8 is a graphical representation of this data showing the error bars associated with the resolution of the instrumentation.

Table 4. Specific heat of the $5 \%$ uranyl fluoride fuel

Mass of the thermos prior to filling $=2397 \mathrm{gm}$

Mass of the thermos with uranyl fluoride $=8715 \mathrm{gm}$

Mass of uranyl fluoride used in this experiment $=6318 \mathrm{gm}$

\begin{tabular}{|c|l|c|c|c|c|}
\hline Time & $\begin{array}{c}\text { Temperature } \\
{ }^{\circ} \mathbf{C}\end{array}$ & $\begin{array}{c}\Delta \text { Temp } \\
{ }^{\circ} \mathbf{C}\end{array}$ & $\begin{array}{c}\text { Energy } \\
\mathbf{k W} \text {-hrs }\end{array}$ & $\begin{array}{c}\Delta \text { Energy } \\
\mathbf{k W}-\mathbf{h r s}\end{array}$ & $\begin{array}{c}\text { Specific Ht } \\
\mathbf{J} / \mathbf{g}-{ }^{\circ} \mathbf{C}\end{array}$ \\
\hline 0 & $10.1 \pm .05$ & 0 & & & \\
\hline 3 & $15.5 \pm .05$ & 5.4 & $0.020 \pm .0005$ & .020 & $2.11 \pm .15$ \\
\hline 3 & $21.2 \pm .05$ & 5.6 & $0.039 \pm .0005$ & .029 & $1.89 \pm .15$ \\
\hline 3 & $26.7 \pm .05$ & 5.5 & $0.059 \pm .0005$ & .020 & $2.07 \pm .15$ \\
\hline 3 & $32.1 \pm .05$ & 5.4 & $0.079 \pm .0005$ & .020 & $2.11 \pm .15$ \\
\hline 3 & $37.6 \pm .05$ & 5.5 & $0.099 \pm .0005$ & .020 & $2.07 \pm .15$ \\
\hline & & & & & \\
\hline 15 & & 27.5 & $0.099 \pm .0005$ & .099 & $2.05 \pm .03$ \\
\hline
\end{tabular}

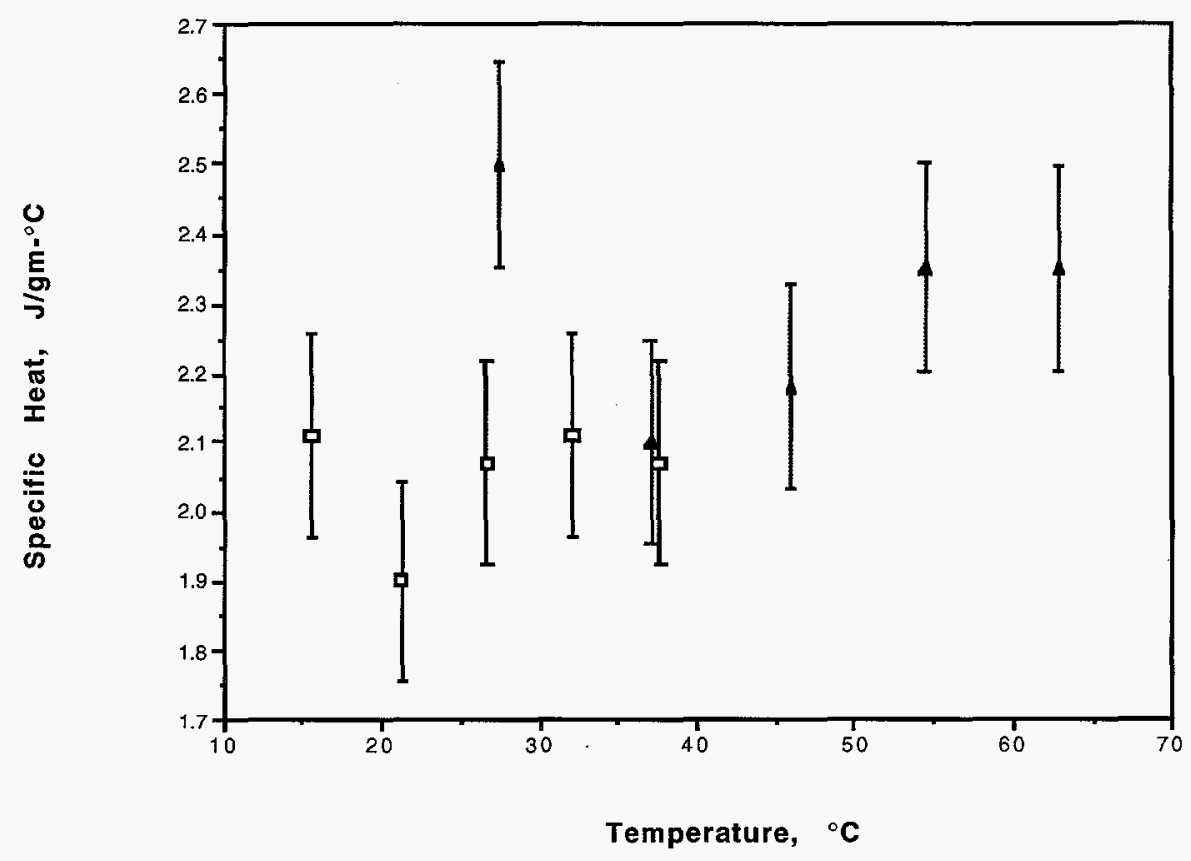

Fig. 8. Specific heat of $5 \%$ enriched uranyl fluoride. 


\subsubsection{Sources of Error}

Possible sources of error in this experiment include the lack of resolution in the watt-hour meter and the thermocouple, each giving the data in only two significant figures. In addition, an unknown amount of heat was lost through the lid of the container. The quartz heater also showed some plateout of the fuel on the heater which is not accounted for in the results. It is also noted that the second measurement in both experiments was considerably lower than the other measurements (even though they were taken at substantially different temperatures), suggesting that the watt-hour meter, the thermocouple, or the stirring technique may have had some initial lag.

\subsubsection{Conclusions}

The main difficulty in the specific heat experiment lies in the fact that only two significant figures are available for computing the results.

However, the experiments were not without merit. The uranyl fluoride experiment gave an indication that the calculated value of the specific heat of the uranyl fluoride of $2.16 \mathrm{~J} / \mathrm{g}-{ }^{\circ} \mathrm{C}$ is quite good. The range of the data recorded is 1.89 to $2.50 \mathrm{~J} / \mathrm{g}-{ }^{\circ} \mathrm{C}$.

\subsection{Volumetric Coefficient of Expansion Experiment}

An experiment was designed to determine the volumetric expansion rate of the SHEBA fuel.

\subsubsection{Definition of Volumetric Expansion}

Volumetric expansion is the change in volume of one unit of volume for a temperature change of $1{ }^{\circ} \mathrm{C}$. For reference, the volumetric expansion of water is $0.000207^{\circ} \mathrm{C}-1$. It can be mathematically defined as

$$
\frac{\Delta V / V_{\text {init }}}{\Delta T}
$$

where $V_{\text {init }}$ is the initial volume of the fuel at a given temperature, $T_{0}$, and $\Delta V$ is the change in volume, due to a change in temperature, $\Delta \mathrm{T}$.

If the initial mass is known, it is possible to determine a density vs. temperature relationship with this experiment. Since the initial mass is known, and the density results are useful as well, both the coefficient of volumetric expansion and the density vs. temperature will be reported for these experiments.

\subsubsection{Experiment Setup}

A large flask (of approximately one liter volume) is fully filled with the fuel to be investigated. The exact volume and mass of fuel in the flask is measured using a graduated cylinder and a balance. A rubber stopper is placed in the opening of the flask. A graduated pipette is placed through a hole in the stopper to allow the fuel to expand into the pipette. In addition, a thermocouple is placed through an additional hole in the stopper to provide a means of measuring the temperature of the fuel.

The flask is placed on a stirring hot plate with a ceramic stir bar to provide even heating during the experiment. 
As the temperature of the fuel increases, the fuel will expand. Since the pipette is graduated, the volume change can be easily determined to within $0.05 \mathrm{ml}$. At small intervals, the temperature and volume are recorded. A diagram of the experimental apparatus is shown in Fig. 9.

The results of this experiment are presented in Table 5 .

The coefficient of volumetric expansion appears to increase with temperature. Over the temperature range tested of $17.7^{\circ} \mathrm{C}$ to $40^{\circ} \mathrm{C}$, the volumetric coefficient of expansion varied from $2.88 \times 10^{-6}{ }^{\circ} \mathrm{C}^{-1}$ to $5.71 \times 10^{-6}{ }^{\circ} \mathrm{C}^{-1}$. The average is $4.34 \times 10^{-6}{ }^{\circ} \mathrm{C}^{-1}$.

The density decreased as the temperature increased at a slightly nonlinear rate.

Figures 10 and 11 show the results of these measurements.

\subsubsection{Sources of Error}

Possible sources of error in this experiment include the lack of resolution in the pipette and the thermocouple.

\subsubsection{Conclusions}

The volumetric coefficient of expansion values ranged from $2.88 \times 10^{-6} \mathrm{C}^{-1}$ to $5.71 \times 10^{-6}{ }^{\circ} \mathrm{C}^{-1}$ for the uranyl fluoride. The density values ranged from 2.13 to $2.15 \mathrm{~g} / \mathrm{ml}$.

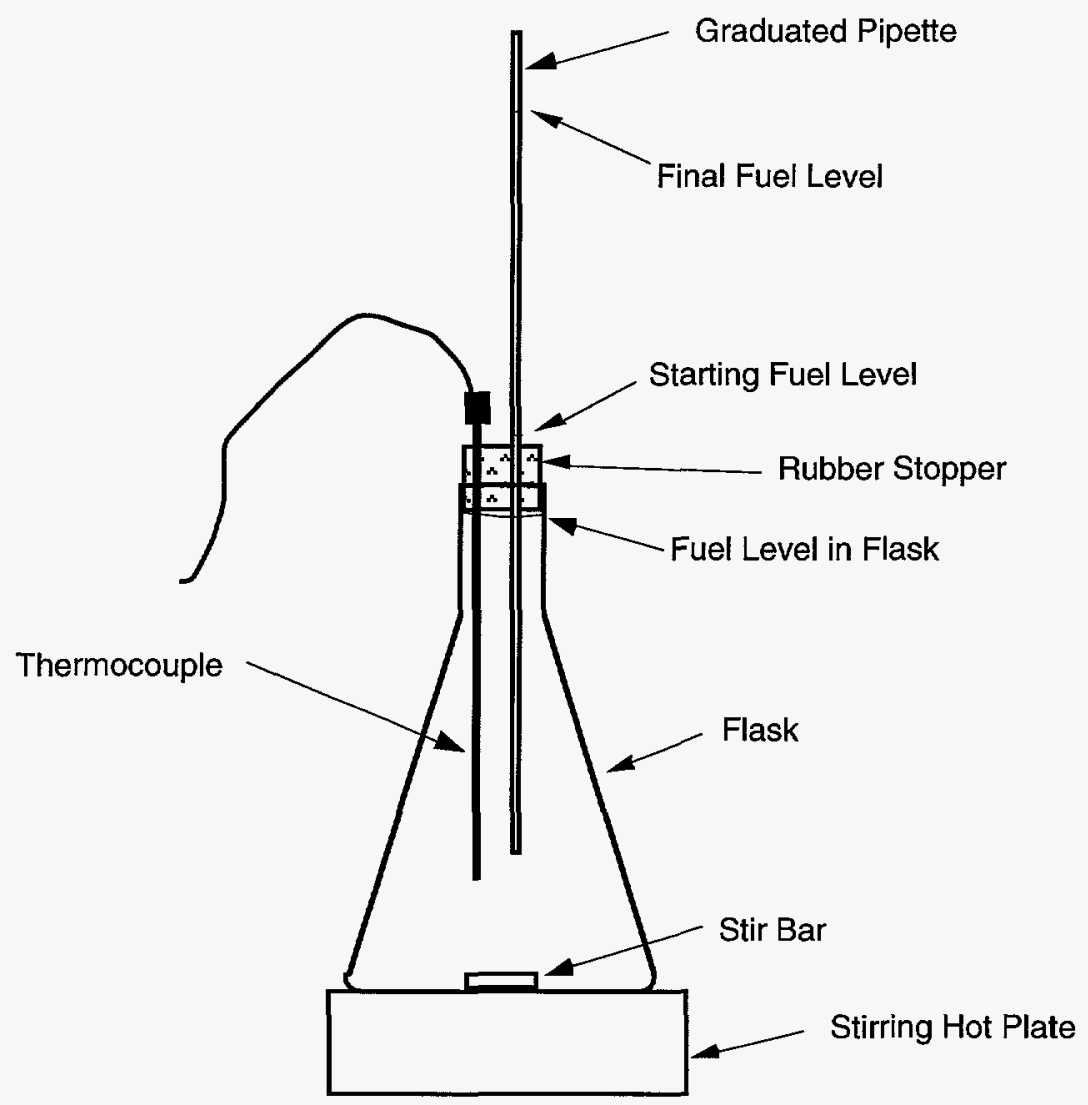

Fig. 9. Experimental apparatus for volumetric coefficient of expansion experiment. 
Table 5. Volumetric coefficient of expansion for $5 \%$ uranyl fluoride

Mass of uranyl fluoride $=2352 \mathrm{gm}$

Initial volume of uranyl nitrate $=1095 \mathrm{~mL}$

\begin{tabular}{|c|c|c|c|}
\hline $\begin{array}{c}\text { Temperature } \\
\left({ }^{\circ} \mathrm{C}\right) \\
\end{array}$ & $\begin{array}{c}\text { Pipette Level } \\
(\mathbf{m L})\end{array}$ & $\begin{array}{c}\text { Volume Coeff of } \\
\text { Expansion }\left(\mathrm{x} \mathrm{10}^{-4}{ }^{\circ} \mathrm{C}^{-1}\right)\end{array}$ & $\begin{array}{l}\text { Density } \\
(\mathrm{g} / \mathrm{ml})\end{array}$ \\
\hline 17.7 & 8.4 & & $2.148 \pm .002$ \\
\hline 19.6 & 9.0 & $2.9 \pm 0.7$ & $2.147 \pm .002$ \\
\hline 22.0 & 10.0 & $3.8 \pm 0.6$ & $2.145 \pm .002$ \\
\hline 24.2 & 11.0 & $4.2 \pm 0.6$ & $2.143 \pm .002$ \\
\hline 26.4 & 12.0 & $4.2 \pm 0.6$ & $2.141 \pm .002$ \\
\hline 28.4 & 13.0 & $4.6 \pm 0.7$ & $2.139 \pm .002$ \\
\hline 30.8 & 14.0 & $3.8 \pm 0.6$ & $2.137 \pm .002$ \\
\hline 32.4 & 15.0 & $5.7 \pm 1.0$ & $2.135 \pm .002$ \\
\hline 34.6 & 16.0 & $4.2 \pm 0.6$ & $2.133 \pm .002$ \\
\hline 36.5 & 17.0 & $4.8 \pm 0.8$ & $2.131 \pm .002$ \\
\hline 38.3 & 18.0 & $5.1 \pm 0.8$ & $2.129 \pm .002$ \\
\hline \multirow[t]{2}{*}{40.0} & 19.0 & $5.4 \pm 0.9$ & $2.127 \pm .002$ \\
\hline & Total & $4.34 \pm 0.6$ & \\
\hline
\end{tabular}

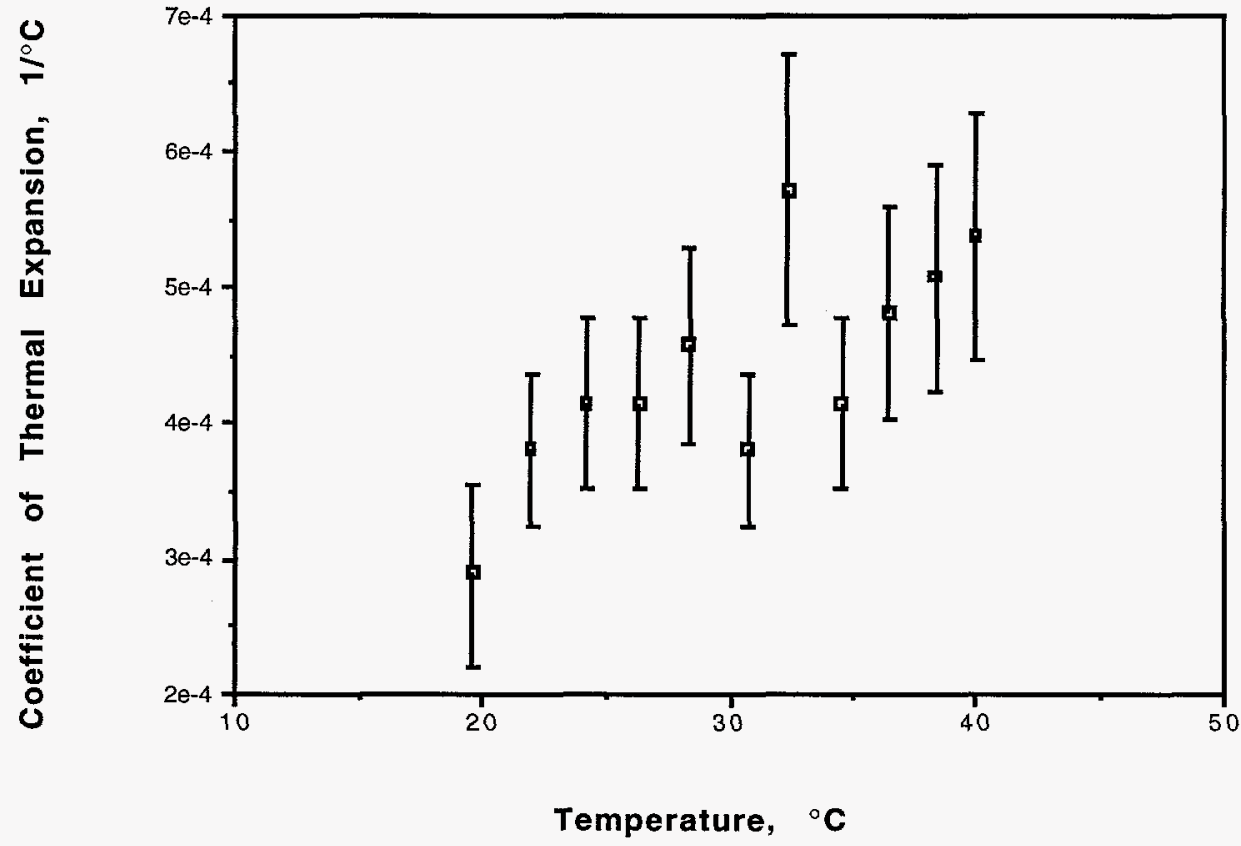

Fig. 10. Coefficient of thermal expansion for 5\%-enriched uranyl fluoride. 


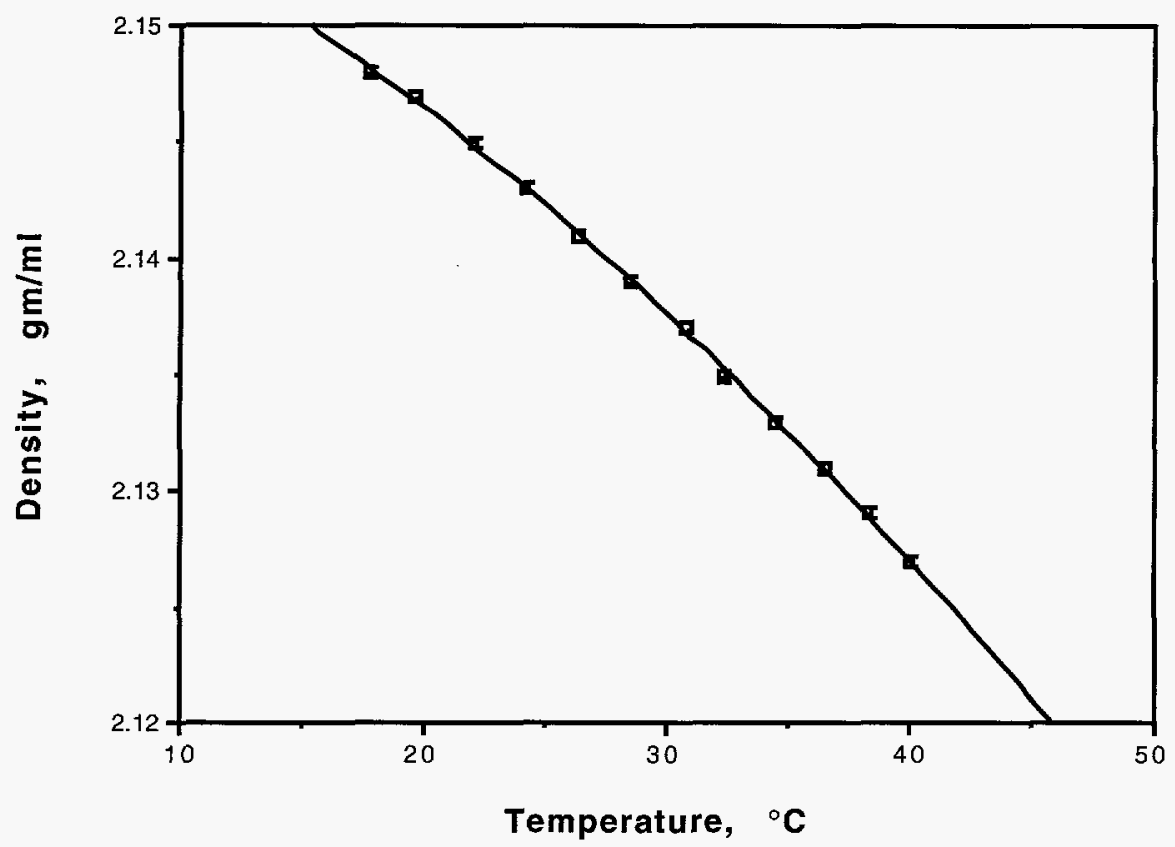

Fig. 11. Density of 5\%-enriched uranyl fluoride.

\subsection{Viscosity}

Viscosity of the SHEBA uranyl fluoride fuel was measured using a calibrated falling ball viscosity meter. This type of meter uses a ball of known density in a close fitting-tube. At a given time, the ball is released into the fluid. The time it takes the ball to fall through the fluid from one mark to the next on the tube is measured. This time is then used to calculate the viscosity of the fluid. The results from this experiment showed that the SHEBA fuel has a viscosity of $18.5 \mathrm{cp}$, or more than 18 times that of room-temperature water.

\subsection{SHEBA Operating Experience}

This section describes the accumulated experience in operating SHEBA both in free run and steady state modes.

\subsection{SHEBA Free Runs Simulating Uranium-Solution Criticality Accidents}

During the past few years, SHEBA has been operated in the "free run" mode to observe the behavior of the system. A "free run" consists of establishing an initial reactor period and then the assembly is allowed to operate itself (or free run).

Initial measurements on SHEBA provided some revealing results. The process-line-accident experiment simulations involved a slow approach to a slightly supercritical configuration in the absence of an extraneous neutron source, as might happen with a slow pipe leak into a drum. The experiment was then allowed to run free until termination of the transient occurred. Initial termination resulted from the slow thermal expansion produced by the energy release resulting from approximately $4 \times 10^{16}$ fissions that induced a $3-$ to $4^{\circ} \mathrm{C}$ temperature rise. There was no boiling, thermal shock, or gas evolution. 
Subsequent free runs gradually increased the initial reactor period. At an initial period of about 40 seconds, evidence of radiolytic gas production was first seen. Based on the free run data, radiolytic gas evolution begins with a total energy deposition of $1.3 \times 10^{-2}$ amp-sec (approximately $3 \times 10^{15}$ fissions). Subsequent runs with faster initial periods dramatically increased the effect of radiolytic gas. Figure 12 shows a plot of four typical free runs with 20 -second, 14-second, 5-second, and 1 -second initial periods. The fast initial periods produce multiple peaks.

A composite graph was compiled to compare the initial reactivity insertion with the final peak power achieved during the series of free runs. Figure 13 shows this comparison. A composite graph was also compiled to compare the total number of fissions from the free run as a function of the initial reactivity insertion. This comparison is shown in Fig. 14. With the exception of the anomalous 10-second free run (see below), the data are consistent.

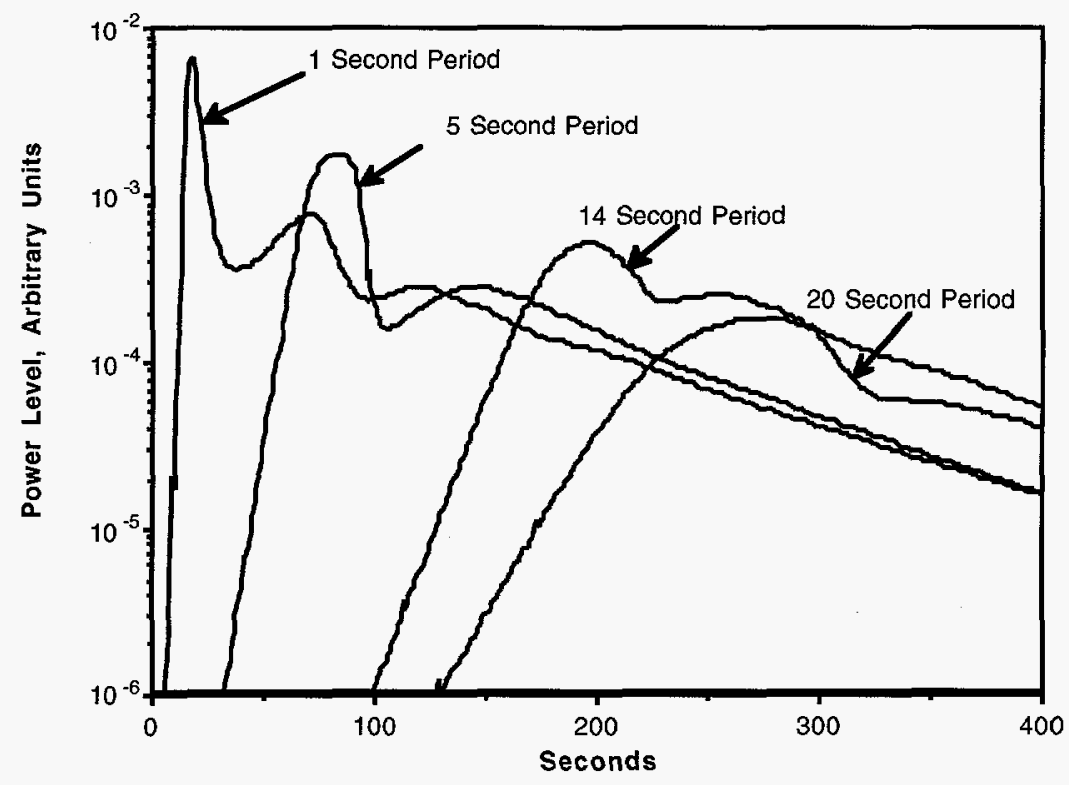

Fig. 12. Comparison of four free runs on SHEBA. 


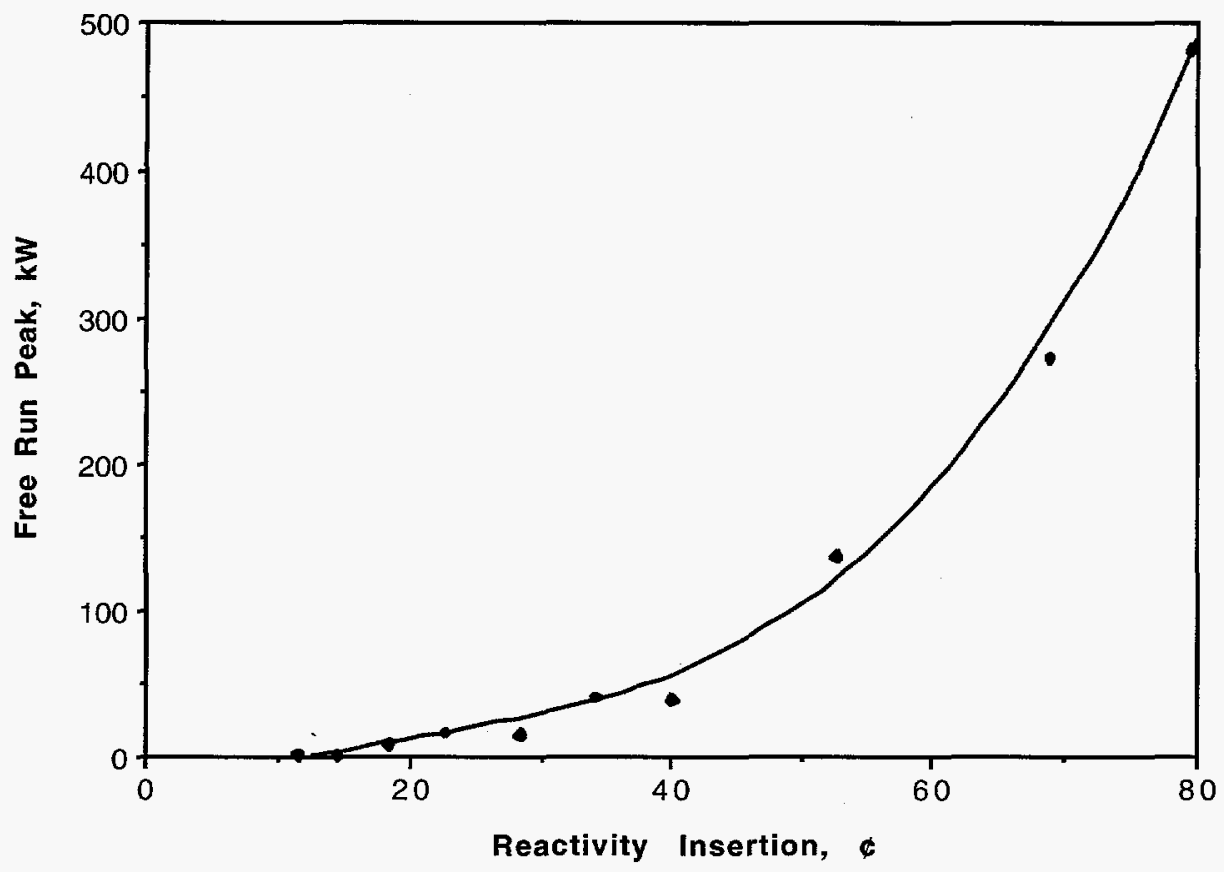

Fig. 13. Free run peak power vs. initial reactivity insertion.

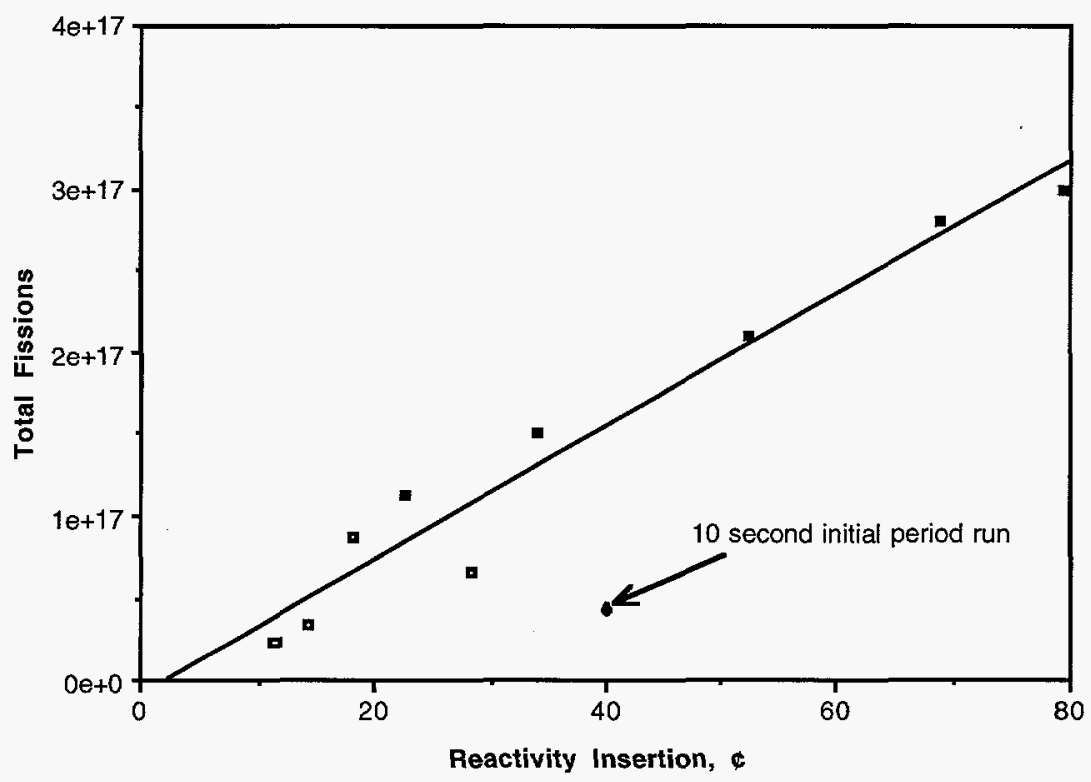

Fig. 14. Total fissions vs. initial reactivity insertion.

Figure 15 is a plot of the reactor power level, temperature, and fuel height recorded during the 14-second free run. During this run, the rise in power is initially terminated by the rising temperature and then, on the down slope of the run, the radiolytic gas appears and drops the power rapidly for some period of time. The evolution of radiolytic gas is first seen as a dramatic rise in fuel height and then considerable noise on the sensor indicating an initial large bubble of gas with subsequent frothing. Similar plots for all of the free runs conducted to date are included as Appendix 2. 
During the second half of FY95, development began on a viewing device to visually observe the radiolytic gas bubbles. The 3.5-in.-diameter experiment port was fitted with a Plexiglas flange. The initial attempt placed a small CCD camera and a high-intensity light directly on this flange. The picture quality at the beginning of the run was excellent in this configuration, but the neutron flux soon swamped the camera with "snow" long before we reached the power level required for gas production.

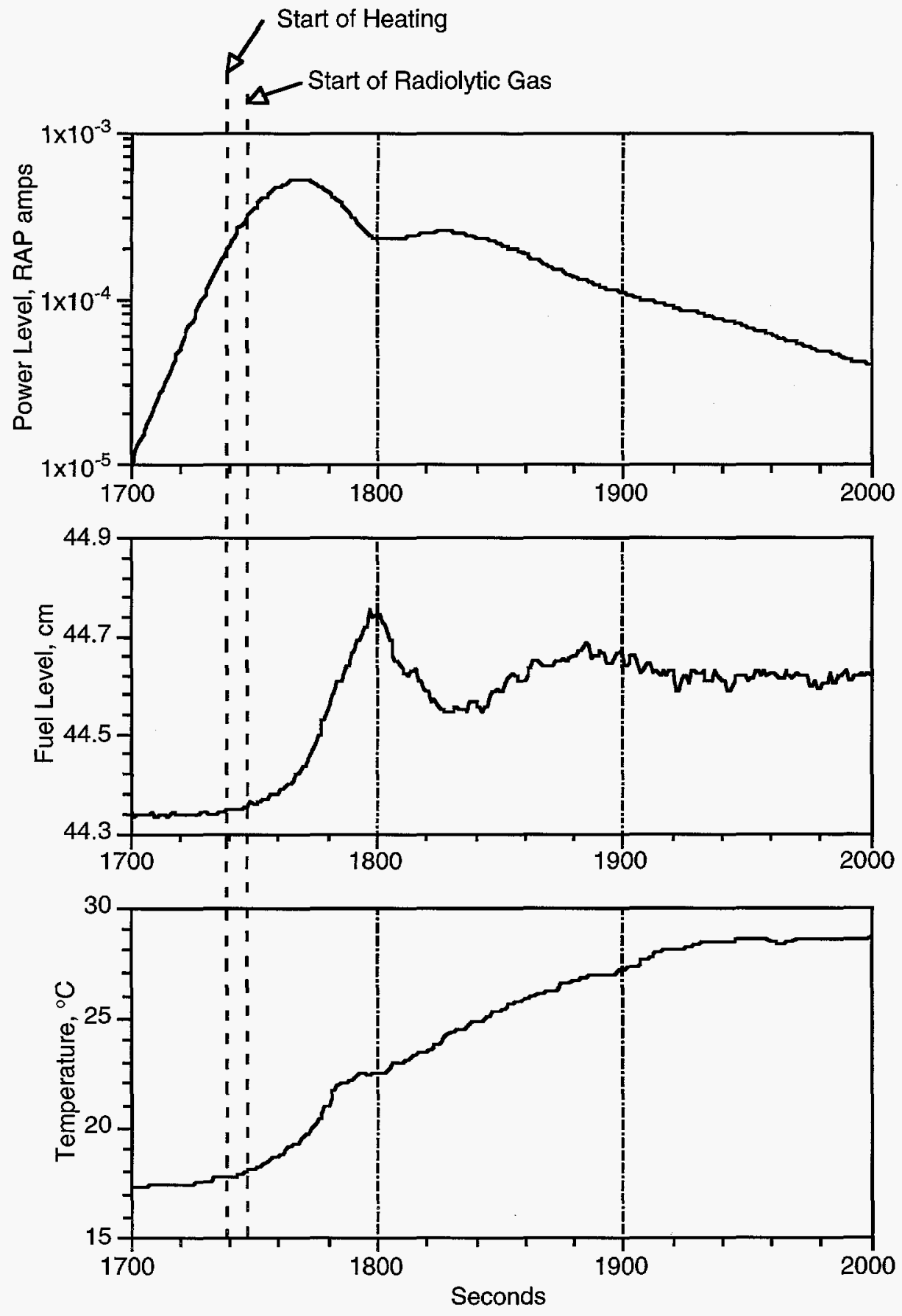

Fig. 15. Data from the 14-second initial period free run. 
A periscope was then designed to allow operation of the camera outside of the shielding pit. A camera with a long zoom lens was used to peer down the tube, through the Plexiglas flange, and into the tank. This new camera/lens arrangement requires a doubling of the light to get the same illumination in the picture from that of the small camera. Several different lighting schemes were tried, but since SHEBA has only one port for both lighting and viewing, the same quality of picture that was seen with the camera and light directly on the Plexiglas flange was never achieved.

On July 12, 1995, the first video tape of radiolytic gas bubbles in the SHEBA assembly was made. The assembly was put on a 9-second period and allowed to free run. It hit a peak power of approximately $40 \mathrm{~kW}$ before the temperature and radiolytic gas production shut down the assembly. Following the peak of the free run, radiolytic gas bubbles could be clearly seen by the video camera. The solution appeared very viscous and the bubbles caused large surface disturbances as groups of bubbles overcame the fluid viscosity and burst to the surface at a period of about 10-15 seconds. Between these bursts of bubbles, the surface was relatively calm. The image was still plagued by neutron "snow" and poor lighting.

A radiation-hardened Viticon camera has now been purchased that should be less sensitive to the neutron flux. Several other lighting schemes are also being investigated to improve the picture quality.

One free run produced a very different power profile. The free run was started with a 10 -second initial reactor period. For the first time, the radiolytic gas was produced so quickly that the free run ramp was terminated by the gas production and not the temperature rise. Figure 16 is a plot of the power level and fuel height of SHEBA during this free run. At the start of radiolytic gas production, the power level of the machine dropped nearly two orders of magnitude in a few seconds. Then the system continued to outgas for several minutes, at which time the power shot back up an order of magnitude and then decayed at the same decay rate seen in the previous free runs. These dramatic power fluctuations were seen again in SHEBA during what was intended to be steady-state operation as described in Section 4.2.

Conclusions from this series of free runs include

- Bubble formation significantly affects the total dose,

- Bubbles may limit the peak power for some types of excursions, and

- Most criticality accidents will have multiple pulses. ${ }^{10}$ 


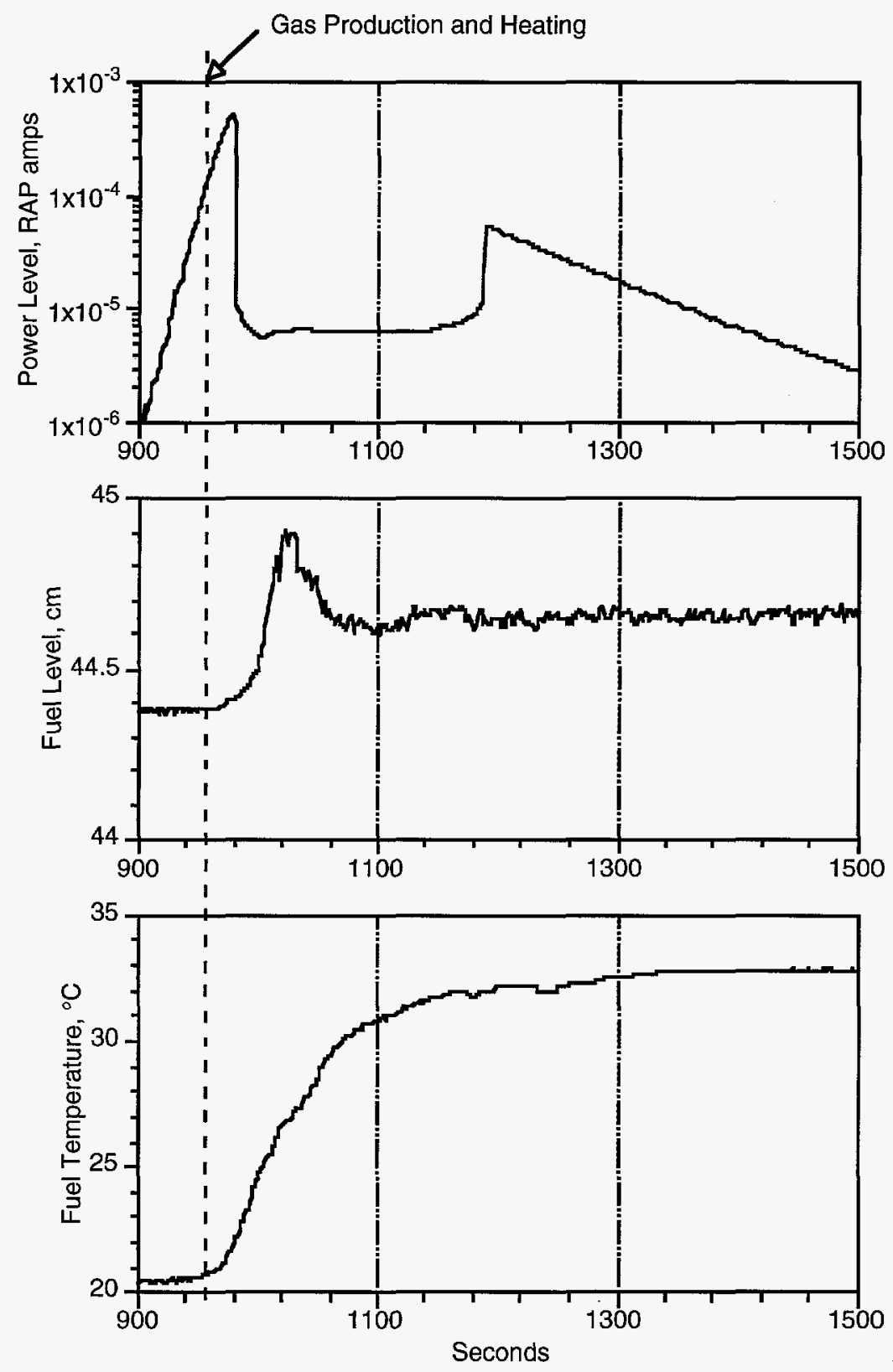

Fig. 16. Data from 10-second initial period free run.

\subsection{Steady-State Runs}

As part of a dosimetry workshop and tritium production efforts with the SHEBA assembly, the assembly has been operated at "steady state" at a variety of power levels. Several interesting features of the assembly were noted during these operations.

Figure 17 shows the operation of SHEBA during one of the tritium production runs. The assembly was operated at steady state at a power level of about $8.3 \times 10^{-6}$ amps (approximately 640 watts). After a total energy deposition of about $8 \times 10^{16}$ fissions, radiolytic gas production began. This is a significant increase in the amount of energy deposition required to begin gas production than was observed when operating in the free run mode (See Section 4.1). Figure 18 expands the 
portion of Fig. 17 where radiolytic gas is being produced. Enough fuel was added to increase the fuel height by about $0.1 \mathrm{~mm}$ each time the power level dropped to $8.2 \times 10^{-6}$ amps. Each resulting power increase and subsequent decrease is essentially a miniature "free run." Each "free run" is very unique with many of them displaying multiple peaks, plateaus, etc. It is clear that the effects of radiolytic gas on the power level is a very random phenomenon.

Figure 19 shows an attempt at a steady-state run with a peak power level that was a factor of two larger than a successful steady-state run the previous day. We again experienced the large power fluctuations that had been observed during a fast initial period free run. The power dropped nearly two orders of magnitude in a few seconds while radiolytic gas was expelled and then, after several minutes, shot back up. No fuel was added during this excursion. The run was completed at a lowerpower level.

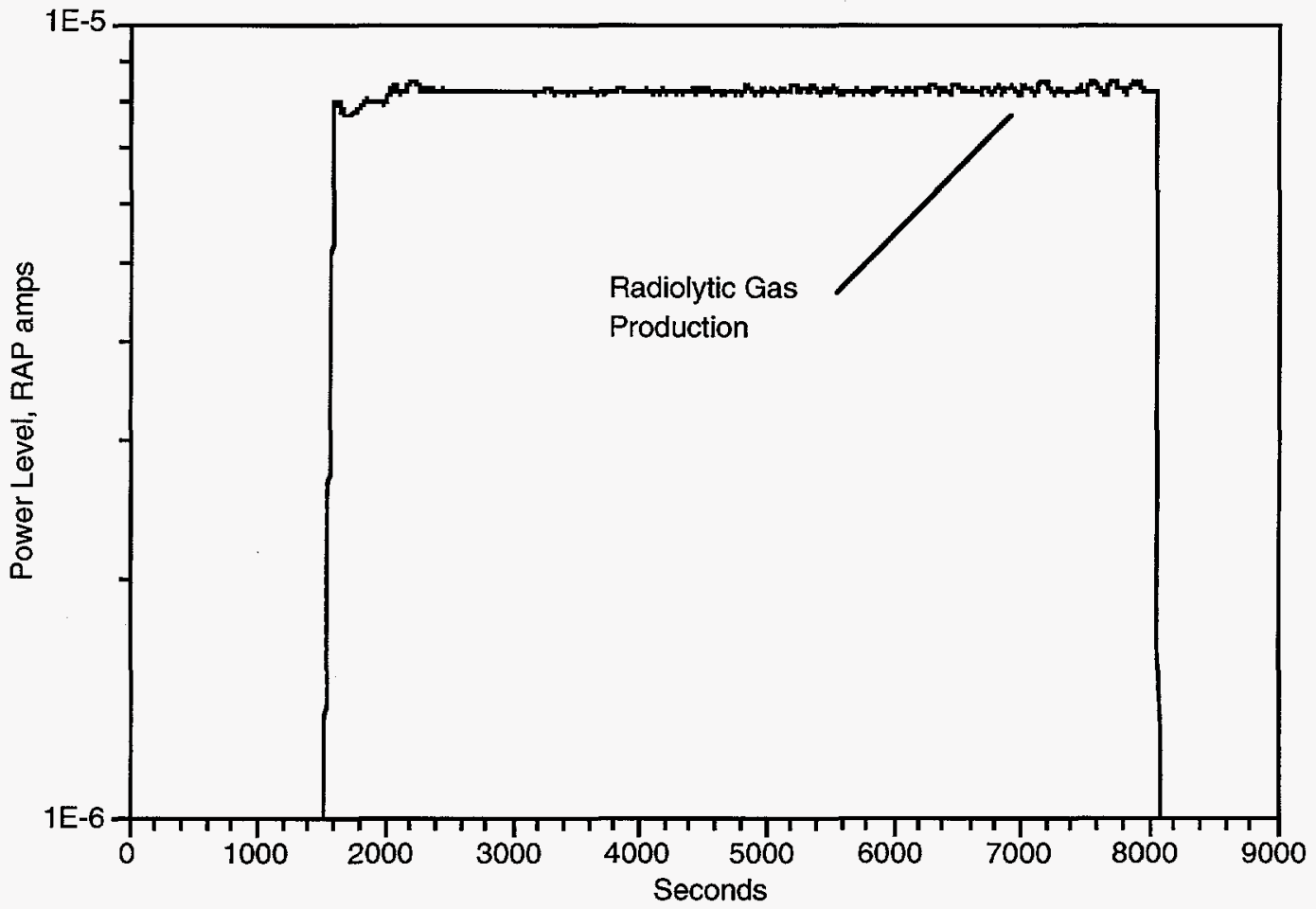

Fig. 17. Power level for a typical steady-state run in SHEBA. 


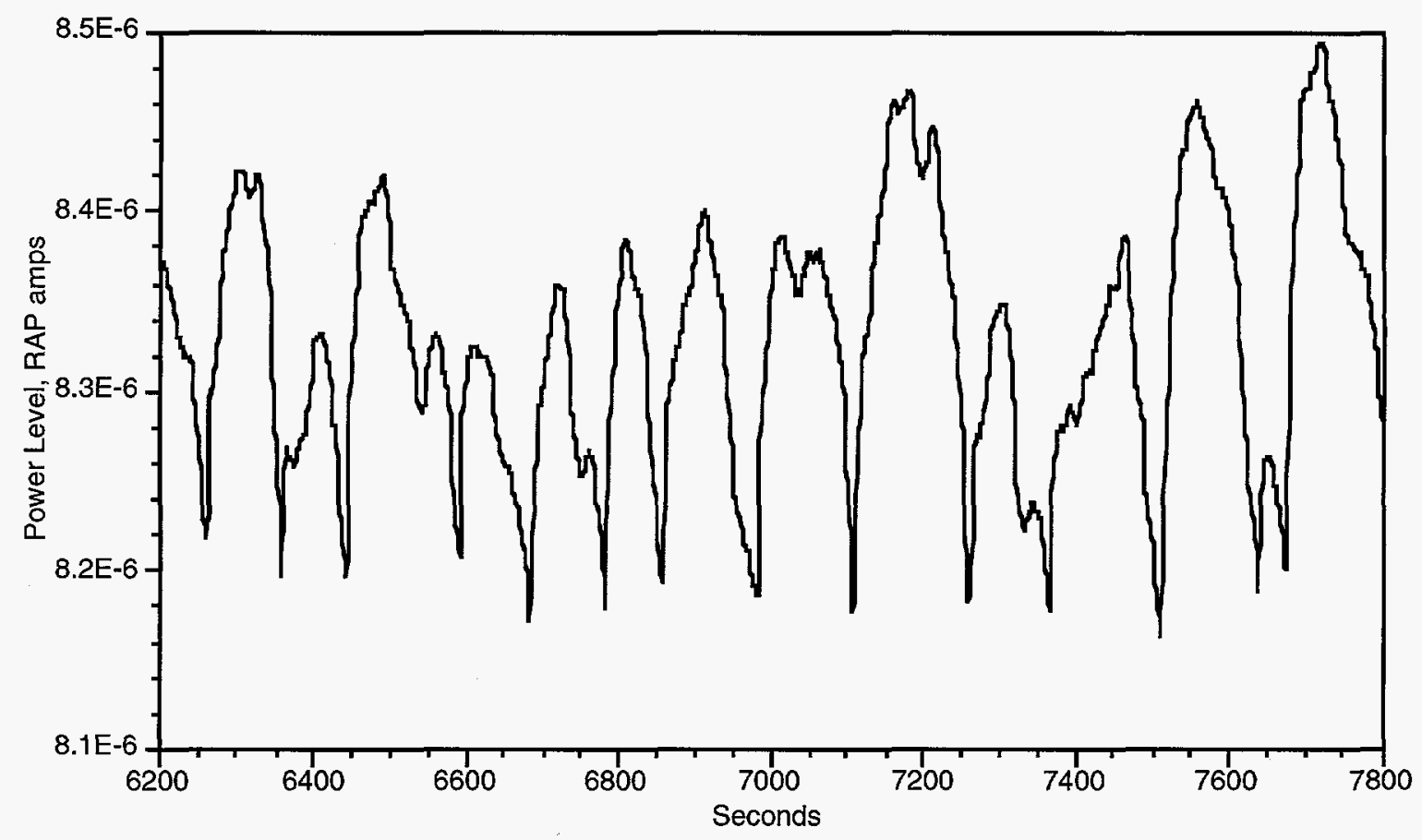

Fig. 18. Expanded view of steady-state run showing radiolytic gas effects.

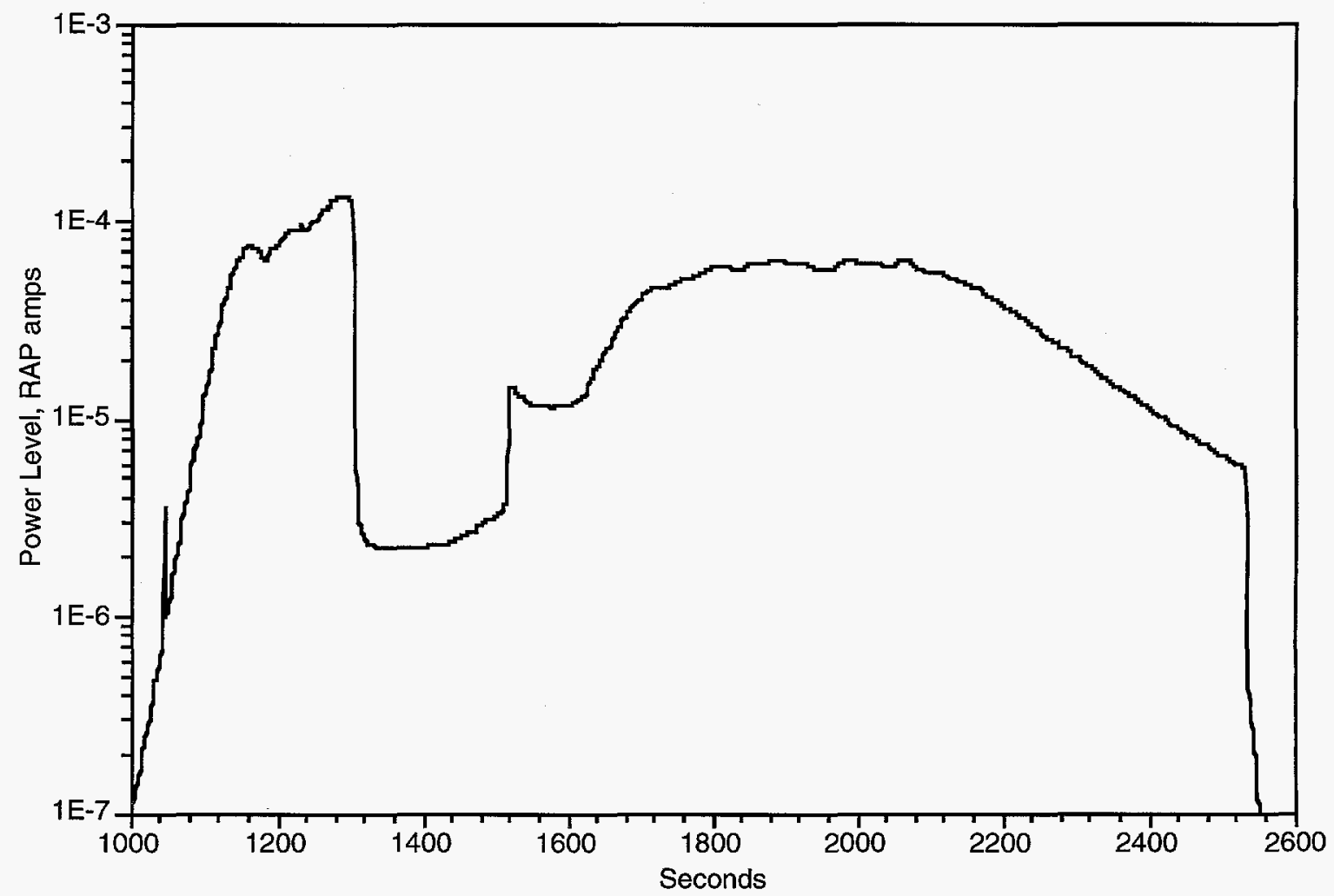

Fig. 19. High-power "steady-state" run in SHEBA. 


\subsection{Effect of Entrained Radiolytic Gas}

As part of the dosimetry workshop in June, 1995, SHEBA was operated four times in five days at sufficiently high power levels to produce radiolytic gases. The last two of these operations exhibited a phenomenon that had not been observed before. The assembly was put on an initial period and then, with no manipulation of the controls, the period gradually accelerated.

On examination of the data after the run, it was noted that while the period was accelerating, the level was also gradually dropping, and the usually quiet level sensor signal showed a significant amount of noise, indicating radiolytic gas production at a lower power level than in other free runs. Figure 20 is a plot of the reactor power and the fuel level during one of these operations.

One explanation for these observations is that some of the radiolytic gas remains entrained in the fuel following operation. If the system sits for several days between operations, the gas gradually escapes. But when the system is operated frequently, the initial fill of the reactor vessel initiates the release of some of the gas, causing small bubbles to form throughout the solution (similar to pouring a carbonated beverage into a glass). These bubbles then migrate out of the solution, causing an increase in reactivity and a drop in the solution height. The migration of the bubbles also enables newly formed radiolytic gases to escape more easily.

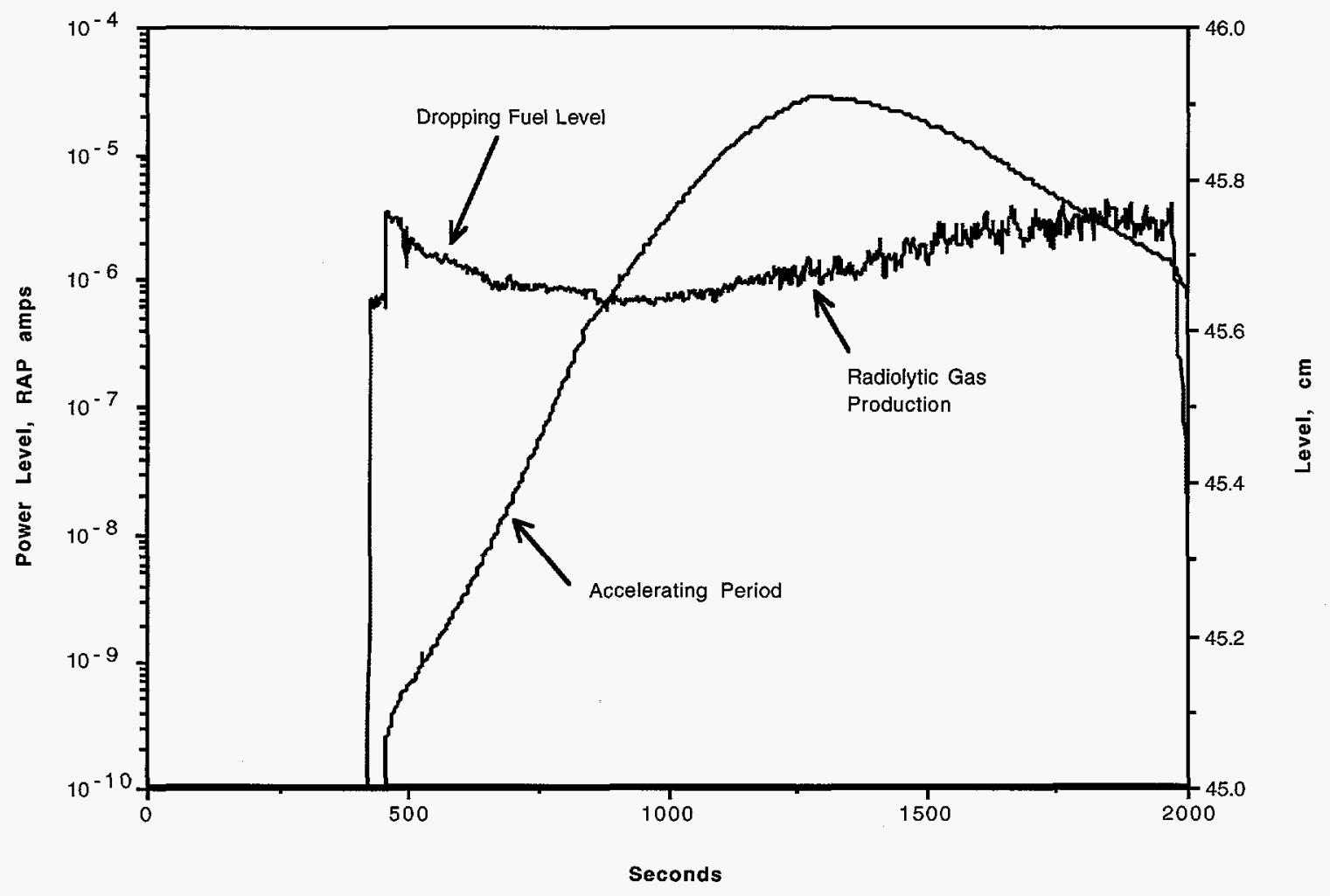

Fig. 20. Reactor power and fuel level for SHEBA, showing accelerating period phenomenon. 


\subsection{SHEBA Operating Parameters}

Operating parameters of the SHEBA assembly have been measured throughout operation since 1993. These parameters include the temperature coefficient, the reactivity vs. solution height, reactor period vs. solution height, a power calibration, flux profile, neutron spectrum, and the worth of voids in the solution. The results of these measurements are presented in this section.

\subsection{Temperature Coefficient}

Throughout operations since 1993, the critical fuel height and temperatures recorded. These data were then plotted to determine the temperature coefficient of the SHEBA assembly. The measured temperature coefficient expressed as the change in critical height due to an increase in temperature was determined to be $0.1 \mathrm{~cm} /{ }^{\circ} \mathrm{C}$.

However, during the spring of 1995, while operating SHEBA in the shielding pit, a significant and repeatable deviation from this temperature coefficient was measured. It appeared that below $15^{\circ} \mathrm{C}$, the temperature coefficient increased by more than a factor of three. Additional measurements show that the phenomenon is not always there.

Figure 21 is a plot of the all of the data. The vertical offset between the data sets is due to the reflection of the pit.

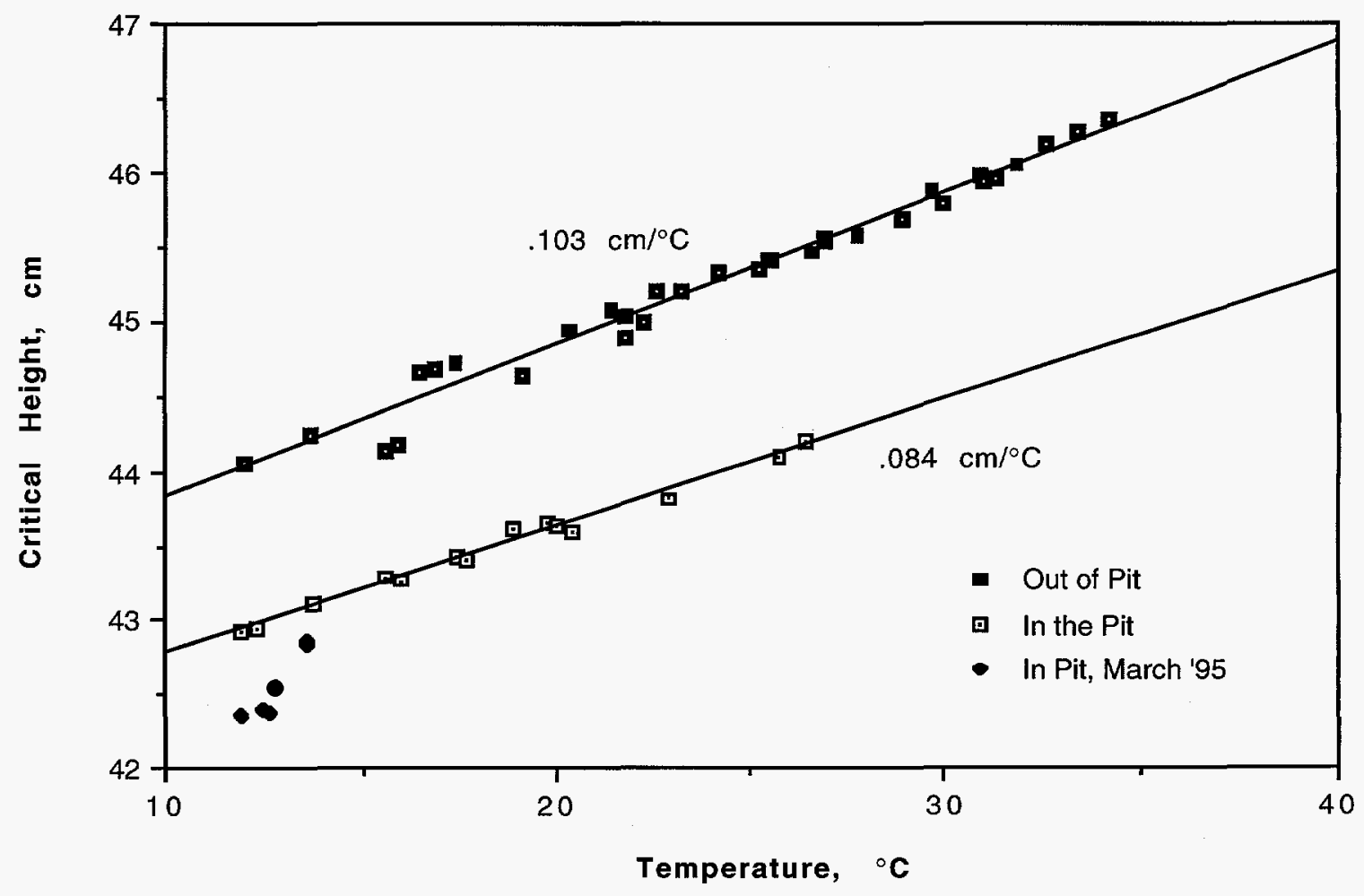

Fig. 21. SHEBA temperature coefficient. 
Postulated causes of this shift included

- A hydration state change or phase change in the SHEBA fuel at this temperature. If this were the case, a similar shift should be seen in the temperature coefficient out of the pit at this temperature;

- Geometry effects when the critical height drops below $43 \mathrm{~cm}$. To investigate this possibility, the fuel would have to be cooled to below $2^{\circ} \mathrm{C}$ to see if the phenomenon repeats out of the pit.

- The pit itself or some type of change to the pit in March 1995 such as an increase in surrounding groundwater.

\subsection{Reactivity and Reactor Period as a Function of Solution Height}

Tabulation of the measurements of the initial reactor period vs. fuel height gives a value of reactivity of $43.3 \phi / \mathrm{cm}$ for SHEBA out of the pit and $50.8 \phi / \mathrm{cm}$ for SHEBA operated in the shielding pit. The results of these measurements are shown graphically in Fig. 22.

Using these numbers and a calculated $B / 1$ of 200 , an inhour equation for SHEBA was derived and the results of period vs. change-in-height measurements were plotted along with this equation. Figure 23 shows the results for SHEBA operation out of the pit. The above value for $\phi / \mathrm{cm}$ and $B / 1$ seem to be very accurate for SHEBA out of the pit.

The procedure was repeated for SHEBA in the pit. However, for reactivity above about $50 \varnothing$ (a change in height of about $1 \mathrm{~cm}$ ), the measured values began to diverge from the predicted curve. A seventh group was added to the Inhour equation to account for the reflection of the shielding pit. The abundance of neutrons was calculated using MCNP and then the measured data were used to derive a neutron lifetime for this group. Figure 24 shows the data and both calculated curves for SHEBA operated in the pit. The derived curve is a much better fit to the shape of the data. The significance of the difference can been seen at prompt critical. The six-group equation predicts that prompt critical will have an initial period of $100 \mathrm{msec}$, while the new equation predicts that prompt critical will occur at a $300-\mathrm{msec}$ initial reactor period.

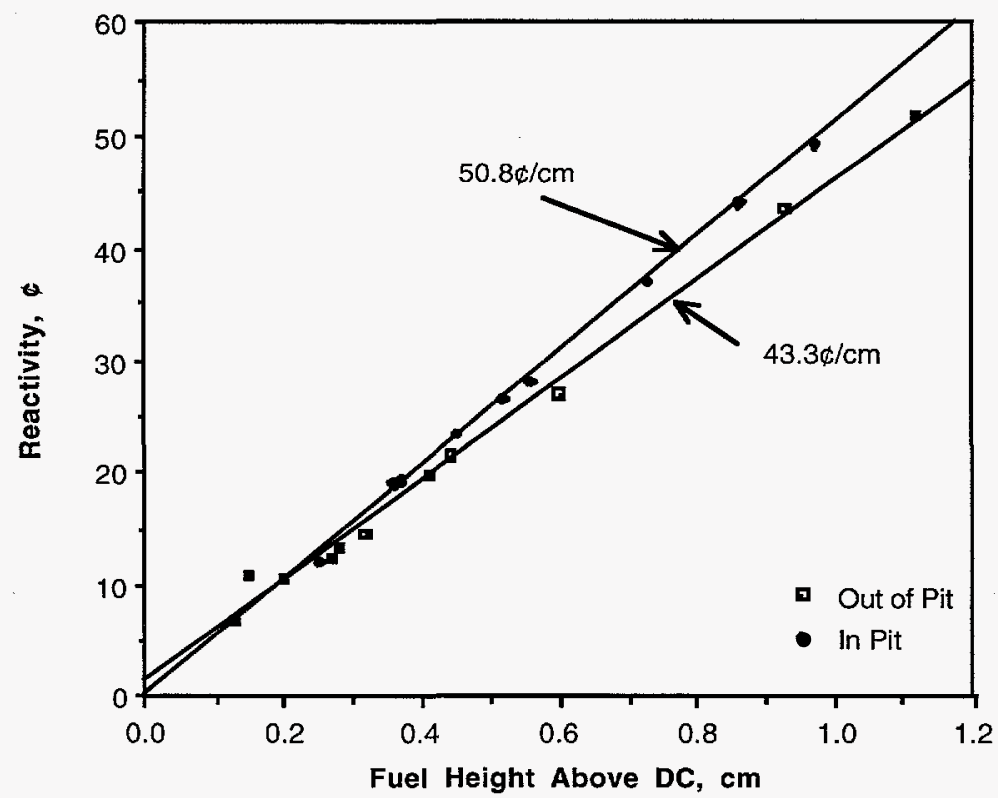

Fig. 22. Measured reactivity above delayed critical versus solution level above critical. 


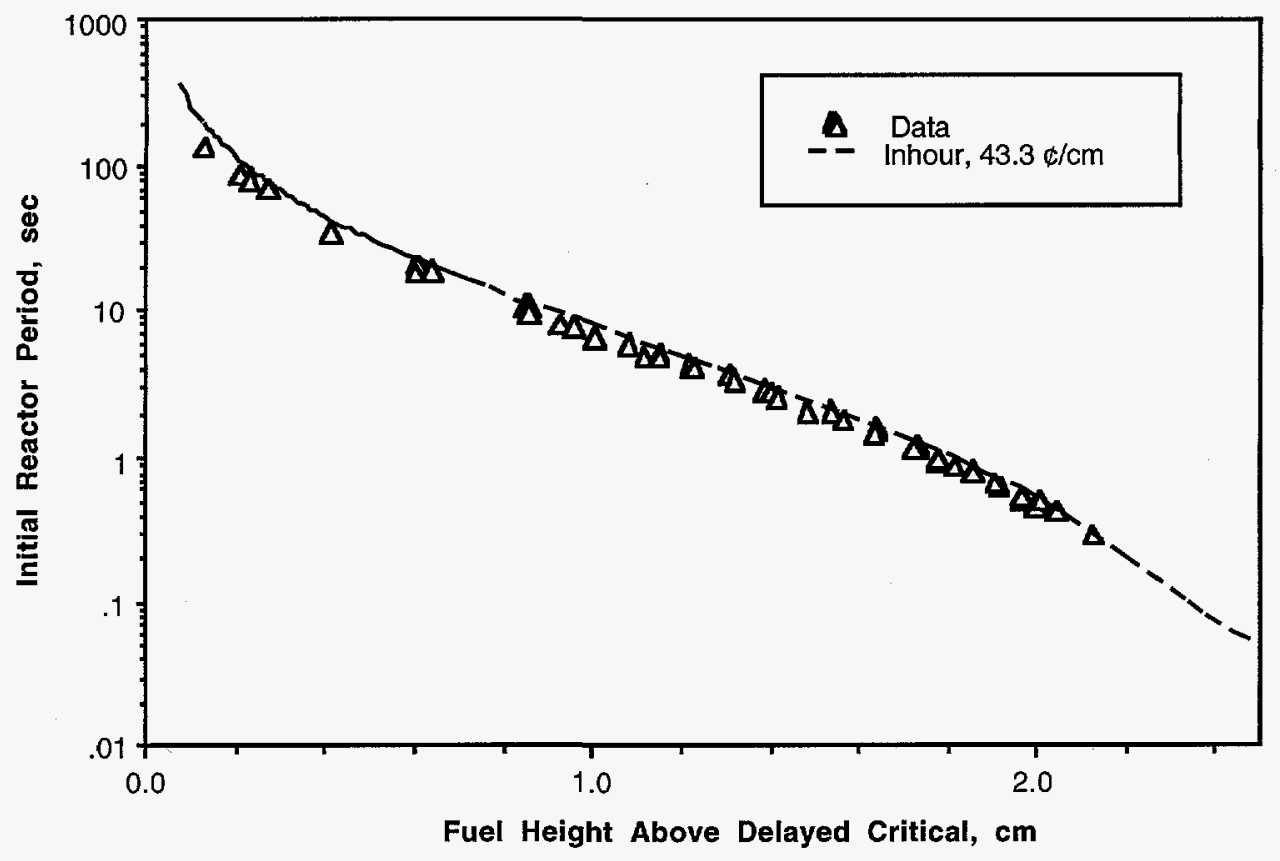

Fig. 23. Period vs. change in critical height for operation out of the pit.

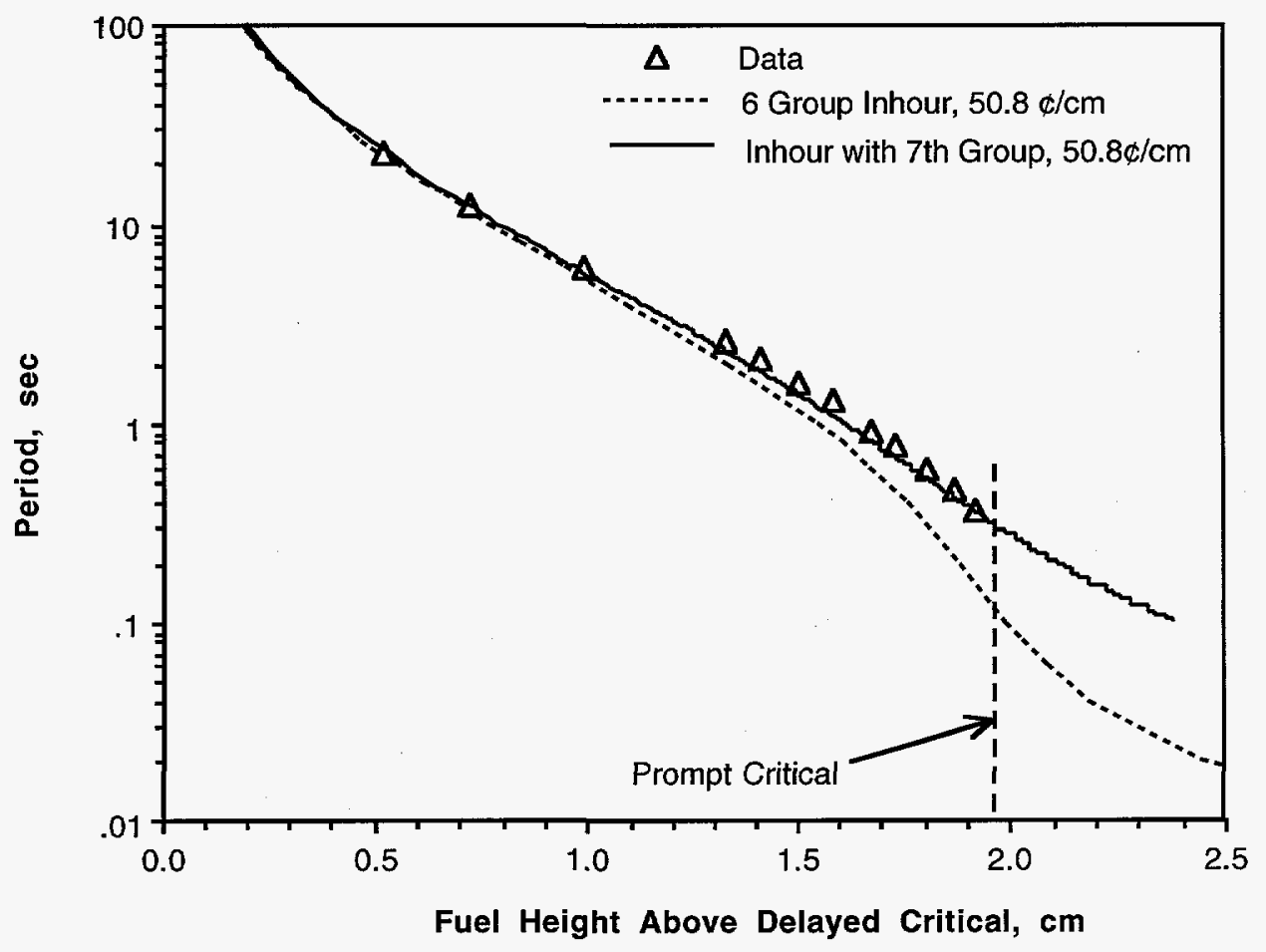

Fig. 24. Period vs. change in critical height for operation in the shielding pit. 


\subsection{Prompt Neutron Decay Constants in SHEBA}

Rossi-Alpha measurements ${ }^{11}$ were performed for SHEBA, ${ }^{12}$ both in and out of the pit, to experimentally determine the prompt neutron decay constants including $\alpha$ ( $\alpha$ is equal to $B / 1$ at delayed critical). These prompt neutron decay constants represent an eigenvalue characteristic of this particular assembly which can be experimentally measured by the Rossi-Alpha, or pulse neutron source, techniques or calculated by a deterministic or Monte Carlo method.

\subsubsection{Description of Experiment}

Four He-3 neutron detectors were placed in several locations in the SHEBA assembly as seen in Table 6. The He-3 detectors were $1.27 \mathrm{~cm}$ in diameter and $15 \mathrm{~cm}$ long. Rossi-Alpha measurements were performed at several subcritical fuel heights and fuel temperatures. The data were collected with two different type I time analyzers. The first time analyzer was a 100-channel device, which had the capability of time tagging each arrival pulse ${ }^{13}$ from several detectors. The second one was an 80 channel Langley Ford correlator which was operated in an autocorrelation mode. ${ }^{14}$

When the detectors were placed in the center, and SHEBA was operated outside the concrete pit, the alphas at the different subcritical fuel heights were obtained from least squares fits to the functional form $f(t)=A^{(-\alpha t)}+C$. Otherwise, the alphas were obtained from least square fits to the functional form $f(t)=A_{1}^{(-\alpha, t)}+B_{2}^{(-\alpha, t)}+C$. The prompt decay constants at delayed critical for a bare and reflected SHEBA were obtained by plotting the alphas at a particular fuel height as a function of the inverse count rate and extrapolating linearly to an inverse count rate of zero.

Table 6. Prompt neutron decay constant at delayed critical SHEBA in and out of the shielding pit.

\begin{tabular}{|l|c|c|}
\hline \multicolumn{1}{|c|}{$\begin{array}{c}\text { Unreflected Assembly } \\
\text { Detector Location }\end{array}$} & $\begin{array}{c}\text { Solution } \\
\text { Temperature }\left({ }^{\circ} \mathbf{C}\right)\end{array}$ \\
\hline $\begin{array}{l}\text { 26.2 cm from bottom (axial) and 13.8 cm from center } \\
\text { (radial) of CAV. Detectors are placed in experiment well. }\end{array}$ & $195.2 \pm 3.6$ & 24.7 \\
\hline $25.5 \mathrm{~cm}$ from the bottom (axial) and at the center 0 cm & $201.7 \pm 3.3$ & 19.6 \\
(radial) of CAV. Experiment well left in SHEBA. & $191.9 \pm 4.4$ & 23.1 \\
\hline 23.5 cm from the bottom (axial) and at center 0 cm & $191.3 \pm 3.5$ & 23.7 \\
(radial) of CAV. No experiment well in SHEBA. & $200.3 \pm 3.6$ & 15.7 \\
\hline
\end{tabular}

\begin{tabular}{|l|c|c|c|}
\hline \multicolumn{1}{|c|}{$\begin{array}{c}\text { Reflected Assembly } \\
\text { Detector Location }\end{array}$} & $\alpha_{\mathbf{1}}\left(\mathbf{s e c}^{-1}\right)$ & $\alpha_{\mathbf{2}}\left(\mathbf{s e c}^{-1}\right)$ & $\begin{array}{c}\text { Solution } \\
\text { Temperature }\left({ }^{\circ} \mathbf{C}\right)\end{array}$ \\
\hline $\begin{array}{l}23 \mathrm{~cm} \text { from the bottom (axial) and } \\
\text { at the center 0 cm of CAV. No } \\
\text { experiment well in SHEBA. }\end{array}$ & $\begin{array}{l}195.1 \pm 3.0 \\
202.5 \pm 3.2\end{array}$ & $408.5 \pm 122.5$ & 20.9 \\
\hline
\end{tabular}




\subsubsection{Results}

Table 6 shows the delayed critical prompt neutron decay constant measured at different locations in the vessel for the SHEBA assembly in and out of the pit. When SHEBA was operated outside the pit (unreflected) and the detectors were placed in the center, there was only one exponential and one decay constant associated with this system. However, when the detectors were placed off-center or SHEBA was operated in the pit, the least squares fits yielded two major exponentials and two decay constants. The reason for the two major prompt decay constants when the detectors were off-center with SHEBA outside the pit is that the system is not in a fundamental mode because of the strong intrinsic source of neutrons in the solution and the location of the detectors. The ratio of the amplitude of the fundamental mode exponential, $\mathrm{A}$, to the second exponential amplitude, $\mathrm{B}$, tends to increase as the system approached delayed critical.

When SHEBA was operated in the pit, two exponentials and two decay constants were observed with the detectors in the center. One constant was associated with the neutron lifetime of the core and the other one was associated with the neutron lifetime of the concrete reflector. Note that the huge uncertainty associated with the second decay constant is due to the small number of reflected neutrons reaching the He-3 detectors which were located at the center of the assembly. Finally, we plan to investigate how the magnitude of the decay prompt neutron constant for this system changes as a function of the solution temperature.

\subsection{Power Calibration}

SHEBA's reactor power level is measured using a compensated ion chamber mounted on the SHEBA rack in a fixed location. The output of this ion chamber is measured in amps. The conversion that has been used to date to convert from amps to fissions/sec and $\mathrm{kW}$ was determined by calculating the heat capacity $\left(\mathrm{C}_{\mathrm{v}}\right)$ for the fuel using the $\mathrm{C}_{\mathrm{V}}$ for each constituent and proportioning each in accordance with the weight percent of that element in fuel. This calculation yields a specific heat for the SHEBA fuel of $2.16 \times 10^{-3} \mathrm{MJ} / \mathrm{kg} /{ }^{\circ} \mathrm{C}$. This value has also been verified experimentally (See Section 3.10). A thermocouple installed in SHEBA was used to measure the temperature rise of the fuel during a free run and the total energy was calculated assuming this temperature represented the average fuel temperature. The original power conversion calculated was $6 \times 10^{18}$ fissions/(amp$\mathrm{sec})$. Additional measurements were made to try to refine this estimate.

A measurement was made to determine if the temperature reading on the thermocouple during a free run was actually the average temperature of the fuel. This was accomplished by operating SHEBA at a sufficient power level to produce significant heating but no radiolytic gas. The safety rod was then inserted and the fuel was stirred using the recirculating feature on SHEBA. The total temperature rise measured during the run was $7.1^{\circ} \mathrm{C}$, and after stirring the temperature was $1.0^{\circ} \mathrm{C}$ lower. The measured energy deposited during the run was $3.03 \times 10^{-2} \mathrm{amp}$-sec on the ion chamber. There is still some uncertainty in the actual average fuel temperature, since the recirculation of the fuel adds some pump heat. During this run, the mass of the fuel was $166 \mathrm{~kg}$. The total amount of heat energy deposited into the fuel was $166 \times\left(2.16 \times 10^{-3}\right) \times 6.1=2.2 \mathrm{MJ}$. Using a value of $3.55 \times 10^{16}$ fissions per MJ for solution fuel, a total of $8.17 \times 10^{16}$ fissions were produced during the run. Dividing this number by the integrated current on the ion chamber gives a calibration factor of $2.7 \times 10^{18}$ fissions/(amp-s).

In conjunction with one of the flux profile measurements (see Section 5.5), small gold and uranium foils were placed in the experiment well to measure the absolute fissions. Two experiments were run with total energy 10 times greater for the second run. The results from these foil irradiations are $7.7 \times 10^{10} \pm 1.9 \times 10^{10}$ fissions/gm of $U^{235}$ for $3.008 \times 10^{-4}$ amp-seconds on the power monitor 
and $6.00 \times 10^{11} \pm 16 \times 10^{11}$ fissions/gm $\mathrm{U}^{235}$ for $3.0 \times 10^{-3} \mathrm{amp}$-seconds. These data were then put into a SHEBA MCNP model to calculate the total number of fissions in SHEBA. A conversion of $1.7 \times 10^{18}$ fissions/(amp-sec) was calculated using this method. Note that this calculation and measurement includes the effects of the empty experiment well (calculated to be worth $-\$ 1.75$ and measured to be worth $-\$ 1.73$ ).

\subsection{Flux Profile Measurement}

Copper wires were used to measure the radial and axial flux in SHEBA. Figure 25 shows the layout for these measurements. One wire was located on the safety rod follower, one on the outside surface of the tank, and three wires were inserted into the tank through the experiment port. These three wires were inserted into 1/4-inch ID, 1/2-inch OD stainless steel tubes. Two of the wires and tubes were bent at the expected half-critical height to provide the radial flux distribution information.

The wires were 0.0571 -inch-diameter soft OFHC copper. SHEBA was operated with a total of $3.015 \times 10^{-3}$ amp-seconds (approximately $8 \times 10^{15}$ fissions). Fuel height was $45.51 \mathrm{~cm}$ at the beginning of the run (DC) and $45.58 \mathrm{~cm}$ at the end. (The fuel was heated $1.2^{\circ} \mathrm{C}$ during the run.)

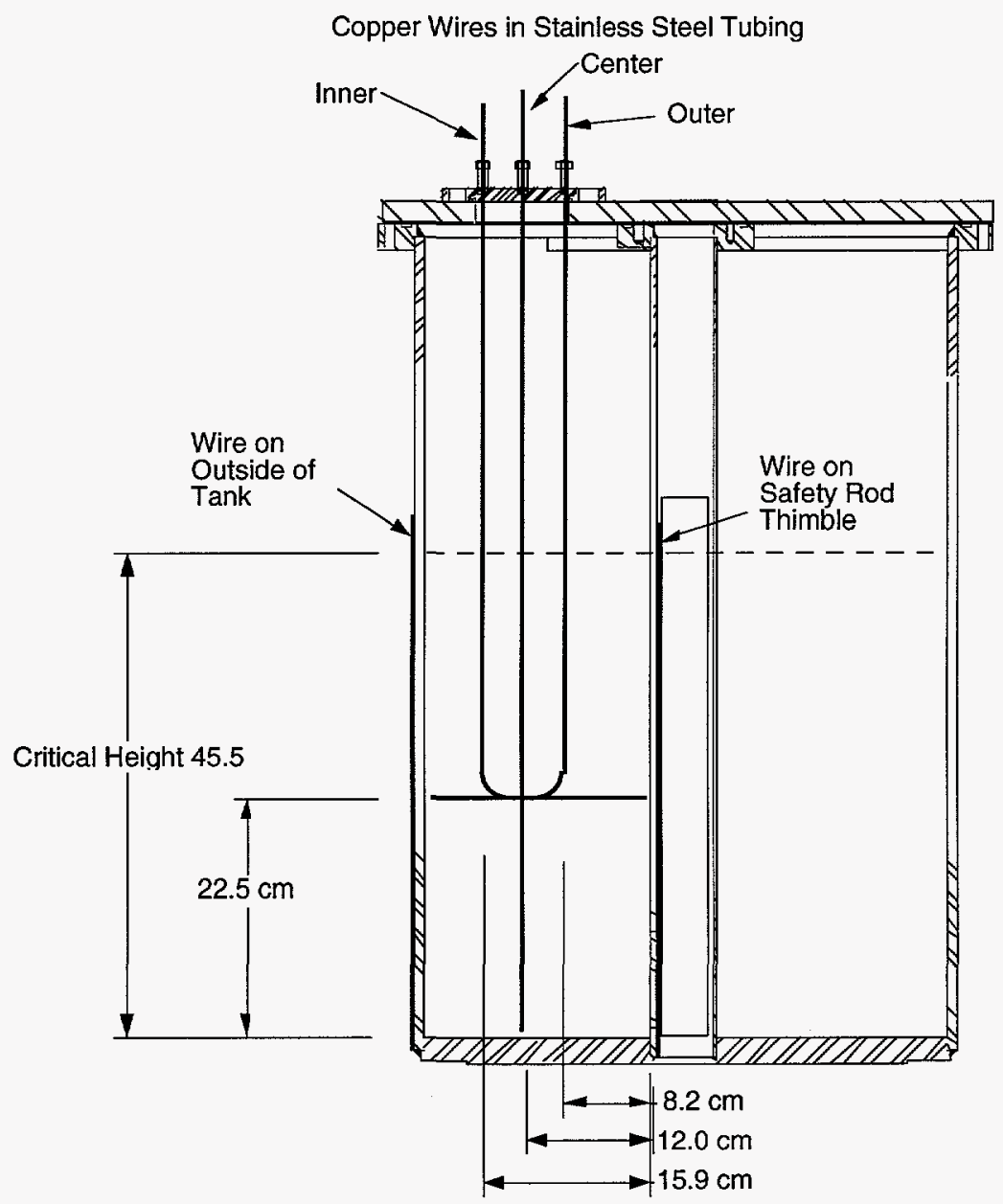

Fig. 25. Layout of copper flux wires in SHEBA. 
Figures 26 and 27 show the results from this experiment. The three wires installed through the experiment port were intentionally placed close to each other to provide relative information. However, the wires and tubes apparently caused enough flux depression at this location, due to displacement of the fuel, to produce a dip in the vertical flux profile at the location of the horizontal wires.

Information from these wires was then used to generate a three-dimensional plot of the flux profile. For this plot, the values for the flux at the inner walls of the tank and safety rod thimble were found by setting the relative flux of the wires that were outside the tank and on the safety rod follower at $22.5 \mathrm{~cm}$, equal to the flux measured at the ends of the horizontal wires. Figure 28 shows this plot.

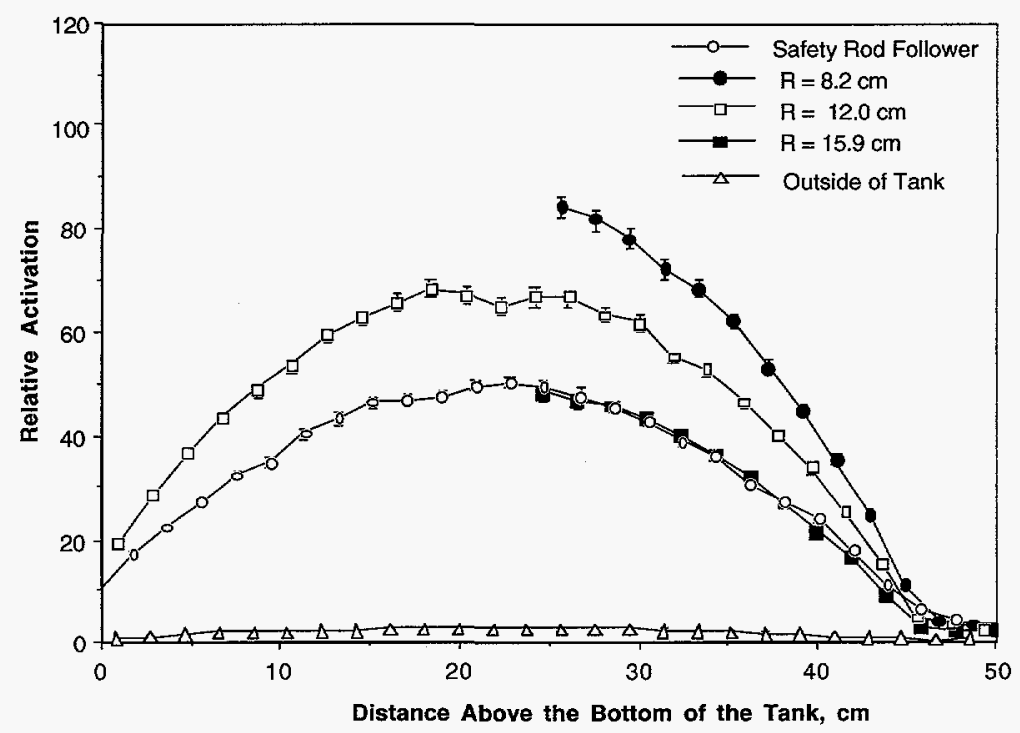

Fig. 26. Measured vertical flux profile in SHEBA.

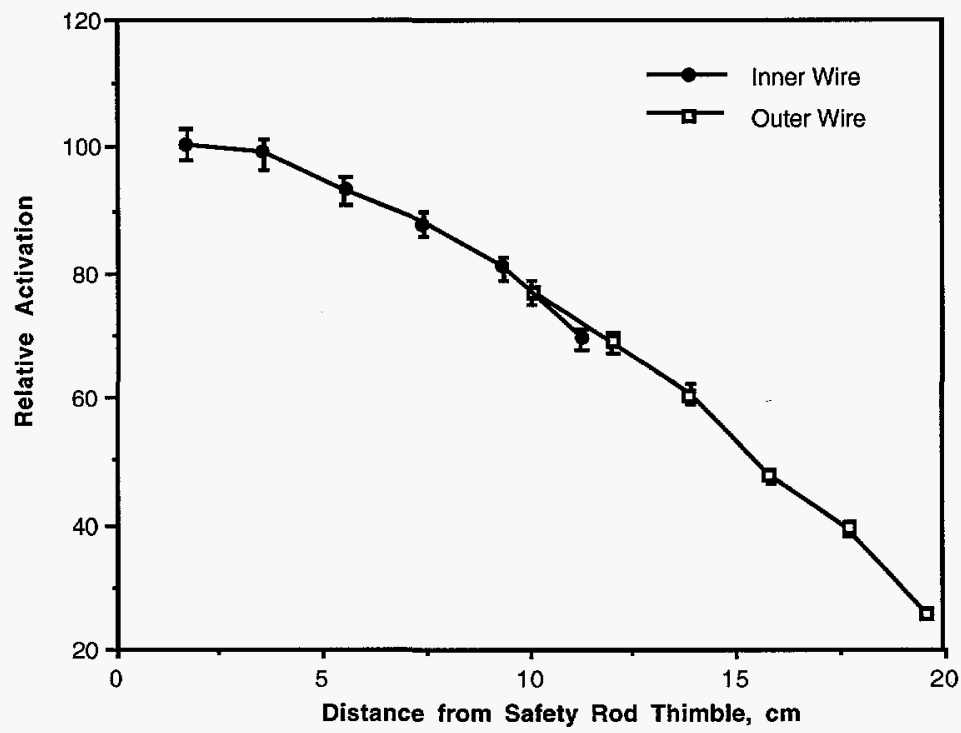

Fig. 27. Measured horizontal flux profile in SHEBA. 


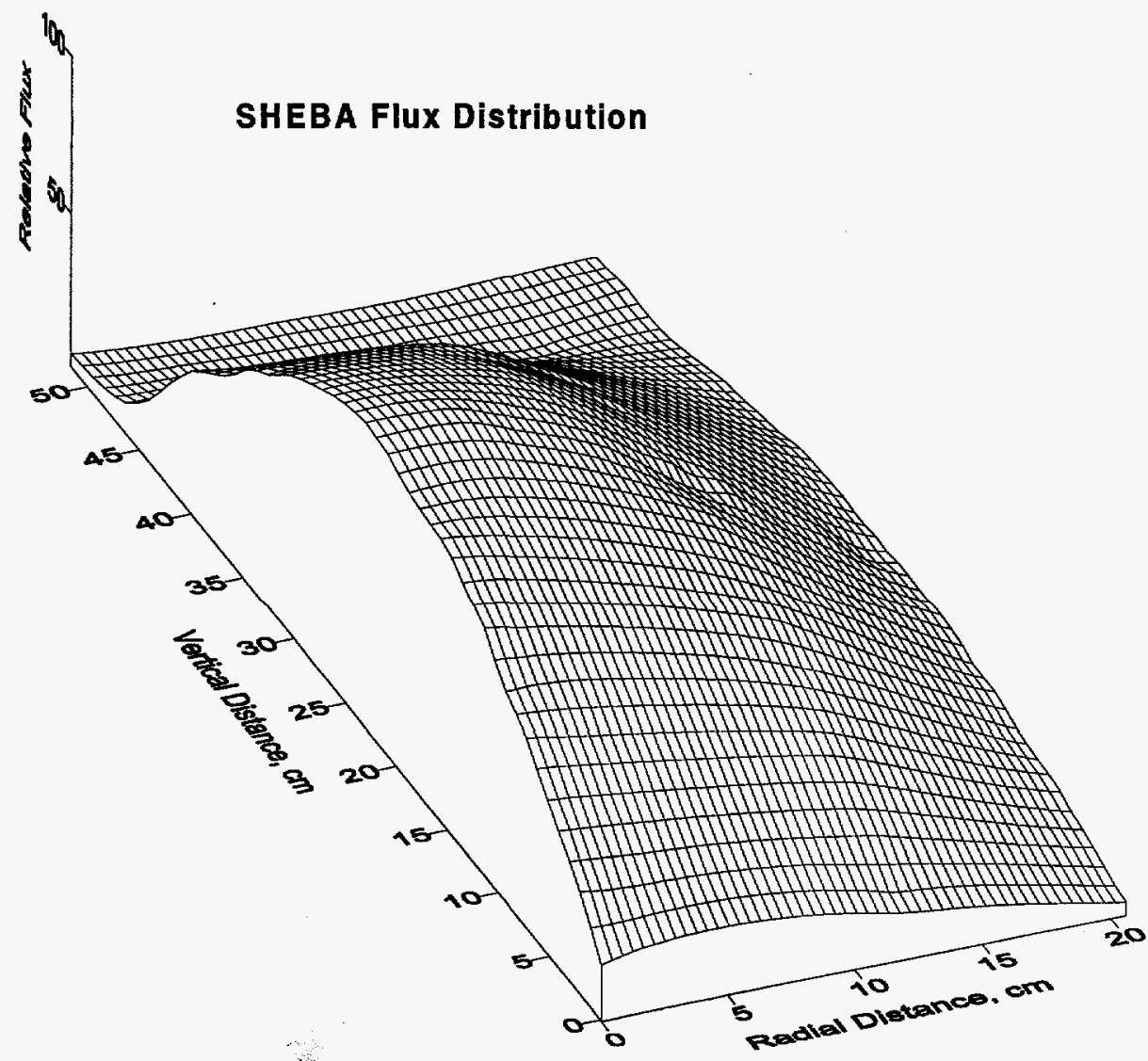

Fig. 28. SHEBA flux profile.

A second measurement of the axial flux profile was made using copper activation foils as part of the tritium production experiments. Figure 29 shows the layout for these measurements. One foil was located on the safety rod-follower, one in the experiment well and one on the outside surface of the tank. The foils were approximately 0.125 inch wide and $30 \mathrm{~cm}$ long and weighed between 1.9 and 2.7 grams. One foil at each location was lined up with the bottom of the tank and a second foil was placed just above the first in the experiment well location. The experiment was run with the experiment well empty and with the tritium target inserted. Figure 30 shows the results from these foils for the empty experiment well and the well with the target containing a neutron absorber.

As can be seen from the figure, there is a significant flux depression between the empty thimble and the absorber due to the negative worth of the absorber. The measured worth of the empty well was $-\$ 1.73$ and the worth of the well with the absorber installed was $-\$ 2.91$. 


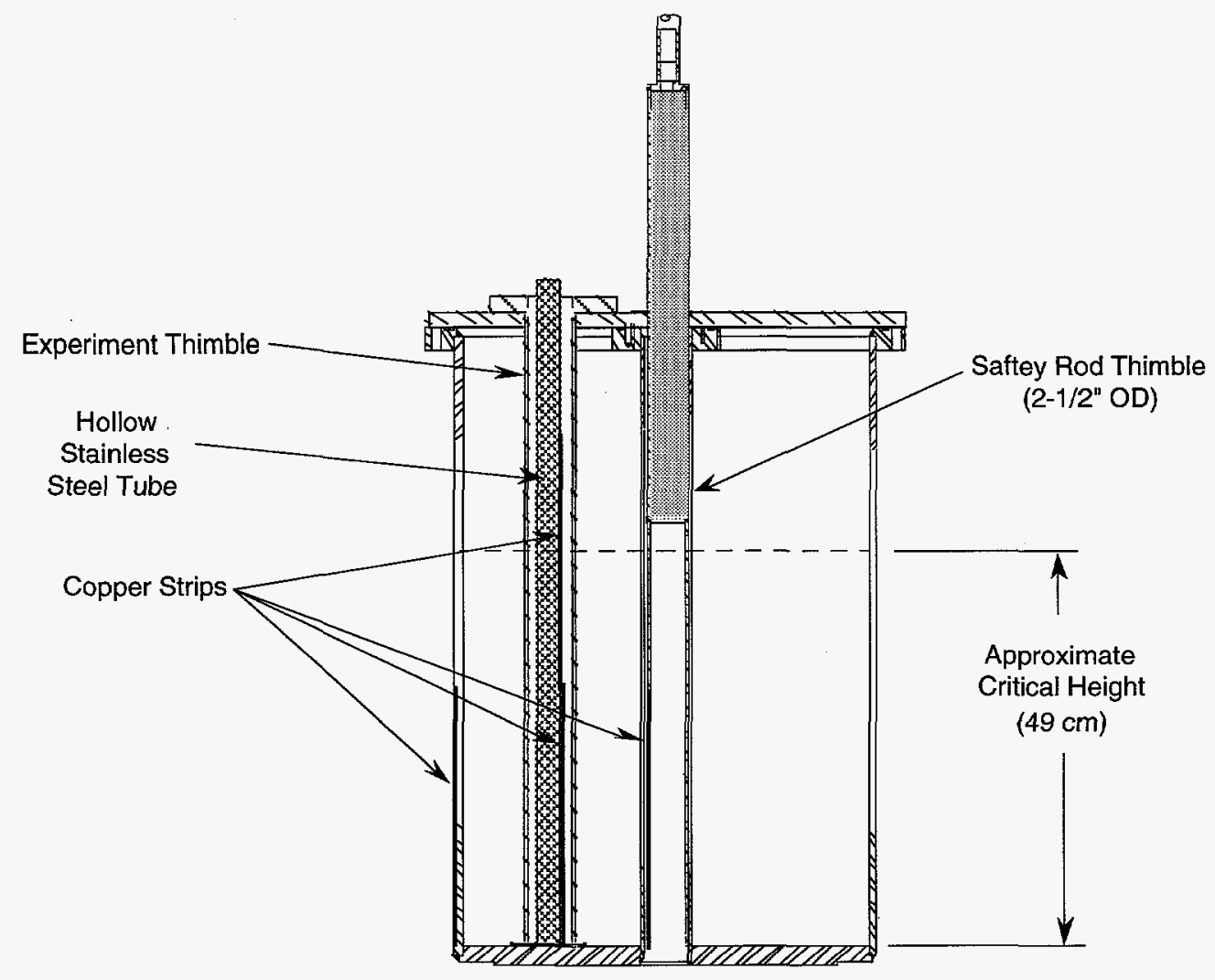

Fig. 29. Layout of copper strips for flux profile measurement in SHEBA.

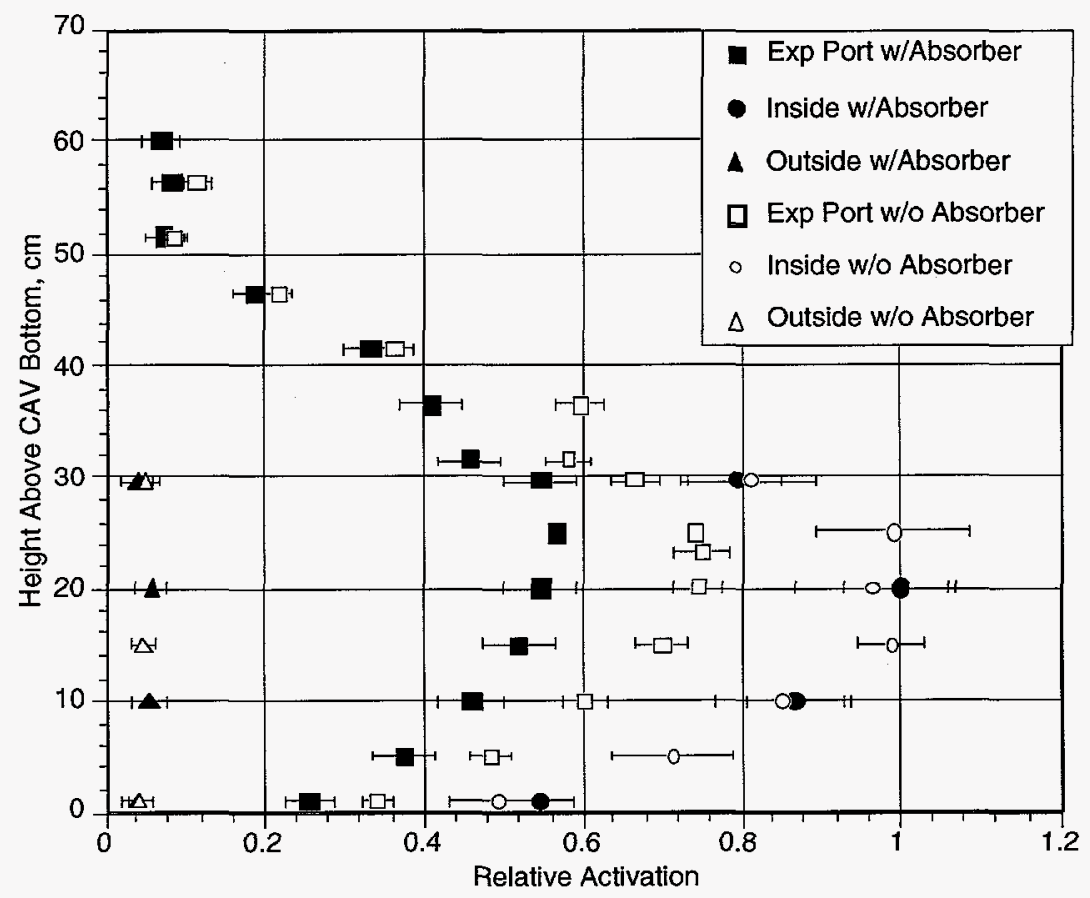

Fig. 30. Flux profile measurement in SHEBA with tritium target and with air. 


\subsection{SHEBA Spectra}

Figure 31 shows a comparison of the measured leakage neutron spectra for Godiva and SHEBA. The leakage spectra were measured using a set of nine Bonner spheres based on a spherical ${ }^{3} \mathrm{He}$ detector system. Due to the uncertainties inherent in the unfolding algorithms used to interpret the data from such a system, some uncertainty exists in the accuracy of spectra. In addition, the Bonner sphere system does not have high resolution in the region from about 3 to $5 \mathrm{Mev}$ and above. Note that only about $0.6 \mathrm{n} /$ fission in the assembly actually leak out of the assembly, compared to about 1.5 leakage $\mathrm{n} /$ fission in a fast metal system, such as Godiva.

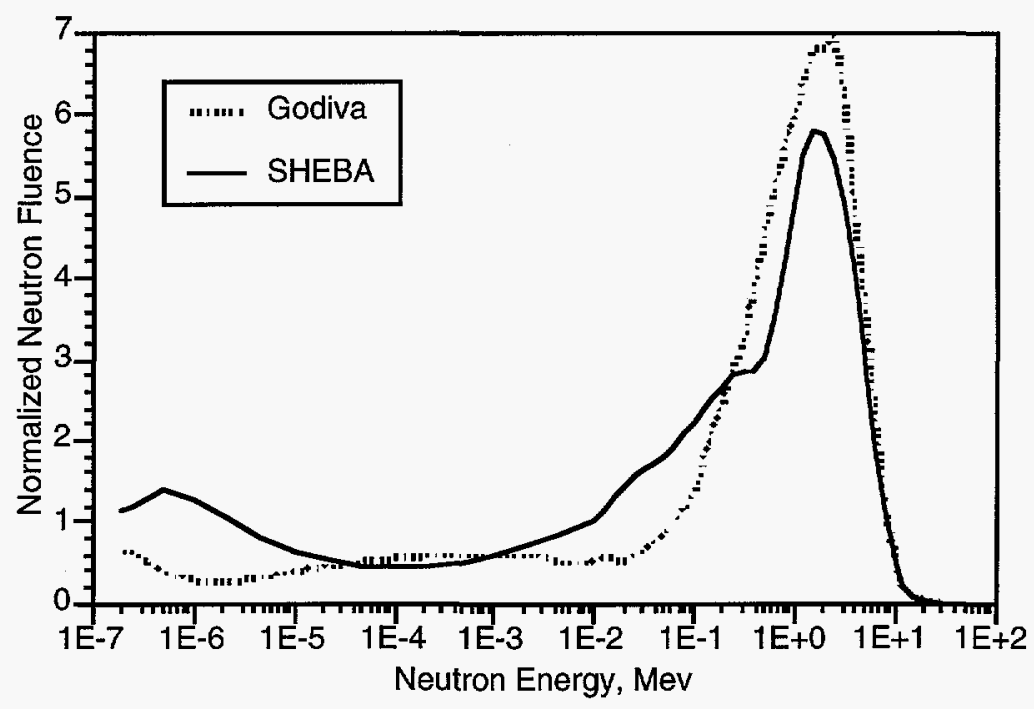

Fig. 31. Measured neutron leakage spectra from SHEBA and Godiva-IV.

\subsection{Void Worth Experiments}

\subsubsection{Introduction}

One of the parameters of interest in solution reactors is the formation and the effect of the voids caused by radiolytic gas production. The investigation of this phenomenon in SHEBA was separated into two parts. The first part uses large aluminum "voids" to simulate the MCNP and 3DANT calculations of the effects of voids. The second part of the investigation includes a series of "highpower" free-run experiments in SHEBA to produce radiolytic gas and observe the effects. This section describes the results of the aluminum void experiments. The results to date of bubble formation during free-run experiments are presented elsewhere in this report.

\subsubsection{Experimental Apparatus}

The void experiments were designed to simulate the voids used to calculate void worth in Ref. 15 . The experiments were performed by positioning relatively large aluminum void simulants at various locations in the SHEBA tank and finding the critical height of the system for each void position.

The experimental apparatus is shown in Fig. 32. Three void simulants and a void manipulation apparatus were fabricated. Two of the voids fit around the central thimble of the CAV and one fits the inside contour of the outer wall of the vessel. The two large voids were fabricated to match the calculational voids in Ref. 15 and the third void is one-third the size of the calculational voids. All of the voids are cylindrical shell segments. The two inner voids are $574 \mathrm{cc}$ and $190 \mathrm{cc}$. The outer void is $558 \mathrm{cc}$. Figures 33, 34, and 35 show the dimensions of the voids. The voids are made of aluminum to 
reduce the contribution of the material to the neutronics of the system. Aluminum corrodes slowly in the uranyl fluoride, but for short (on the order of days) periods of time there was no noticeable effect.

The manipulation apparatus consisted of an aluminum stalk that passed through a gas seal in the CAV cover and attached to a ball-screw mechanism. The ball screw was turned with a stepping motor that was controlled from the Kiva 1/SHEBA control room. Two limit switches are installed on the ball screw, one to stop the void simulant just above the bottom of the tank and one to stop the simulant when it is completely retracted from the fuel.

\subsubsection{Experimental Procedure}

Measurements of the critical height of the SHEBA system were taken with the three void simulants (one at a time) in the middle position and at the bottom position and in several intermediate positions. A sequence of operations was followed for each measurement to insure that negative or very small positive reactivity insertions occurred between steps.

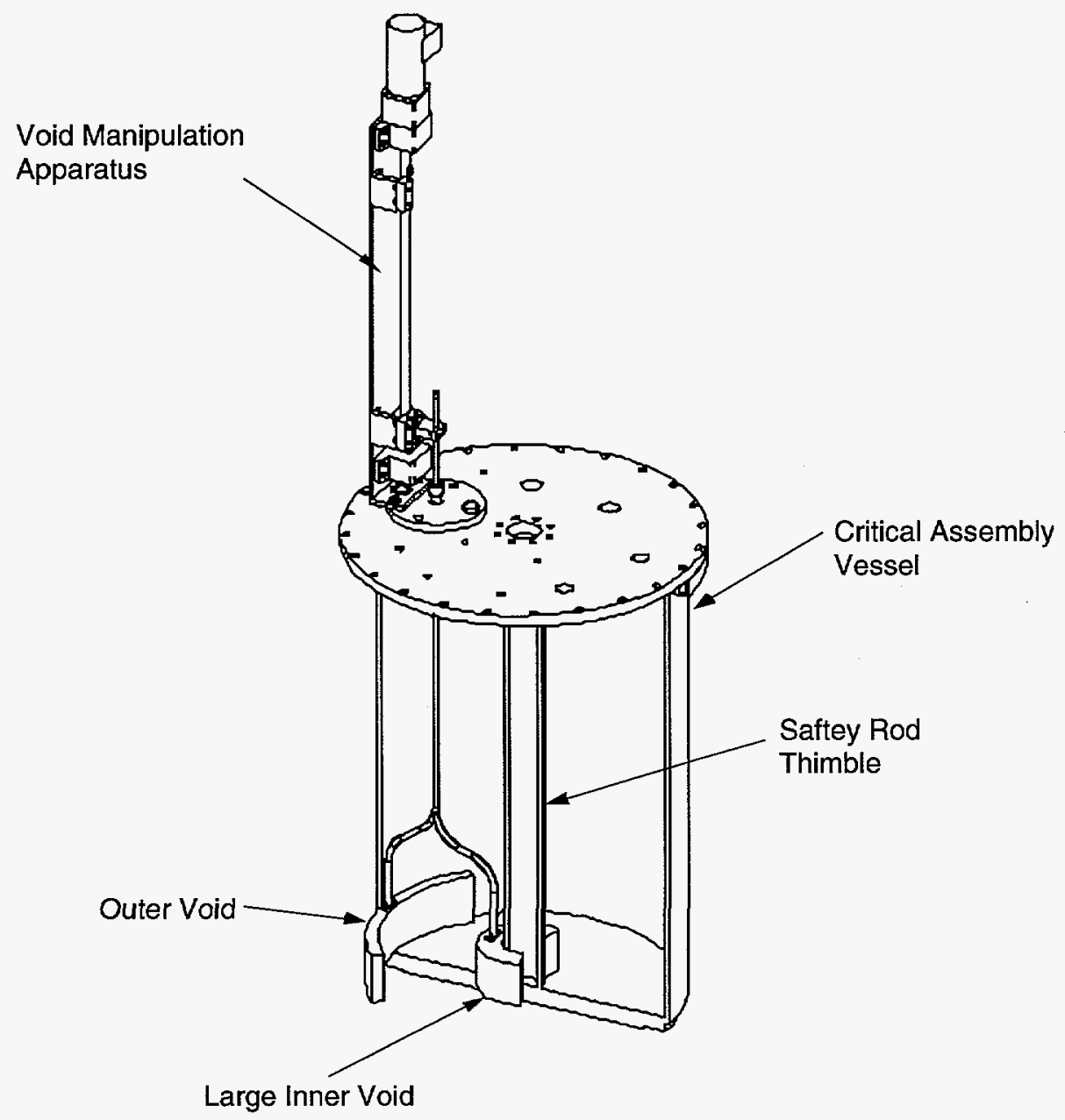

Fig. 32. Experimental apparatus. 

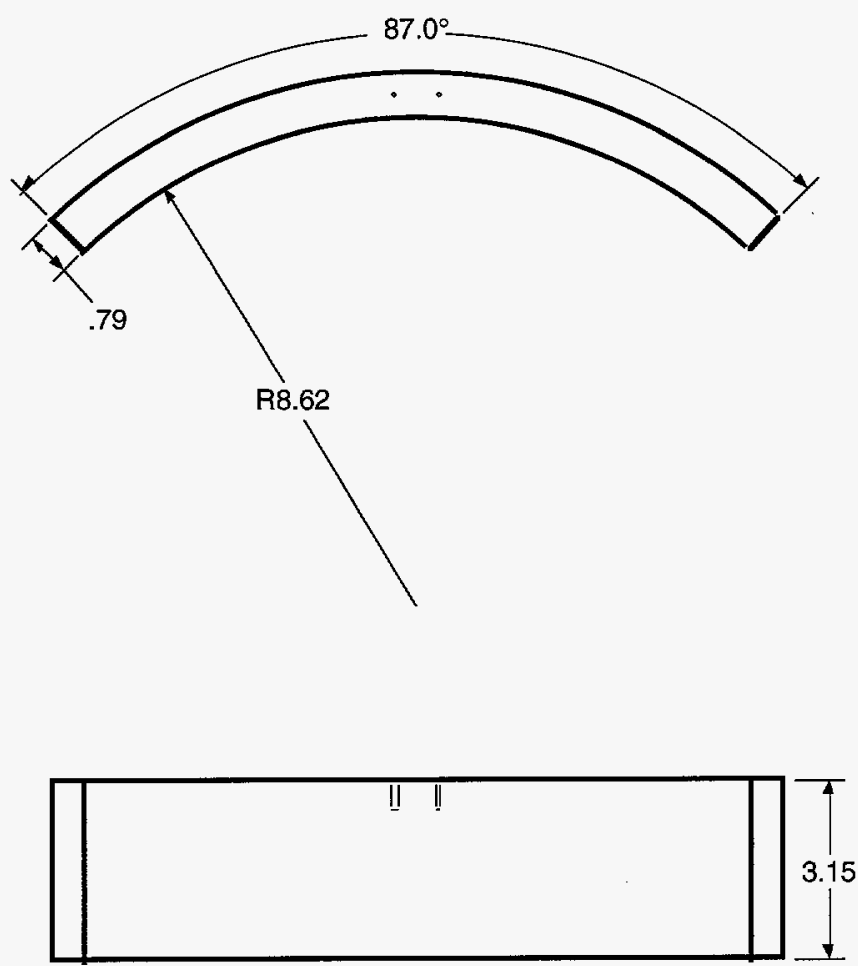

Fig. 33. Outer void (measurements are in inches).
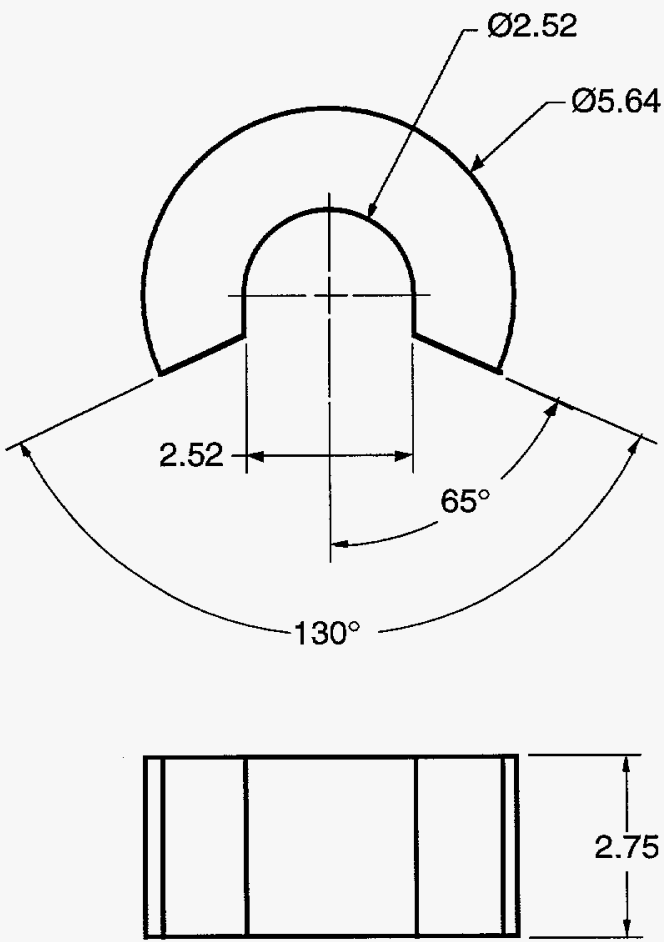

Fig. 34. Large inner void (measurements are in inches). 

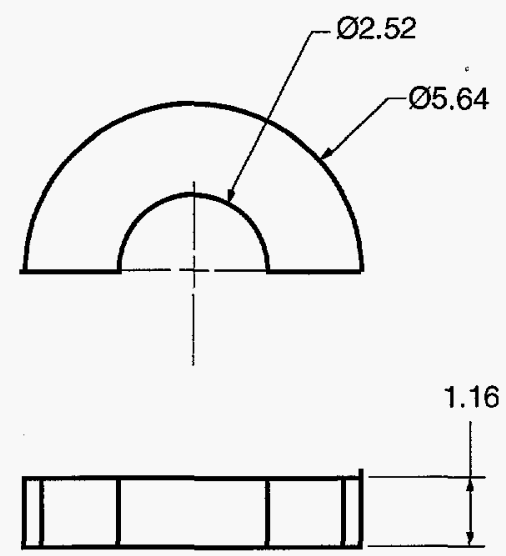

Fig. 35. Small inner void (measurements are in inches).

\subsubsection{Results}

Tables 7, 8, and 9 show the data for the void at the outside edge, the large void in the center and the small void in the center, respectively. Figure 36 is a schematic diagram depicting the layout of the system and the meaning of delayed critical (DC) and void position for these experiments.

Table 7. Void at the outside edge

Void Volume $=558.2 \mathrm{~cm}^{3}, \Delta$ height due to void $=.31 \mathrm{~cm}$

Date: $8 / 24 / 94$

\begin{tabular}{|c|c|c|c|c|}
\hline $\begin{array}{l}\text { Void Position } \\
\text { (cm) }\end{array}$ & $\begin{array}{c}\mathrm{DC} \\
(\mathrm{cm})\end{array}$ & $\begin{array}{c}\text { Temperature } \\
{ }^{\circ} \mathrm{C}\end{array}$ & $\begin{array}{c}\text { DC } \\
\text { at } 29.3^{\circ} \mathrm{C}\end{array}$ & $\begin{array}{l}\triangle \mathrm{DC} \text { due to } \\
\text { void }(\mathrm{cm})\end{array}$ \\
\hline No void & 45.60 & 28.1 & 45.72 & \\
\hline Void at top, $10 \mathrm{~cm}$ & 45.91 & 29.1 & 45.93 & -0.10 \\
\hline Void at top, $10 \mathrm{~cm}$ & 45.90 & 29.3 & 45.90 & -0.13 \\
\hline Void at $27 \mathrm{~cm}$ & 46.33 & 29.3 & 46.33 & 0.30 \\
\hline Void at bottom & 46.02 & 29.3 & 46.02 & -0.01 \\
\hline Void at $12.7 \mathrm{~cm}$ & 46.01 & 29.3 & 46.01 & -0.02 \\
\hline
\end{tabular}

Table 8. Large void at the center

Void Volume $=574.04 \mathrm{~cm}^{3}, \Delta$ height due to void $=.31 \mathrm{~cm}$

Date: $8 / 30 / 94$

\begin{tabular}{|l|c|c|c|c|}
\hline \multicolumn{1}{|c|}{$\begin{array}{c}\text { Void Position } \\
(\mathbf{c m})\end{array}$} & $\begin{array}{c}\text { DC } \\
(\mathbf{c m})\end{array}$ & $\begin{array}{c}\text { Temperature } \\
{ }^{\circ} \mathbf{C}\end{array}$ & $\begin{array}{c}\text { DC } \\
\text { at 25.7 }\end{array}$ & $\begin{array}{c}\Delta \text { CC due to } \\
\text { void }(\mathbf{c m})\end{array}$ \\
\hline No void & 45.19 & 24.4 & 45.32 & \\
\hline Void at top, $9 \mathrm{~cm}$ & 46.25 & 25.3 & 46.29 & .93 \\
\hline Void at center, $25 \mathrm{~cm}$ & $\begin{array}{c}>48.43, \\
\text { Not Critical }\end{array}$ & 25.7 & $>48.43$ & $>3.07$ \\
\hline
\end{tabular}


Table 9. Small void at the center

Void Volume $=190.09 \mathrm{~cm}^{3}, \Delta$ height due to void $=.11 \mathrm{~cm}$

Date: $9 / 20 / 94$

\begin{tabular}{|l|c|c|c|c|}
\hline \multicolumn{1}{|c|}{$\begin{array}{c}\text { Void Position } \\
(\mathbf{c m})\end{array}$} & $\begin{array}{c}\text { DC } \\
(\mathbf{c m})\end{array}$ & $\begin{array}{c}\text { Temperature } \\
{ }^{\circ} \mathbf{C}\end{array}$ & $\begin{array}{c}\text { DC } \\
\text { at 22 }{ }^{\circ} \mathbf{C}\end{array}$ & $\begin{array}{c}\Delta \text { DC due to } \\
\text { void }(\mathbf{c m})\end{array}$ \\
\hline No void & 45.05 & 21.8 & 45.07 & \\
\hline Void at top, $6 \mathrm{~cm}$ & 45.34 & 21.8 & 45.36 & 0.18 \\
\hline Void at center, $25 \mathrm{~cm}$ & 46.13 & 21.8 & 45.15 & 0.97 \\
\hline Void at $26 \mathrm{~cm}$ & 46.13 & 21.8 & 45.15 & 0.97 \\
\hline Void at $21 \mathrm{~cm}$ & 46.03 & 21.9 & 46.04 & 0.86 \\
\hline Void at $16 \mathrm{~cm}$ & 45.81 & 22.0 & 45.81 & 0.63 \\
\hline Void at $11 \mathrm{~cm}$ & 45.56 & 22.1 & 45.55 & 0.37 \\
\hline Void at $6 \mathrm{~cm}$ (top) & 45.35 & 22.1 & 45.34 & 0.16 \\
\hline Void at $0 \mathrm{~cm}$ (no void) & 45.08 & 22.1 & 45.07 & \\
\hline
\end{tabular}

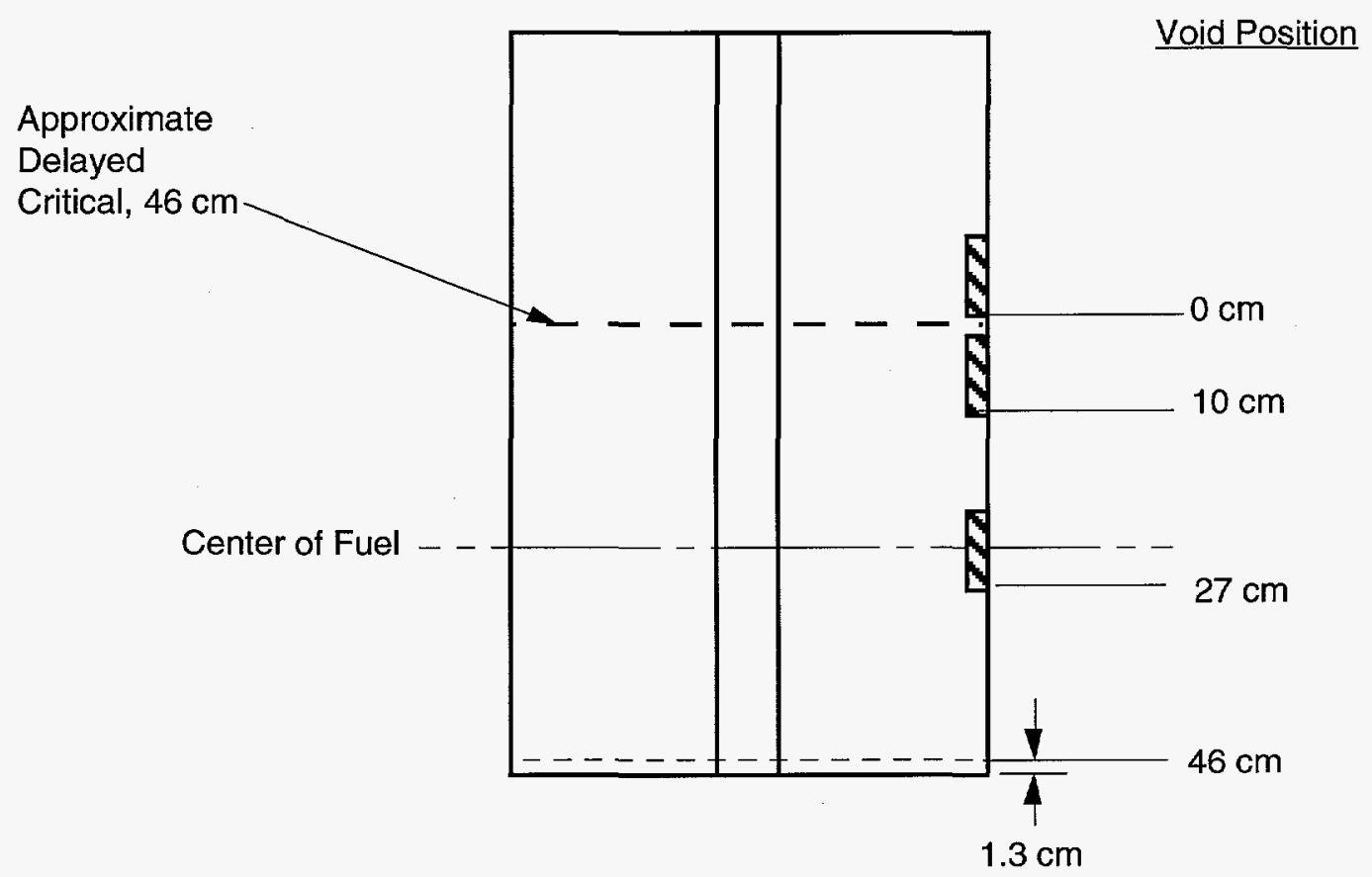

Fig. 36. Layout of void experiment. 
The first experiment was the outer void experiment. The data taken was within the calculational tolerance of the expected data (See Table 10 below). However, when the large center void was used, the worth of the void at the center had been grossly underestimated by the calculations and the experiment was terminated. At that time, the third void was constructed to be $\sim 1 / 3$ the size of the large inner void and the experiment was then repeated.

\subsubsection{Comparison of Experiment with Calculations}

Table 10 is a comparison of the Ref. 3 calculations with the experimental data. For the void on the outside edge, the results agree fairly well with 3DANT, including the prediction that the void at the outer corner has a negative worth. This is because the fuel is being displaced from an area of low importance in toward the center where it is worth more. The MCNP calculations did not predict a negative worth in this area and overestimated the worth of the void at both locations. Figure 37 is a plot of the small inner void data.

Voids, in general, have a negative effect on reactivity. Voids near the outside top or bottom of the tank have a positive effect because displaced fuel goes to a position of more worth. Most bubbles formed due to radiolytic dissociation of the fuel will be formed in the high flux regions of the tank near the position of greatest negative worth and thus, the overall reactivity effect of radiolytic gas production will be negative.

Table 10. Comparison of measured vs. calculated values for voids

\begin{tabular}{|l|c|c|c|c|}
\hline \multicolumn{1}{|c|}{ Void /Location } & $\begin{array}{c}\text { Ref. 3, MCNP } \\
\text { Large Voids } \\
\text { (cm) }\end{array}$ & $\begin{array}{c}\text { Ref. 3, } \\
\text { 3-DANT Large } \\
\text { Voids (cm) }\end{array}$ & $\begin{array}{c}\text { Experiment } \\
\text { Large } \\
\text { Voids (cm) }\end{array}$ & $\begin{array}{c}\text { Experiment } \\
\text { Small Inner } \\
\text { Void (cm) }\end{array}$ \\
\hline Delayed Critical & $41.31 \pm 0.3$ & 44.13 & 45.0 & 45.0 \\
\hline Outside/Top & $0.50 \pm 0.3$ & -0.19 & -0.13 & \\
\hline Outside/Middle & $0.98 \pm 0.3$ & 0.17 & 0.30 & \\
\hline Outside -- Difference & $0.48 \pm 0.6$ & 0.43 & 0.43 & \\
\hline Inner /Top & $1.01 \pm 0.3$ & 0.33 & 0.93 & 0.18 \\
\hline Inner / Middle & $1.08 \pm 0.3$ & 0.27 & $>3.07$ & 0.97 \\
\hline Inner -- Difference & $0.07 \pm 0.6$ & -0.06 & & 0.79 \\
\hline
\end{tabular}




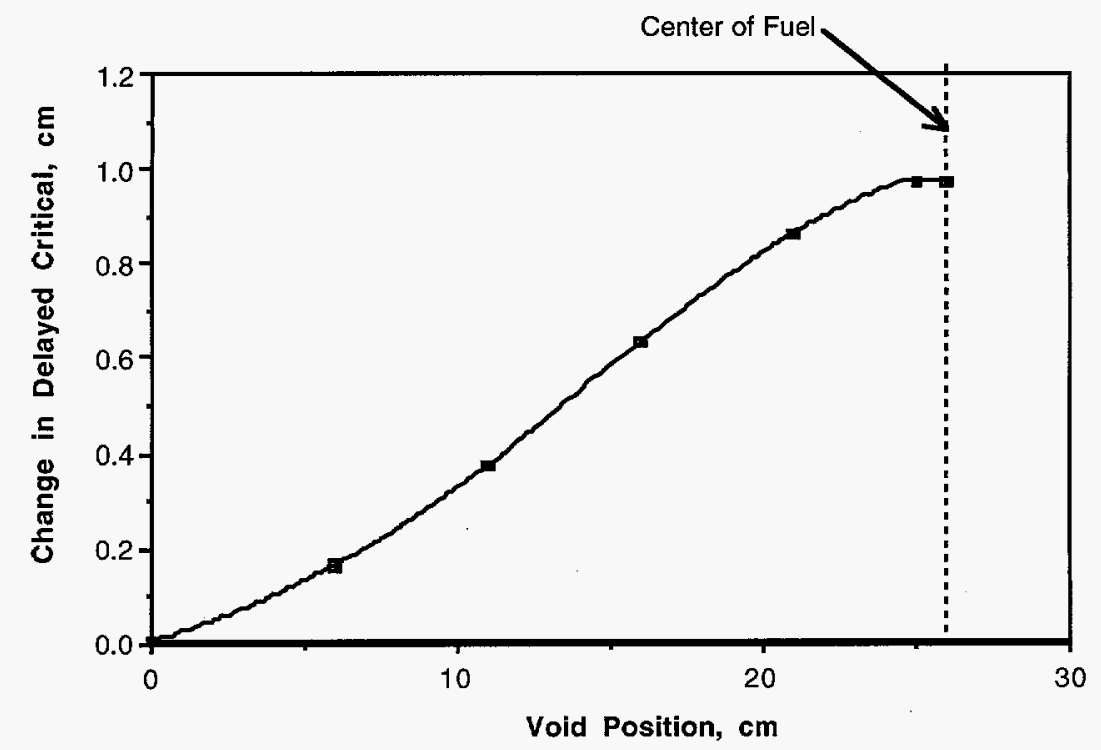

Fig. 37. Measured void worth for small central void. 


\section{References}

1. P. LeCorche and R. L. Seale, "A Review of the Experiments Performed to Determine the Radiological Consequences of a Criticality Accident," Y-CDC-12, UC-46 (November 1973).

2. "OMEGA Complete Temperature Measurement Handbook and Encyclopedia," Omega Engineering, Inc., 1992.

3. LaBauve, Raphael et. al., "Unreflected $\mathrm{UO}_{2} \mathrm{~F}_{2}+\mathrm{H}_{2} \mathrm{O}$ Cylindrical Assembly-SHEBA II," International Handbook of Evaluated Criticality Safety Benchmark Experiments, Evaluation Number LEU-SOL-THERM-001.

4. "Safety Analysis Report for the Los Alamos Critical Experiments Facility and Hillside Vault," Los Alamos National Laboratory report LA-CP-92-235, June 1, 1994.

5. Los Alamos National Laboratory CLS-1 Sample Management report, February 7, 1989.

6. Los Alamos National Laboratory CLS-1 Sample Management report, February 14, 1989.

7. Los Alamos National Laboratory CLS-1 Sample Management report, March 19, 1991.

8. Westinghouse Nuclear Division Analytical Services report, September 22, 1995.

9. Los Alamos National Laboratory Analytical Chemistry report, February 5, 1996.

10. "Accidental Radiation Excursion at the Y-12 Plant," Union Carbide Nuclear Company report Y-1234, June 16, 1958.

11. J. Orndoff, "Prompt Neutron Periods of Metal Critical Assemblies," Nucl. Sci. Eng., 2, 450 (1957).

12. R. Sanchez and P. Jaegers, "Prompt Neutron Decay Constants in SHEBA," Los Alamos National Laboratory report LA-UR-97-158 (1997).

13. G. J. Arnone et al., "A Pulse Arrival-Time Recording Module for Analyzing Neutron Multiplicities," Los Alamos National Laboratory report LA-UR-92-3460 (1992).

14. Langley Ford Instruments Model 1096 Correlator Instruction Manual, July 1984.

15. S. G. Walters, "Reactivity Effects of Void Formations in a Solution Critical Assembly," Los Alamos National Laboratory report LA-12716-T. 
Appendix 1

Data Tables for Figures

Figure No.

13

14

21

22

23

24

26

27

30
Title

Free Run Peak Power vs. Initial

Reactivity Insertion

Total Fissions vs. Initial Reactivity Insertion

SHEBA Temperature Coefficient

Reactivity vs. Solution Height

Period vs $\Delta H$, out of pit

Period vs $\Delta H$, in the pit

SHEBA Flux Profile

SHEBA Horizontal Flux Profile

SHEBA Flux Profile
Page of Data Table

$1-2$

$1-2$

$1-3$

$1-5$

$1-6$

1-6

$1-7$

$1-9$

$1-10$ 
Data Table for Figures 13 and 14

\begin{tabular}{|r|r|r|r|r|r|r|}
\hline $\begin{array}{c}\text { Date } \\
\text { of Run }\end{array}$ & $\begin{array}{c}\text { Initial } \\
\text { Period, } \\
\text { seconds }\end{array}$ & $\begin{array}{c}\text { Reactivity } \\
\text { Insertion, } \varnothing\end{array}$ & $\begin{array}{c}\text { Peak, } \\
\text { RAP amps }\end{array}$ & Peak, $\mathrm{kW}$ & $\begin{array}{c}\text { Total Energy, } \\
\text { Amp-sec }\end{array}$ & Fissions \\
\hline \hline $1 / 26 / 95$ & 83 & 11.48 & $1.97 \mathrm{E}-05$ & 1.52 & & $2.15 \mathrm{E}+16$ \\
\hline $6 / 14 / 95$ & 60 & 14.50 & $2.77 \mathrm{E}-05$ & 2.13 & $1.24 \mathrm{E}-02$ & $3.35 \mathrm{E}+16$ \\
\hline $4 / 11 / 95$ & 42 & 18.40 & $1.10 \mathrm{E}-04$ & 8.47 & & $8.73 \mathrm{E}+16$ \\
\hline $5 / 4 / 94$ & 31 & 22.25 & $2.00 \mathrm{E}-04$ & 15.40 & $4.18 \mathrm{E}-02$ & $1.13 \mathrm{E}+17$ \\
\hline $12 / 7 / 94$ & 30 & 22.70 & $9.30 \mathrm{E}-05$ & 7.16 & $1.81 \mathrm{E}-02$ & $4.89 \mathrm{E}+16$ \\
\hline $2 / 9 / 95$ & 20 & 28.50 & $1.80 \mathrm{E}-04$ & 13.84 & & $6.60 \mathrm{E}+16$ \\
\hline $7 / 21 / 95$ & 14 & 34.20 & $5.21 \mathrm{E}-04$ & 40.15 & & $1.52 \mathrm{E}+17$ \\
\hline $6 / 30 / 95$ & 10 & 40.00 & $4.98 \mathrm{E}-04$ & 38.33 & & $4.26 \mathrm{E}+17$ \\
\hline $7 / 12 / 95$ & 9 & 40.05 & $6.00 \mathrm{E}-04$ & 46.20 & & \\
\hline $12 / 19 / 96$ & 5 & 52.60 & $1.77 \mathrm{E}-03$ & 136.29 & & $2.15 \mathrm{E}+17$ \\
\hline $12 / 20 / 96$ & 2 & 68.90 & $3.55 \mathrm{E}-03$ & 273.35 & & $2.78 \mathrm{E}+17$ \\
\hline $12 / 21 / 96$ & 1 & 79.40 & $6.27 \mathrm{E}-03$ & 482.79 & & $3.00 \mathrm{E}+17$ \\
\hline
\end{tabular}


Data Table for Figure 21

SHEBA Temperature Coefficient

\begin{tabular}{|c|c|c|c|}
\hline Date & DC, Out of Pit -- cm & Temperature $--{ }^{\circ} \mathrm{C}$ & $\mathrm{DC}$, In Pit -- cm \\
\hline $5 / 19 / 94$ & & 15.60 & 43.30 \\
\hline $5 / 23 / 94$ & 44.67 & 16.50 & \\
\hline $5 / 23 / 94$ & 44.68 & 16.90 & \\
\hline $5 / 23 / 94$ & 44.73 & 17.40 & \\
\hline $6 / 10 / 94$ & & 17.70 & 43.41 \\
\hline $7 / 15 / 94$ & 45.40 & 25.40 & \\
\hline $7 / 15 / 94$ & 45.53 & 26.90 & \\
\hline $7 / 15 / 94$ & 45.87 & 29.70 & \\
\hline $7 / 15 / 94$ & 45.97 & 30.90 & \\
\hline $7 / 15 / 94$ & 46.06 & 31.80 & \\
\hline $7 / 15 / 94$ & 46.20 & 32.60 & \\
\hline $7 / 15 / 94$ & 46.27 & 33.40 & \\
\hline $7 / 15 / 94$ & 46.35 & 34.20 & \\
\hline $7 / 22 / 94$ & 45.35 & 25.20 & \\
\hline $7 / 22 / 94$ & 45.47 & 26.60 & \\
\hline $7 / 22 / 94$ & 45.59 & 27.70 & \\
\hline $7 / 22 / 94$ & 45.69 & 28.90 & \\
\hline $7 / 22 / 94$ & 45.80 & 30.00 & \\
\hline $7 / 22 / 94$ & 45.93 & 31.00 & \\
\hline $7 / 22 / 94$ & 45.95 & 31.30 & \\
\hline $9 / 20 / 94$ & 45.04 & 21.80 & \\
\hline $11 / 9 / 94$ & 44.89 & 21.80 & \\
\hline $11 / 29 / 94$ & 44.18 & 15.90 & \\
\hline $11 / 29 / 94$ & 44.13 & 15.60 & \\
\hline $12 / 7 / 94$ & 45.33 & 24.20 & \\
\hline $12 / 22 / 94$ & 44.95 & 20.30 & \\
\hline $1 / 18 / 95$ & 45.09 & 21.40 & \\
\hline $2 / 2 / 95$ & 45.20 & 22.60 & \\
\hline $2 / 9 / 95$ & 45.01 & 22.30 & \\
\hline $2 / 28 / 95$ & 45.20 & 23.20 & \\
\hline $3 / 2 / 95$ & 45.40 & 25.60 & \\
\hline $3 / 2 / 95$ & 45.56 & 26.90 & \\
\hline $3 / 9 / 95$ & & 13.60 & 42.85 \\
\hline $3 / 9 / 95$ & & 13.60 & 42.86 \\
\hline $3 / 16 / 95$ & & 11.90 & 42.36 \\
\hline $3 / 16 / 95$ & & 12.50 & 42.41 \\
\hline $3 / 16 / 95$ & & 12.60 & 42.38 \\
\hline $3 / 23 / 95$ & & 12.80 & 42.54 \\
\hline $4 / 11 / 95$ & & 18.90 & 43.61 \\
\hline $4 / 11 / 95$ & & 19.80 & 43.65 \\
\hline $4 / 21 / 95$ & 44.24 & 13.70 & \\
\hline $5 / 7 / 95$ & 44.05 & 12.00 & \\
\hline $5 / 19 / 95$ & 44.65 & 19.10 & \\
\hline $6 / 30 / 95$ & & 20.40 & 43.60 \\
\hline $7 / 12 / 95$ & & 17.50 & 43.44 \\
\hline
\end{tabular}


Data Table for Figure 21

SHEBA Temperature Coefficient

\begin{tabular}{|c|c|c|c|}
\hline Date & DC, Out of Pit $-\mathrm{cm}$ & Temperature $-{ }^{\circ} \mathrm{C}$ & $\mathrm{DC}, \ln$ Pit $-\mathrm{cm}$ \\
\hline $1 / 3 / 96$ & & 20.00 & 43.63 \\
\hline $1 / 11 / 96$ & & 12.30 & 42.94 \\
\hline $1 / 17 / 96$ & & 11.90 & 42.93 \\
\hline $2 / 21 / 96$ & & 13.80 & 43.11 \\
\hline $2 / 21 / 96$ & & 16.00 & 43.28 \\
\hline $2 / 22 / 96$ & & 22.90 & 43.82 \\
\hline $2 / 22 / 96$ & & 26.40 & 44.19 \\
\hline $2 / 23 / 96$ & & 25.70 & 44.09 \\
\hline
\end{tabular}


Data Table for Figure 22

Measured Reactivity vs. Solution Height

\begin{tabular}{|c|c|c|c|}
\hline Fuel Height & Reactivity & Fuel Height & Reactivity \\
\hline Above DC, $\mathrm{cm}$ & Out of Pit, $\varnothing$ & Above DC, $\mathrm{cm}$ & In Pit, $\varnothing$ \\
\hline 0.32 & 14.67 & 0.56 & 28.17 \\
\hline 0.41 & 19.88 & 0.73 & 37.09 \\
\hline 0.20 & 10.50 & 0.36 & 19.01 \\
\hline 0.28 & 13.31 & 0.25 & 12.07 \\
\hline 0.15 & 10.83 & 0.45 & 23.51 \\
\hline 0.44 & 21.57 & 0.86 & 44.06 \\
\hline 0.13 & 6.85 & 0.97 & 49.19 \\
\hline 0.27 & 12.30 & 0.52 & 26.49 \\
\hline 0.60 & 26.99 & 0.37 & 19.33 \\
\hline 0.93 & 43.30 & & \\
\hline 1.12 & 51.64 & & \\
\hline
\end{tabular}


Data Table for Figures 23 and 24

Period vs. Change in Fuel Height

\begin{tabular}{|c|c|c|c|}
\hline \multicolumn{2}{|c|}{ Out of Pit } & \multicolumn{2}{|c|}{$\ln \mathrm{Pit}$} \\
\hline$\Delta \mathrm{H}, \mathrm{cm}$ & Period, sec & $\Delta \mathrm{H}, \mathrm{cm}$ & Period, sec \\
\hline 0.23 & 79.00 & $7.20 \mathrm{E}-01$ & $1.29 \mathrm{E}+01$ \\
\hline 0.21 & 88.00 & $5.20 \mathrm{E}-01$ & $2.29 \mathrm{E}+01$ \\
\hline 0.41 & 35.80 & $9.90 \mathrm{E}-01$ & $6.20 \mathrm{E}+00$ \\
\hline 0.64 & 19.00 & $1.33 \mathrm{E}+00$ & $2.61 E+00$ \\
\hline 0.61 & 21.00 & $1.41 E+00$ & $2.16 E+00$ \\
\hline 0.85 & 11.00 & $1.50 \mathrm{E}+00$ & $1.62 E+00$ \\
\hline 0.96 & 7.70 & $1.58 \mathrm{E}+00$ & $1.35 \mathrm{E}+00$ \\
\hline 1.01 & 6.80 & $1.67 \mathrm{E}+00$ & $9.20 \mathrm{E}-01$ \\
\hline 0.13 & 136.50 & $1.73 \mathrm{E}+00$ & $7.95 \mathrm{E}-01$ \\
\hline 0.27 & 68.10 & $1.80 \mathrm{E}+00$ & $6.00 \mathrm{E}-01$ \\
\hline 0.60 & 20.40 & $1.87 E+00$ & $4.70 \mathrm{E}-01$ \\
\hline 0.93 & 7.99 & $1.92 \mathrm{E}+00$ & $3.75 \mathrm{E}-01$ \\
\hline 0.86 & 11.00 & & \\
\hline 1.12 & 4.88 & & \\
\hline 0.60 & 18.21 & & \\
\hline 0.86 & 9.73 & & \\
\hline 1.08 & 6.08 & & \\
\hline 1.15 & 5.12 & & \\
\hline 1.22 & 4.28 & & \\
\hline 1.31 & 3.65 & & \\
\hline 1.39 & 2.95 & & \\
\hline 1.54 & 2.07 & & \\
\hline 1.64 & 1.57 & & \\
\hline 1.73 & 1.16 & & \\
\hline 1.78 & 0.95 & & \\
\hline 1.86 & 0.81 & & \\
\hline 1.92 & 0.64 & & \\
\hline 2.00 & 0.47 & & \\
\hline 1.01 & 6.70 & & \\
\hline 1.15 & 4.95 & & \\
\hline 1.23 & 4.07 & & \\
\hline 1.32 & 3.36 & & \\
\hline 1.40 & 2.80 & & \\
\hline 1.42 & 2.64 & & \\
\hline 1.49 & 2.12 & & \\
\hline 1.57 & 1.80 & & \\
\hline 1.64 & 1.50 & & \\
\hline 1.73 & 1.16 & & \\
\hline 1.82 & 0.87 & & \\
\hline 1.91 & 0.68 & & \\
\hline 1.97 & 0.52 & & \\
\hline 1.97 & 0.53 & & \\
\hline 2.01 & 0.50 & & \\
\hline 2.05 & 0.43 & & \\
\hline 2.13 & 0.30 & & \\
\hline
\end{tabular}


Data Table for Figure 26

SHEBA Flux Profile

\begin{tabular}{|c|c|c|c|c|c|}
\hline \multicolumn{2}{|c|}{$\mathrm{R}=8.2 \mathrm{~cm}$} & \multicolumn{2}{|c|}{$R=15.9 \mathrm{~cm}$} & \multicolumn{2}{|c|}{$\mathrm{R}=12.0 \mathrm{~cm}$} \\
\hline Dist Above Bottom & Relative & Dist Above Bottom & Relative & Dist Above Botton & Relative \\
\hline $\mathrm{cm}$ & Activation & $\mathrm{cm}$ & Activation & $\mathrm{cm}$ & Activation \\
\hline 24.68 & 48.10 & 25.73 & 84.00 & 0.97 & 19.18 \\
\hline 26.60 & 46.66 & 27.65 & 81.80 & 2.91 & 28.58 \\
\hline 28.52 & 45.78 & 29.56 & 78.00 & 4.84 & 36.48 \\
\hline 30.44 & 43.20 & 31.48 & 72.20 & 6.78 & 43.62 \\
\hline 32.36 & 39.75 & 33.39 & 68.30 & 8.72 & 48.84 \\
\hline 34.28 & 36.09 & 35.31 & 62.00 & 10.65 & 53.48 \\
\hline 36.20 & 32.27 & 37.23 & 53.10 & 12.59 & 59.40 \\
\hline 38.12 & 26.94 & 39.14 & 44.60 & 14.53 & 62.69 \\
\hline 40.04 & 21.21 & 41.06 & 35.30 & 16.46 & 65.67 \\
\hline 41.96 & 16.32 & 42.97 & 24.60 & 18.40 & 68.26 \\
\hline 43.88 & 9.15 & 44.89 & 10.70 & 20.34 & 66.94 \\
\hline 45.80 & 3.04 & 46.81 & 3.90 & 22.28 & 64.81 \\
\hline 47.72 & 2.35 & 48.72 & 3.40 & 24.21 & 66.69 \\
\hline 49.64 & 2.23 & 50.64 & 3.10 & 26.15 & 66.55 \\
\hline 51.56 & 1.93 & 58.30 & 2.00 & 28.09 & 63.22 \\
\hline 63.08 & 1.41 & & & 30.02 & 61.64 \\
\hline & & & & 31.96 & 54.97 \\
\hline & & & & 33.90 & 52.74 \\
\hline & & & & 35.83 & 46.35 \\
\hline & & & & 37.77 & 39.98 \\
\hline & & & & 39.71 & 33.58 \\
\hline & & & & 41.65 & 25.02 \\
\hline & & & & 43.58 & 15.09 \\
\hline & & & & 45.52 & 4.76 \\
\hline & & & & 47.46 & 3.24 \\
\hline & & & & 49.39 & 2.70 \\
\hline & & & & 51.33 & 2.50 \\
\hline & & & & 59.08 & 1.78 \\
\hline & & & & 70.70 & 1.21 \\
\hline & & & & 88.13 & 0.24 \\
\hline & & & & 99.76 & 0.17 \\
\hline
\end{tabular}


Data Table for Figure 26 SHEBA Flux Profile

\begin{tabular}{|c|c|c|c|}
\hline Safety Rod & Follower & Outside & of Tank \\
\hline Dist Above Bottom & Relative & Dist Above Bottom & Relative \\
\hline $\mathrm{cm}$ & Activation & $\mathrm{cm}$ & Activation \\
\hline 47.78 & 4.20 & 48.55 & 0.58 \\
\hline 45.87 & 6.28 & 46.65 & 0.53 \\
\hline 43.95 & 11.03 & 44.74 & 0.61 \\
\hline 42.03 & 17.77 & 42.84 & 0.87 \\
\hline 40.12 & 23.64 & 40.93 & 1.19 \\
\hline 38.20 & 27.21 & 39.02 & 1.51 \\
\hline 36.28 & 30.52 & 37.12 & 1.63 \\
\hline 34.36 & 35.86 & 35.21 & 1.87 \\
\hline 32.45 & 38.69 & 33.31 & 2.05 \\
\hline 30.53 & 42.70 & 31.40 & 2.35 \\
\hline 28.61 & 45.30 & 29.49 & 2.42 \\
\hline 26.70 & 47.58 & 27.59 & 2.50 \\
\hline 24.78 & 49.35 & 25.68 & 2.39 \\
\hline 22.86 & 50.21 & 23.78 & 2.54 \\
\hline 20.95 & 49.38 & 21.87 & 2.58 \\
\hline 19.03 & 47.54 & 19.96 & 2.54 \\
\hline 17.11 & 46.72 & 18.06 & 2.55 \\
\hline 15.19 & 46.46 & 16.15 & 2.44 \\
\hline 13.28 & 43.28 & 14.25 & 2.21 \\
\hline 11.36 & 40.24 & 12.34 & 2.21 \\
\hline 9.44 & 34.68 & 10.43 & 1.92 \\
\hline 7.53 & 32.34 & 8.53 & 1.77 \\
\hline 5.61 & 27.25 & 6.62 & 1.68 \\
\hline 3.69 & 22.02 & 4.72 & 1.31 \\
\hline 1.78 & 17.05 & 2.81 & 1.07 \\
\hline-0.14 & 9.87 & 0.90 & 0.71 \\
\hline & & & \\
\hline & & & \\
\hline & & & \\
\hline & & & \\
\hline & & & \\
\hline
\end{tabular}


Data Table for Figure 27

SHEBA Horizontal Flux Profile

\begin{tabular}{|c|c|c|c|c|}
\hline Wire & 1 & & Wire \\
\hline Horizontal Distance & & & Horizontal Distance & \\
\hline From Safety Follower & Relative & From Safety Follower & Relative \\
\hline $\mathrm{cm}$ & Activation & $\mathrm{cm}$ & Activation \\
\hline 1.66 & 100 & 10.06 & 76.7 \\
\hline 3.58 & 99.02 & 11.98 & 68.9 \\
\hline 5.5 & 92.98 & 13.89 & 60.5 \\
\hline 7.42 & 87.72 & 15.81 & 47.2 \\
\hline 9.34 & 80.81 & 17.73 & 39.2 \\
\hline 11.26 & 69.54 & 19.64 & 25.7 \\
\hline
\end{tabular}




\section{Data Table for Figure 30}

SHEBA Flux Profile

\begin{tabular}{|c|c|c|c|c|c|c|c|c|}
\hline \multicolumn{3}{|c|}{ Experiment Port with Absorber } & \multicolumn{3}{|c|}{ Inside with Absorber } & \multicolumn{3}{|c|}{ Outside with Absorber } \\
\hline Location & Relative & \pm Error & Location & Relative & \pm Error & Location & Relative & \pm Error \\
\hline $\mathrm{cm}$ & Activation & & $\mathrm{cm}$ & Activation & & $\mathrm{cm}$ & Activation & \\
\hline 1 & 0.256 & 0.03 & 1 & 0.545 & 0.043 & 1 & 0.042 & 0.02 \\
\hline 5 & 0.377 & 0.038 & 10 & 0.868 & 0.062 & 10 & 0.056 & 0.021 \\
\hline 10 & 0.459 & 0.042 & 20 & 1.000 & 0.071 & 20 & 0.060 & 0.02 \\
\hline 15 & 0.520 & 0.046 & 29.7 & 0.794 & 0.058 & 29.7 & 0.042 & 0.021 \\
\hline 20 & 0.548 & 0.047 & & & & & & \\
\hline 25 & 0.567 & 0 & & & & & & \\
\hline 29.7 & 0.546 & 0.047 & & & & & & \\
\hline 31.5 & 0.458 & 0.04 & & & & & & \\
\hline 36.5 & 0.411 & 0.038 & & & & & & \\
\hline 41.5 & 0.335 & 0.035 & & & & & & \\
\hline 46.5 & 0.187 & 0.028 & & & & & & \\
\hline 51.5 & 0.075 & 0.025 & & & & & & \\
\hline 56.5 & 0.085 & 0.025 & & & & & & \\
\hline 60.2 & 0.071 & 0.025 & & & & & & \\
\hline & \multicolumn{3}{|c|}{ Inside w/o Absorber } & & \\
\hline Location & Relative & $\begin{array}{l}\text { sorber } \\
\pm \text { Error }\end{array}$ & Location & w/o Abso & \pm Error & $\begin{array}{r}\text { Outs } \\
\text { Location }\end{array}$ & Relative & \pm Error \\
\hline $\mathrm{cm}$ & Activation & & $\mathrm{cm}$ & Activation & & $\mathrm{cm}$ & Activation & \\
\hline 1 & 0.342 & 0.018 & 1 & 0.492 & 0.063 & 1 & 0.043 & 0.017 \\
\hline 5 & 0.483 & 0.024 & 5 & 0.713 & 0.077 & 15 & 0.048 & 0.016 \\
\hline 10 & 0.604 & 0.028 & 10 & 0.853 & 0.086 & 29.7 & 0.053 & 0.015 \\
\hline 15 & 0.700 & 0.031 & 15 & 0.990 & 0.041 & & & \\
\hline 20 & 0.746 & 0.033 & 20 & 0.966 & 0.095 & & & \\
\hline 23.3 & 0.750 & 0.033 & 25 & 0.991 & 0.097 & & & \\
\hline 25 & 0.741 & 0 & 29.7 & 0.812 & 0.086 & & & \\
\hline 29.7 & 0.666 & 0.031 & & & & & & \\
\hline 31.5 & 0.584 & 0.029 & & & & & & \\
\hline 36.5 & 0.599 & 0.031 & & & & & & \\
\hline 41.5 & 0.365 & 0.022 & & & & & & \\
\hline 46.5 & 0.216 & 0.02 & & & & & & \\
\hline 51.5 & 0.088 & 0.016 & & & & & & \\
\hline 56.5 & 0.116 & 0.018 & & & & & & \\
\hline
\end{tabular}


Appendix 2

\section{SHEBA Free Run Graphs}

$\begin{array}{ccc}\text { Date } & \begin{array}{c}\text { Initial Reactor Period, } \\ \text { seconds }\end{array} & \text { Page } \\ 1 / 26 / 95 & 83 & 2-2 \\ 6 / 14 / 95 & \sim 60 & 2-3 \\ 4 / 11 / 95 & 42 & 2-4 \\ 12 / 7 / 94 & 30 & 2-5 \\ 5 / 4 / 94 & 31 & 2-6 \\ 2 / 9 / 95 & 20 & 2-7 \\ 7 / 21 / 95 & 14 & 2-8 \\ 6 / 30 / 95 & 10 & 2-9 \\ 12 / 19 / 96 & 5 & 2-10 \\ 12 / 20 / 96 & 2 & 2-11 \\ 12 / 21 / 96 & 1 & 2-12\end{array}$


SHEBA Free Run, 1/26/95
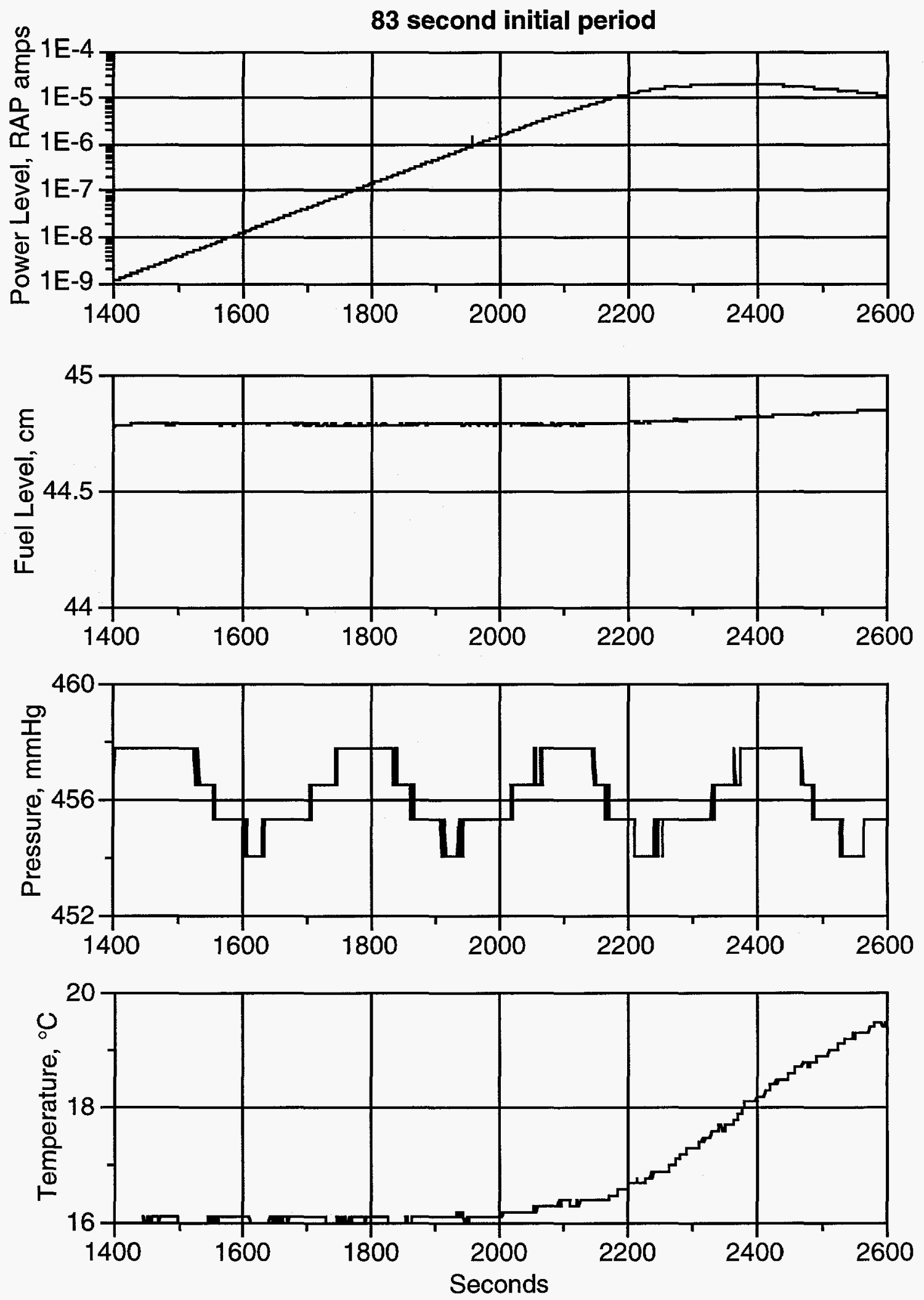
SHEBA Free Run, 6/14/95

approximately 60 second initial period

(See Section 4.3 for more information on this run)
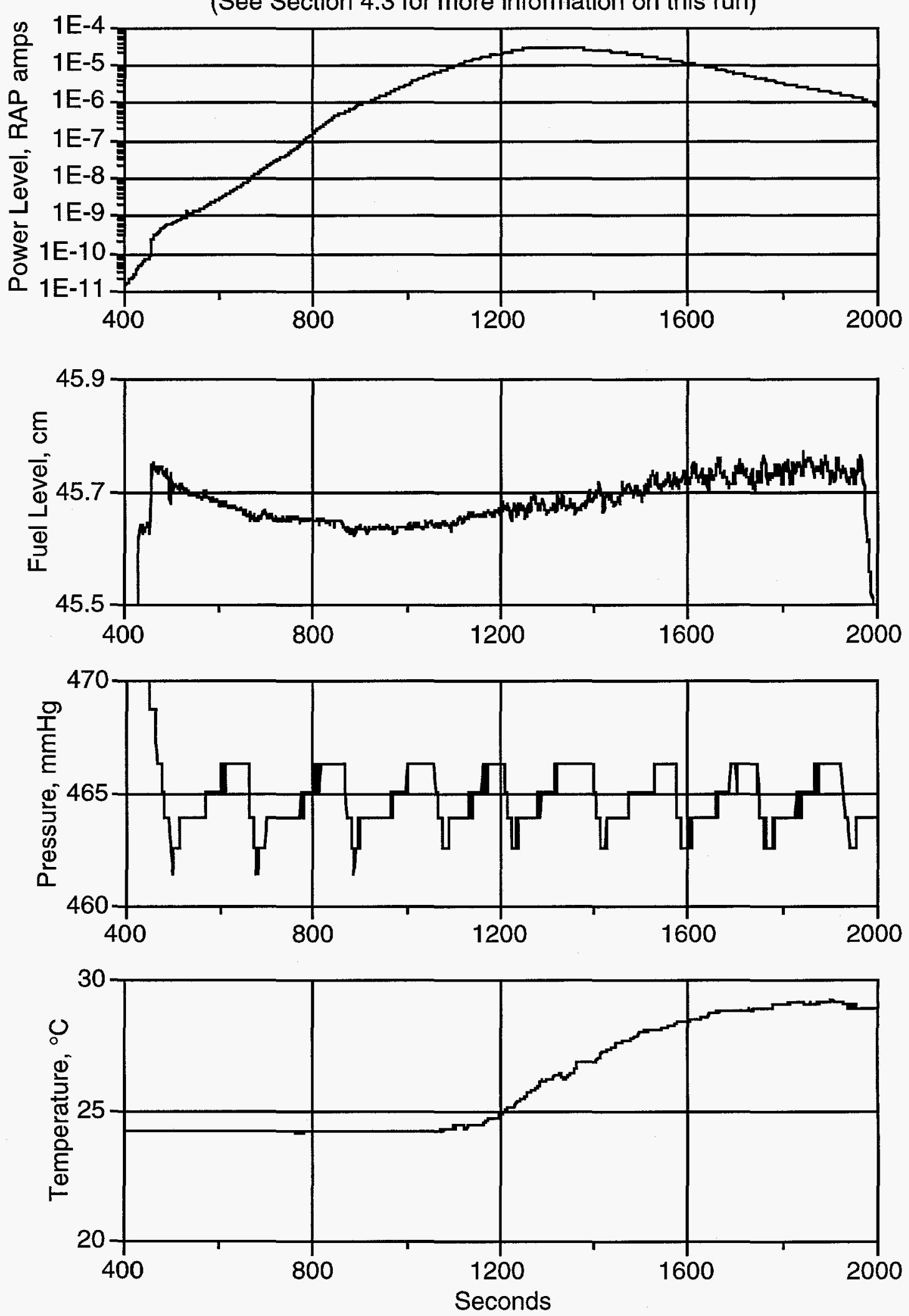
SHEBA Free Run, 4/11/95

42 second initial period
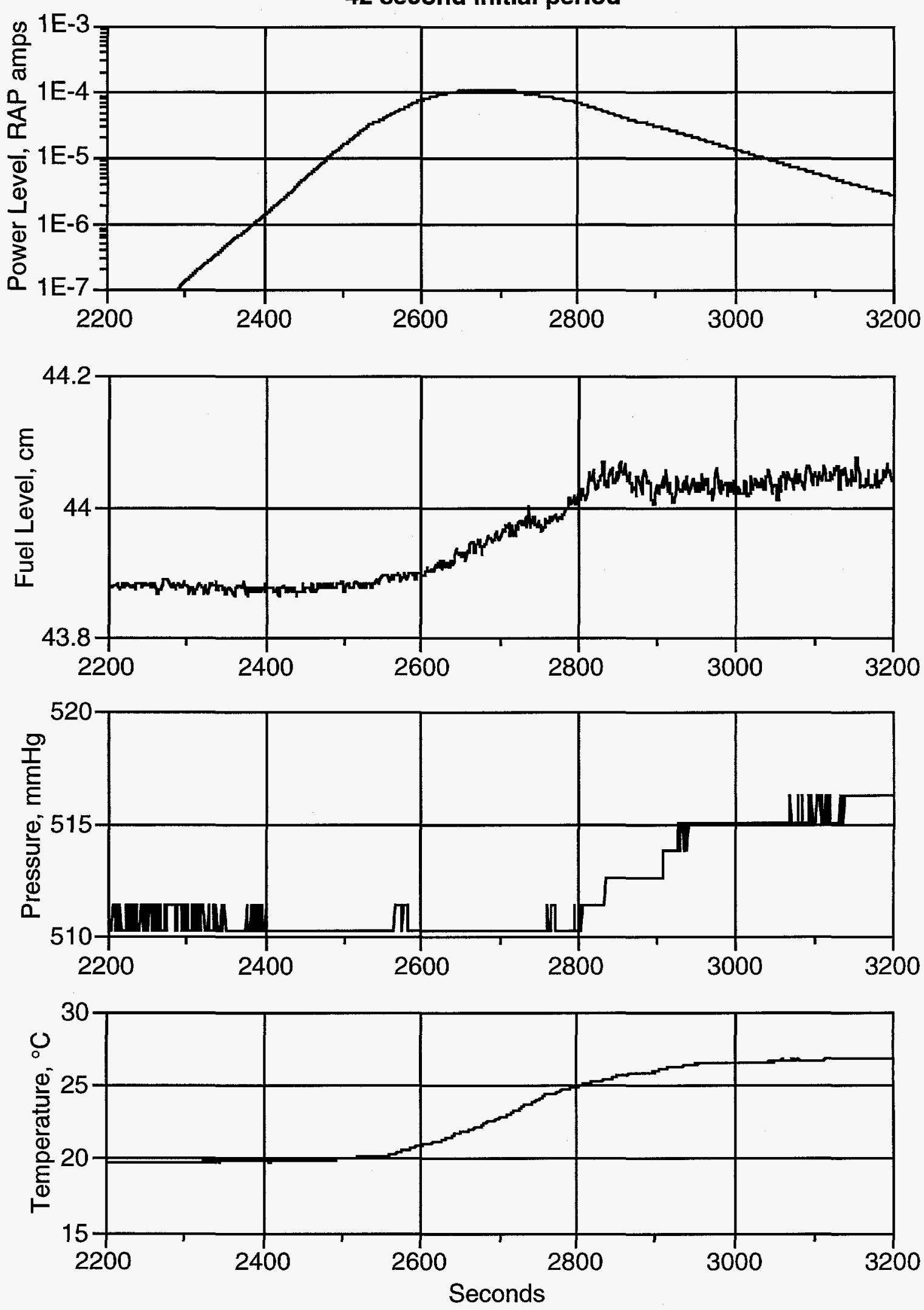
SHEBA Free Run, 12/7/94

30 second initial period
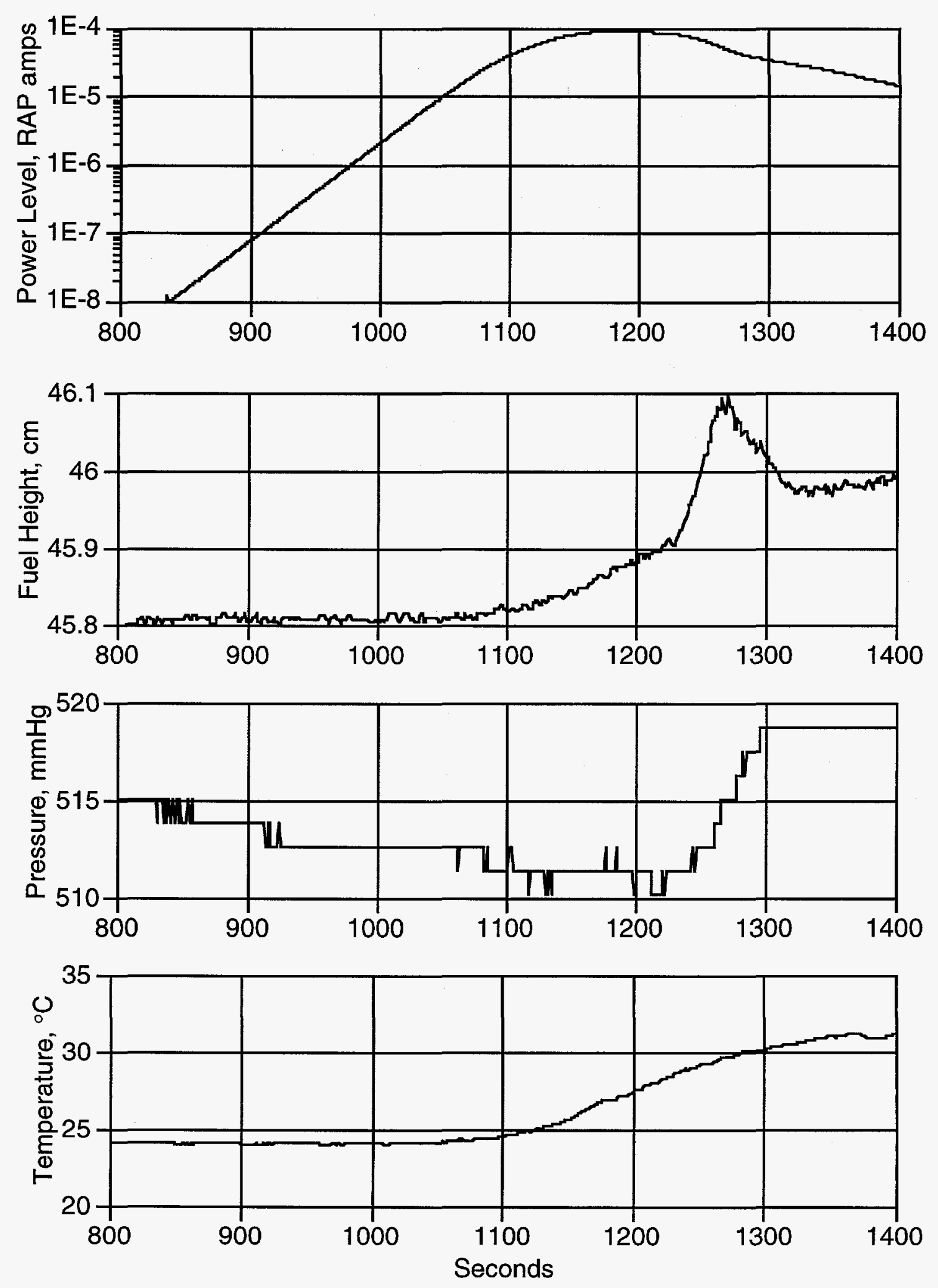
SHEBA Free Run, 5/4/94

31 second initial period
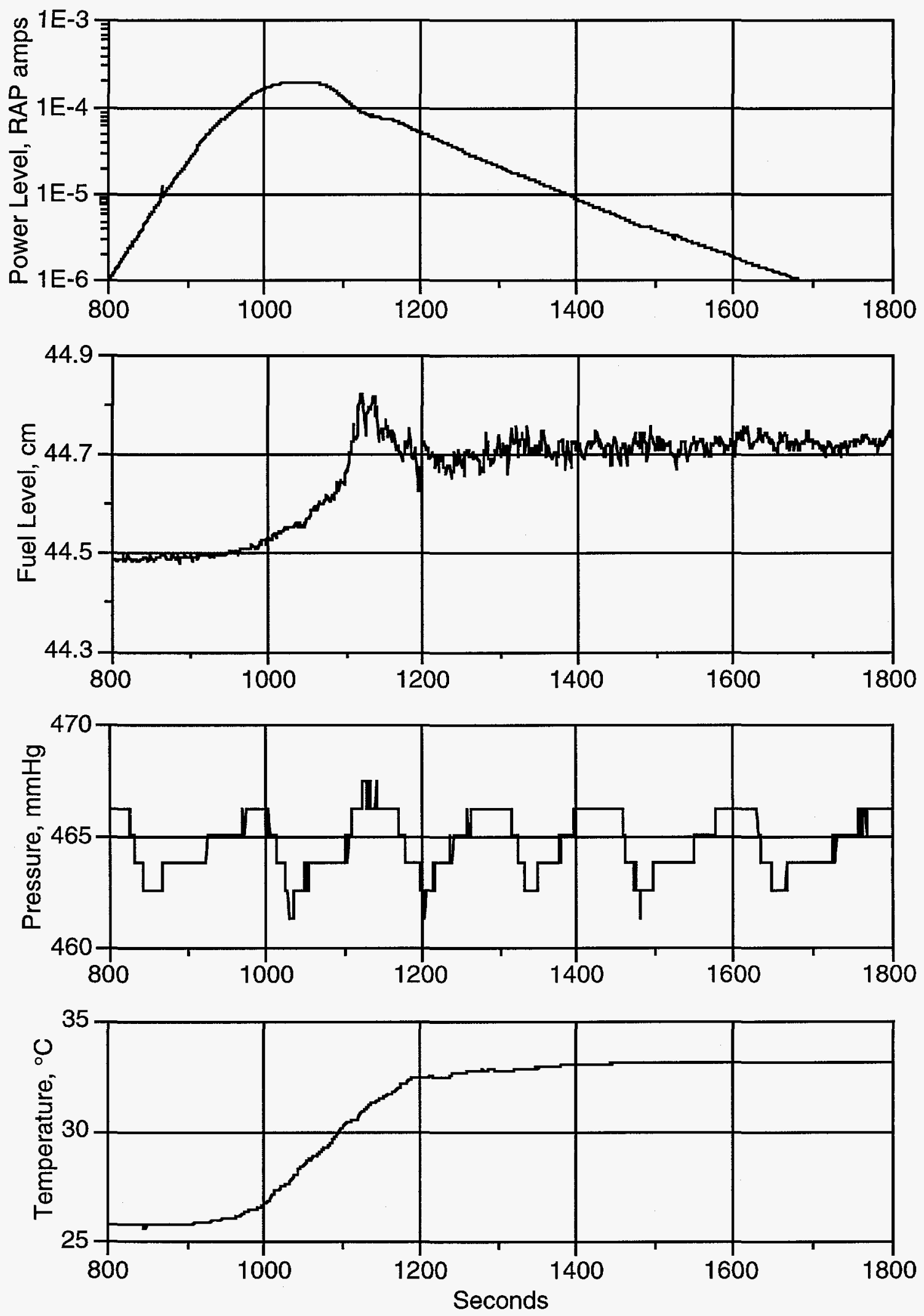
SHEBA Free Run, 2/9/95

20 second initial period
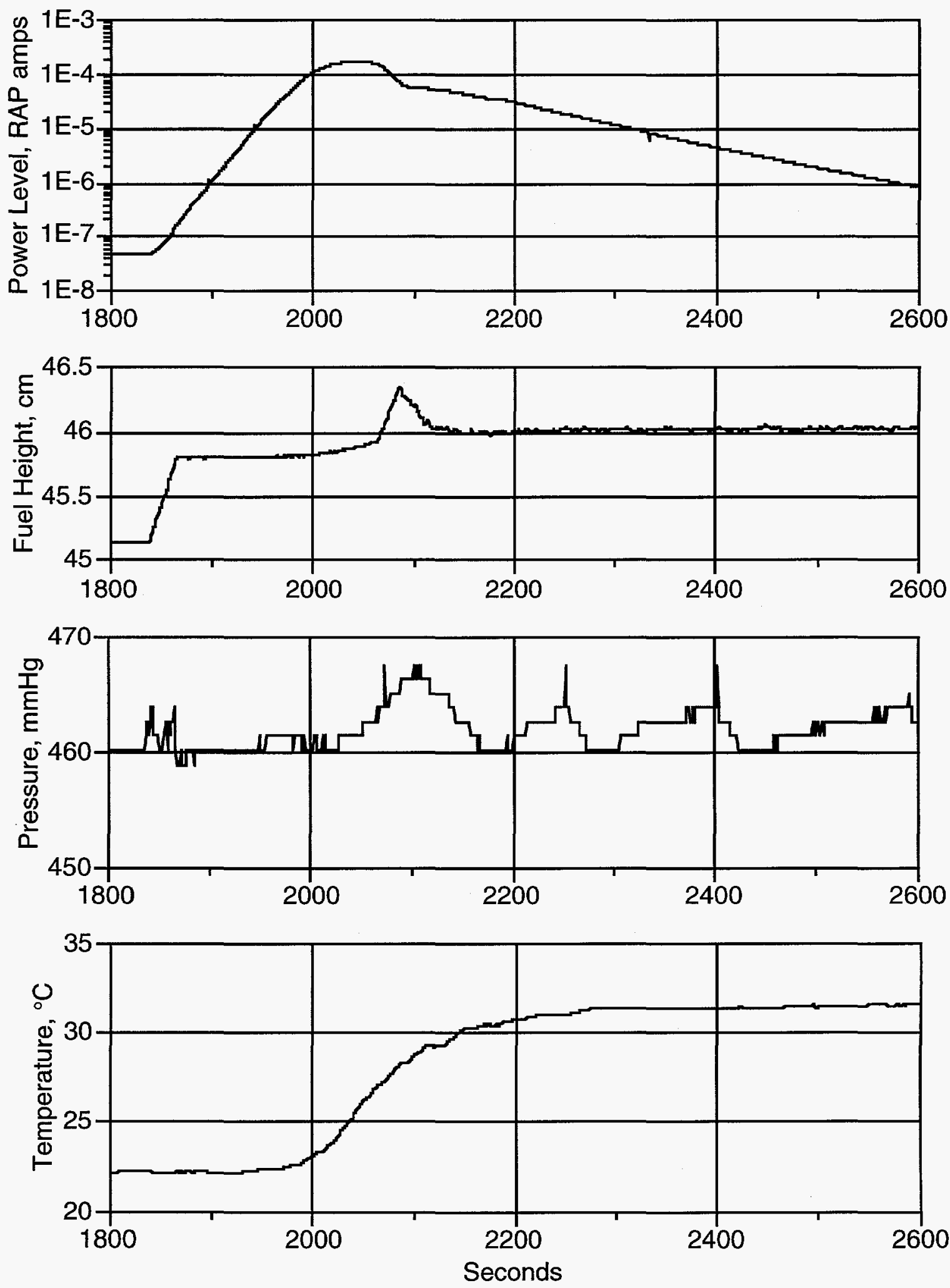
SHEBA Free Run, 7/21/95

14 second initial period
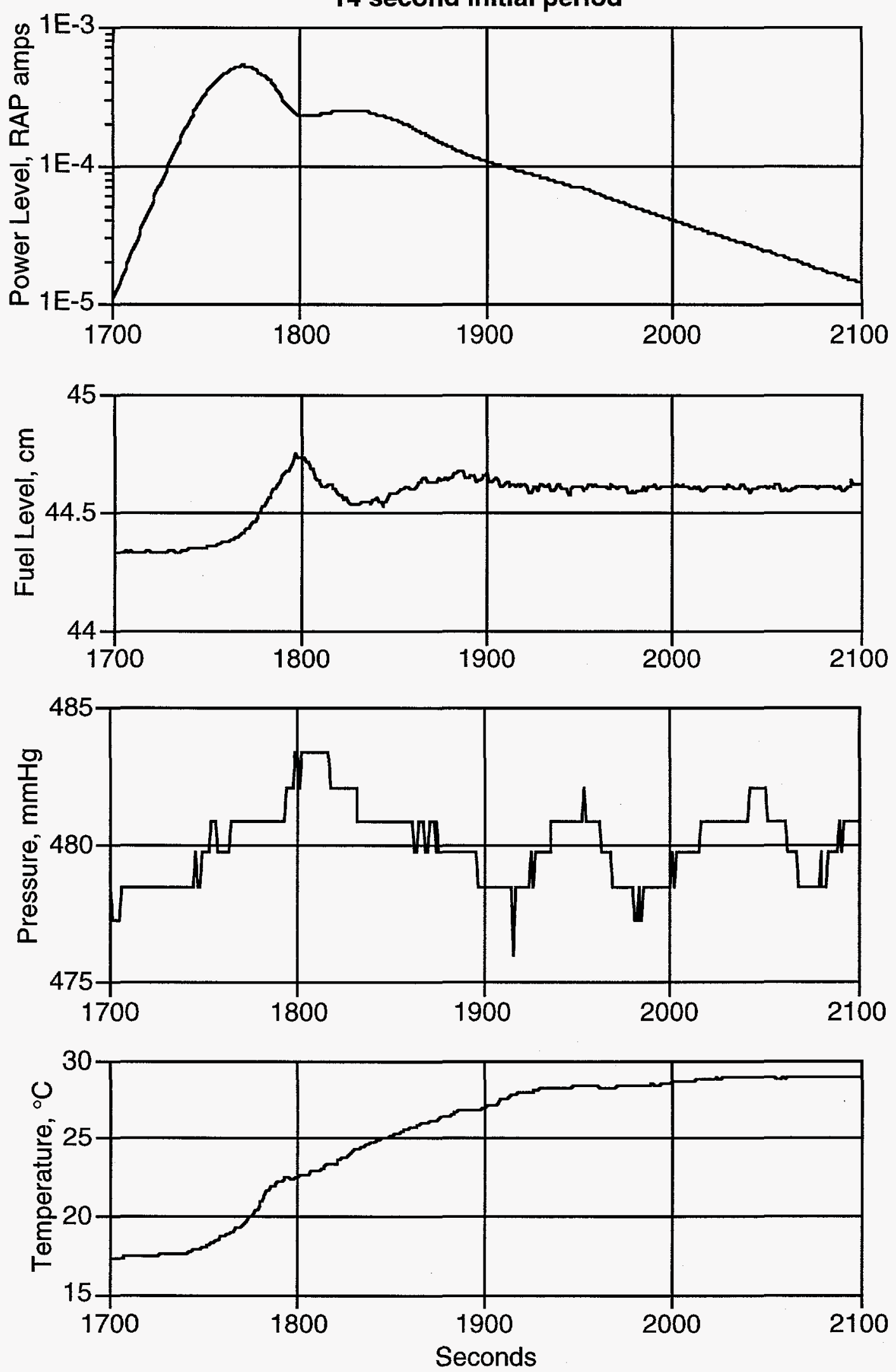
SHEBA Free Run, 6/30/95
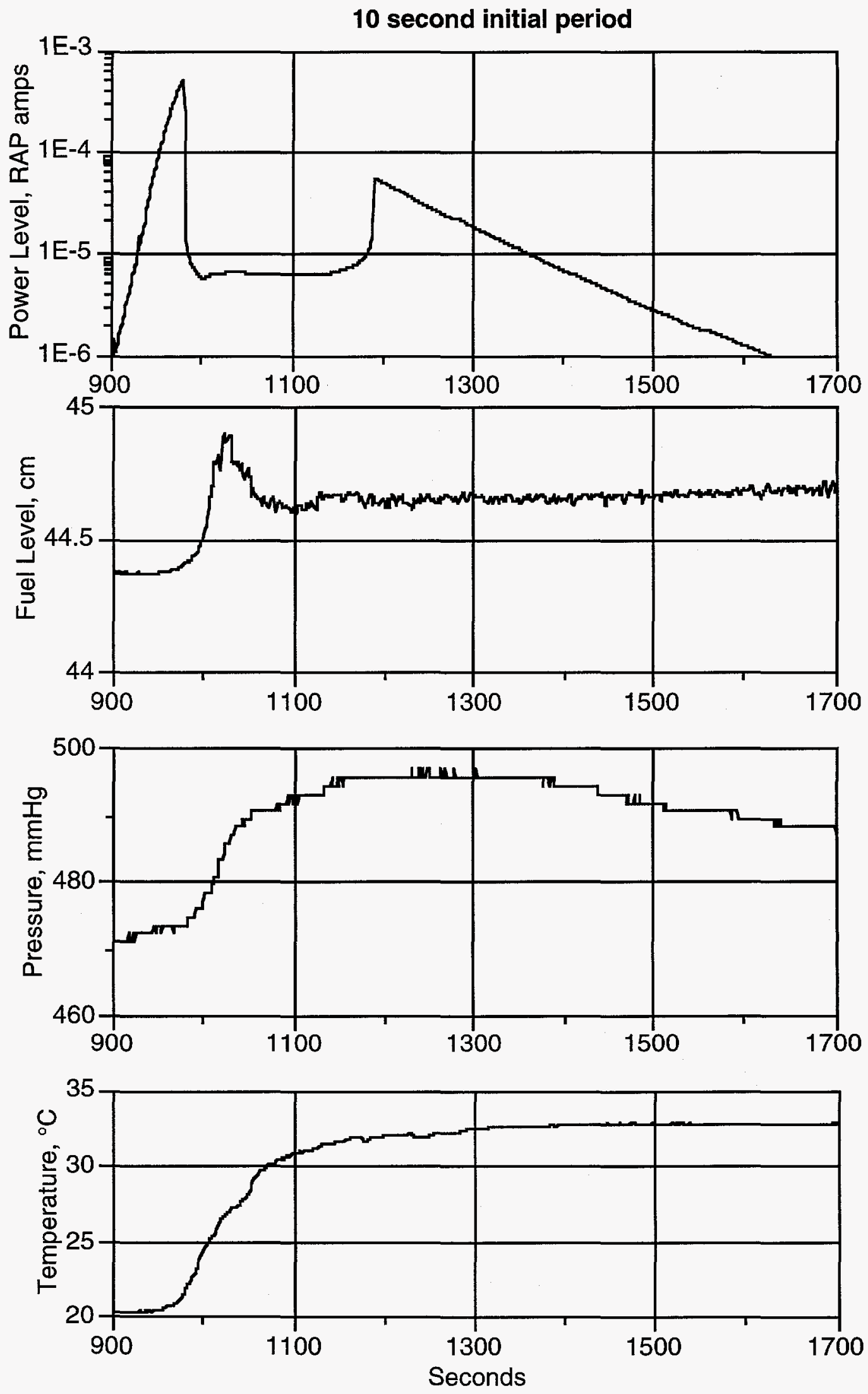
SHEBA Free Run, 12/19/96

5 second initial period
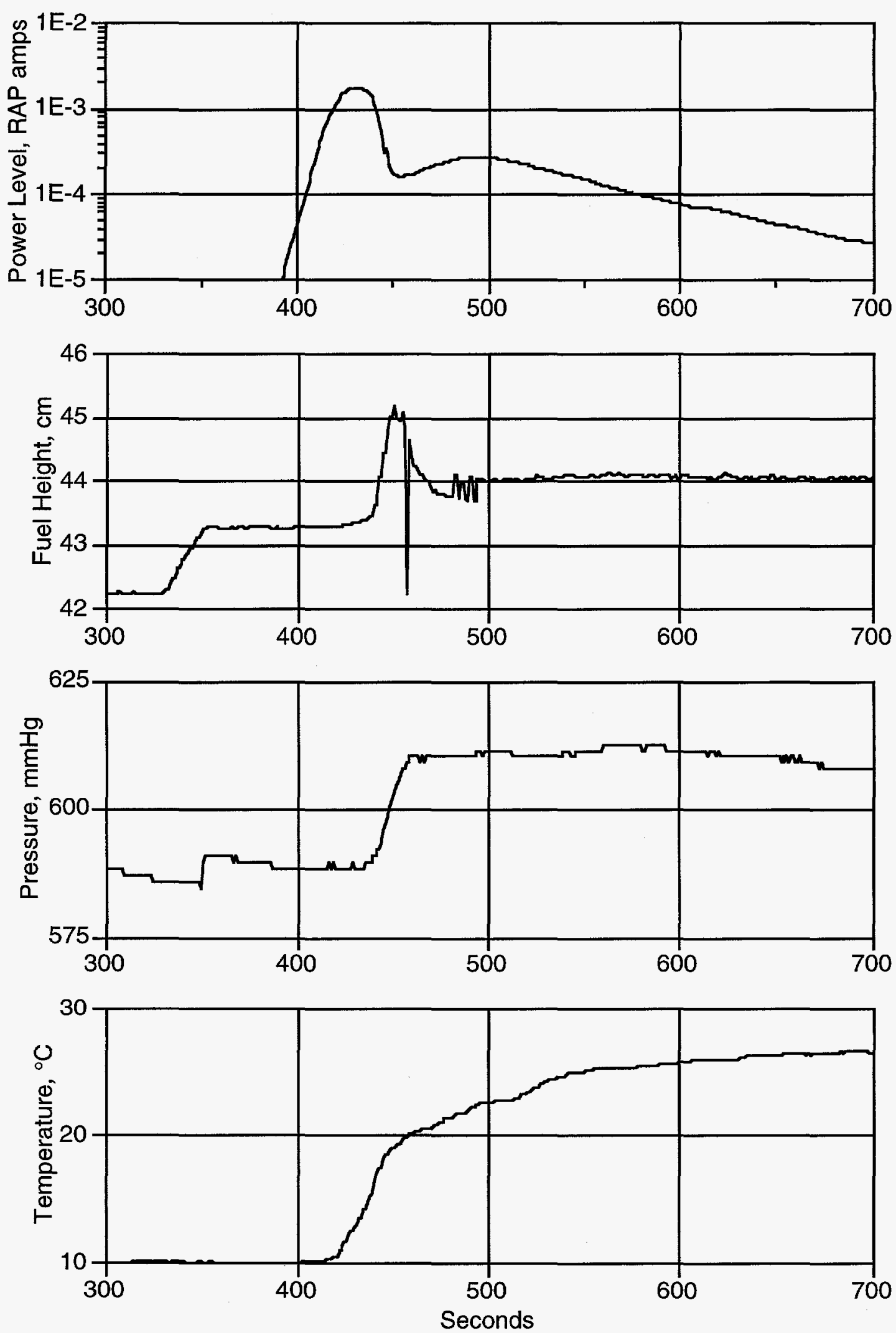
SHEBA Free Run, 12/20/96

2 second initial period
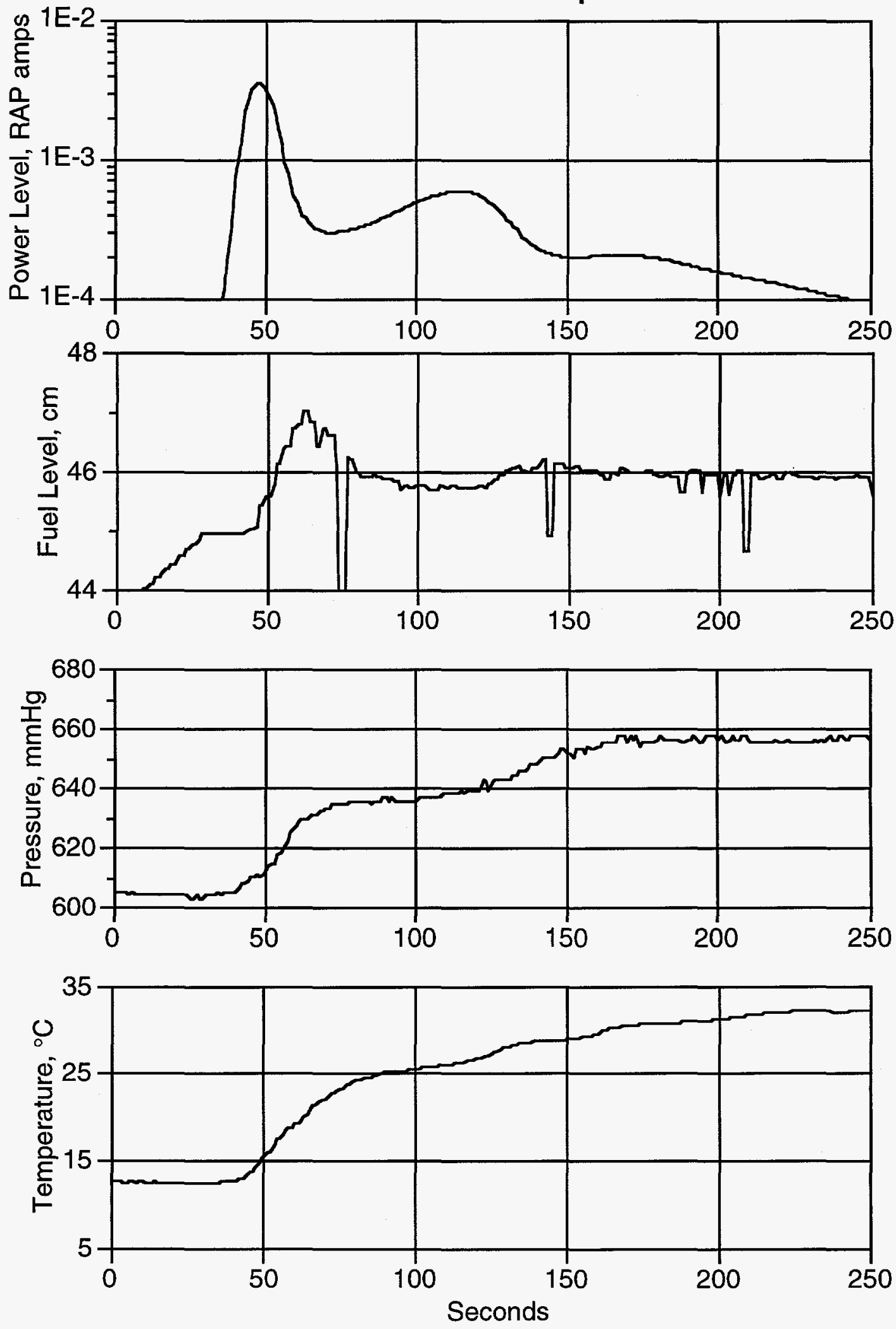
SHEBA Free Run, 12/21/96

1 second initial period
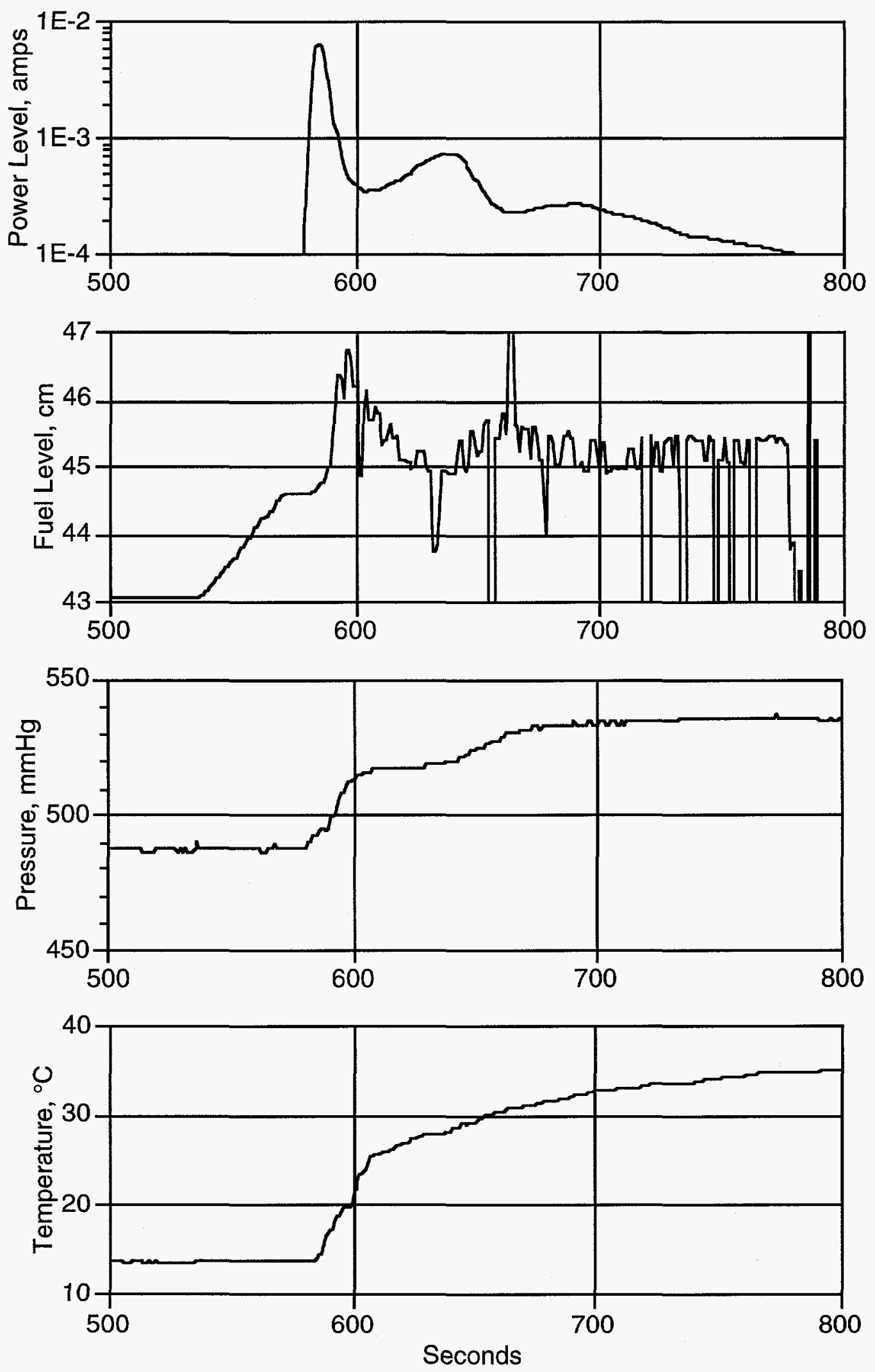